\title{
Antimicrobial hydrogels: promising materials for medical application
}

This article was published in the following Dove Press journal:

International Journal of Nanomedicine

\section{Kerong Yang \\ Qing Han \\ Bingpeng Chen \\ Yuhao Zheng \\ Kesong Zhang \\ Qiang Li \\ Jincheng Wang}

Department of Orthopedics, The Second Hospital, Jilin University, Changchun, Jilin, People's Republic of China
Correspondence: Jincheng Wang Department of Orthopedics, The Second Hospital, Jilin University, No 218 of Ziqiang Street, Changchun, Jilin I3004 I

People's Republic of China

Tel +8643 I 88796747

Fax +8643 I 88796747

Email jinchengwang@hotmail.com

Qing Han; Bingpeng Chen

Department of Orthopedics, The Second Hospital, Jilin University, No 218 of

Ziqiang Street, Changchun, Jilin I3004I,

People's Republic of China

Email my.hanqing@163.com;

53495365@qq.com

\begin{abstract}
The rapid emergence of antibiotic resistance in pathogenic microbes is becoming an imminent global public health problem. Local application of antibiotics might be a solution. In local application, materials need to act as the drug delivery system. The drug delivery system should be biodegradable and prolonged antibacterial effect should be provided to satisfy clinical demand. Hydrogel is a promising material for local antibacterial application. Hydrogel refers to a kind of biomaterial synthesized by a water-soluble natural polymer or a synthesized polymer, which turns into gel according to the change in different signals such as temperature, ionic strength, $\mathrm{pH}$, ultraviolet exposure etc. Because of its high hydrophilicity, unique three-dimensional network, fine biocompatibility and cell adhesion, hydrogel is one of the suitable biomaterials for drug delivery in antimicrobial areas. In this review, studies from the past 5 years were reviewed, and several types of antimicrobial hydrogels according to different ingredients, different preparations, different antimicrobial mechanisms, different antimicrobial agents they contained and different applications, were summarized. The hydrogels loaded with metal nanoparticles as a potential method to solve antibiotic resistance were highlighted. Finally, future prospects of development and application of antimicrobial hydrogels are suggested.
\end{abstract}

Keywords: nanomaterials, hydrogels, nanoparticles, antibiotics, drug delivery, infection

\section{Introduction}

Nowadays, with the rapid development of biomaterials and medical devices, health care-associated infections (HAIs) have posed severe problems on clinicians. For example, in the US, the annual costs associated with HAIs are estimated to be up to $\$ 33$ billion. ${ }^{1}$ The rapid emergence of antibiotic resistance in pathogenic microbes is becoming an imminent global public health problem. ${ }^{2}$ According to a report in Lancet, most acute sequelae and global mortality were caused predominantly by infectious diseases. ${ }^{3}$ Medical devices may bring HAIs to patients in hospital. These biomaterials and medical devices including joint implants, wound dressings, catheters, cardiac pacemakers and contact lenses bring implant-associated infection, calling for an urgent need of inherent antimicrobial biomaterials and medical devices. Among all antimicrobial materials, heavy metals and natural extracts have been used for a long time since first discovered. However, these materials still have inherent disadvantages that restrict their application and efficacy. They fight against microbes as well as normal cells which cause damage to normal organs and tissues of patients. ${ }^{4}$ Antibiotics emerged in antimicrobial history 80 years ago when penicillin was discovered by Sir Alexander Fleming. ${ }^{2}$ For all these decades, antibiotics have brought us consolation until the existence of drug-resistant bacterium was discovered. At the beginning of antibiotic resistance development, conventional antibiotics such as penicillin and methicillin were 
noneffective to resistant strains. Now, vancomycin-resistant and linezolid-resistant strains have emerged. This has led to ceaseless demands for novel antibiotics, putting clinicians in a dilemma whether to test a novel multi-resistant strain with another antibiotic. ${ }^{5}$ Synthetic antimicrobial agents such as salicylate, chlorhexidine, isothiazolinones, thiosemicarbazones, octenidine and even quaternary ammonium compounds also faced progressive threats with the development of drug resistance. ${ }^{6}$ According to the Darwinian view of the role of antibiotics, it is widely accepted that antibiotics and antibiotic-resistant genes act as weapons and shields in shaping the structures of microbial communities. ${ }^{7}$ Nowadays, antibiotic resistance is considered as bacteria's specific response to an injury caused by antibiotics, which means it cannot be totally avoided even if we create a new antibiotic agent. ${ }^{8}$ Increasing rates of antibiotic resistance, drug allergies and antibiotic shortages further complicate the choice of antibacterial agents. ${ }^{9}$ Problems that the traditional antimicrobial agents faced include drug resistance, overdose and cytotoxicity. These problems urgently call for an efficient and safe delivery system of drug release, which can delay the release of toxic antimicrobial agents and reduce the risk of bacterial drug resistance. Apart from antibiotics, other antimicrobial materials also have their own problems in clinical application. In recent years, antimicrobial peptides (AMPs) have been reported to have antimicrobial properties (especially short sequences) because of their ionic structure; so, it is difficult to induce resistance of bacterium or formation of biofilm. ${ }^{10-13}$ However, AMPs are also hemolytic, toxic and easy to lose efficacy and hence, AMPs need an effective drug delivery system to avoid these side effects. ${ }^{12,14}$ Besides, antimicrobial amylolytic polymers, antimicrobial polysaccharides and other antimicrobial components have also been reported, which can be frameworks of biomedical polymers. ${ }^{15,16}$ Yet, how to make these biomaterials play the greatest role in fighting against HAIs remains a problem.

In these cases, a novel drug delivery system with absorbability and delayed release performance is needed. The nanocarrier system or nano-drug delivery systems (DDS) can carry the antibiotic as well as protect it. Nanomaterials with inherent antimicrobial activity or nanomaterials that can improve the efficacy and safety of antimicrobial drugs are called nanoantimicrobials (NAMs). They could be an effective alternative to conventional antibiotics by the provision of improved bioavailability, protection, mucoadhesion, absorption, controlled release and target delivery for the encapsulated or surface-adsorbed drugs. ${ }^{17}$ A set of organic, inorganic and hybrid materials can be identified in the NAM family. ${ }^{18}$ Among all the NAMs, hydrogel is a threedimensional cross-linked polymeric network that can swell dramatically in an aqueous medium such as body fluids, while maintaining its structure and controlling drug release. ${ }^{19,20}$ Hydrogels can also be triggered by stimulations such as changes in $\mathrm{pH}$, temperature, enzyme catalysis, ultraviolet gamma irradiation and even inflammation. ${ }^{21}$ Hydrogel can be coated on urinary catheters, central venous catheters, ${ }^{22}$ contact lenses, joint and dental implants ${ }^{23,24}$ and local injection for drug release and wound healing. ${ }^{25}$ Moreover, some types of hydrogels also have inherent antimicrobial properties. ${ }^{26,27}$ Combined with nanomaterials such as hydrogel, the antibacterial agent may be used at a lower dose than when administered systemically, thus overcoming the problem of resistance and diminishing other undesirable side effects to some extent. ${ }^{28}$ These characteristics have drawn remarkable attention in the pharmaceutical and medical fields especially for antimicrobial application (Figure 1). According

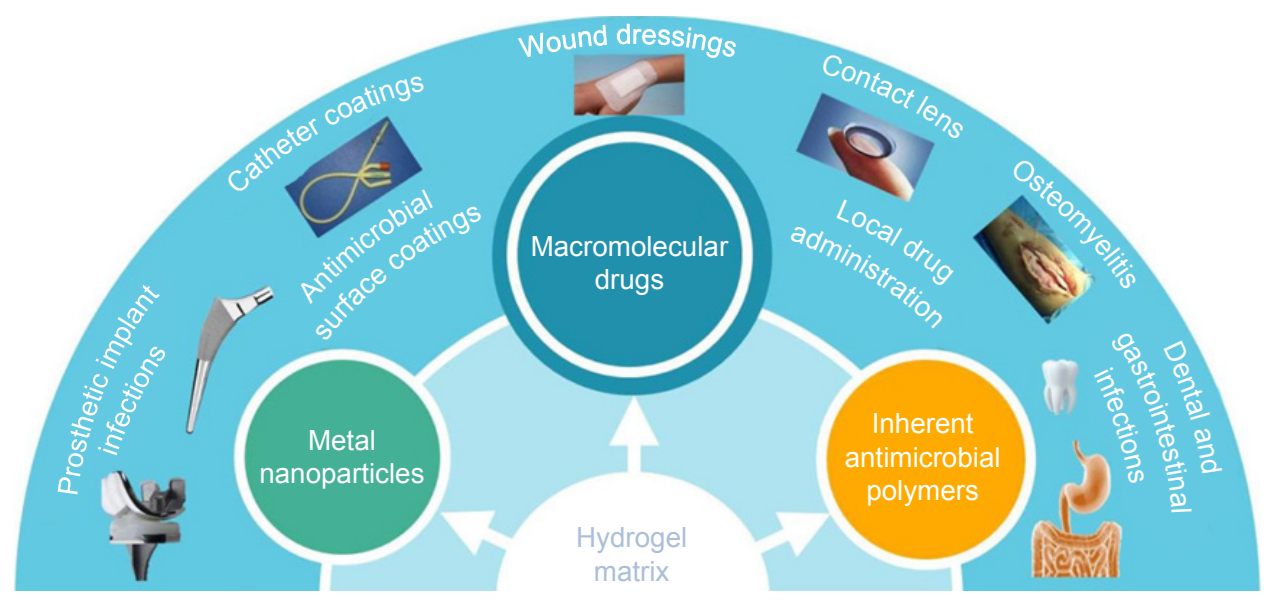

Figure I The different applications of hydrogels. 
to the development of antimicrobial agents, the progresses of antimicrobial hydrogels in recent years are shown in the following section.

\section{Hydrogel loaded with metal nanoparticles}

Heavy metals have been used to fight against microbes for a long time. Silver, gold, copper and zinc were all reported to be used in this area. Among these metals, silver is most widely used due to its good antibacterial property and relatively low toxicity. However, other metals, such as gold, copper and zinc, have their own advantages and antibacterial spectrums.

\section{Sliver nanoparticles (Ag NPs)}

Silver have been regarded as an antimicrobial agent for thousands of years, before people knew about the word "microorganisms". Silver bowls, water vessels, spoons and other containers were used to preserve water, food and wine in their condition., ${ }^{4,29}$ Silver powder was applied in wound healing and treatment of ulcers, which was first documented in medical history by Hippocrates. ${ }^{4}$ Silver still plays an important role in biomedical areas such as wound dressings, textiles, bone implants etc. ${ }^{30}$ Thanks to the development of nanoscience and technology, nowadays silver is mainly applied in the form of nanoparticles. ${ }^{31,32} \mathrm{Ag}$ NPs have antimicrobial activity against a wide spectrum of microbes (probably due to their multiple mechanisms of antimicrobial action), including activity against drug-resistant bacteria, fungi (such as Candida albicans) and viruses. ${ }^{33-36} \mathrm{Ag}$ NPs are emerging as efficient antimicrobial agents because of their different mechanisms of sterilization, ${ }^{32,37,38}$ although no final conclusion about mechanisms has been made. Recent studies suggest that the primary mechanism of the antibacterial action of Ag NPs is to release silver ion $\left(\mathrm{Ag}^{+}\right)$. Particle-specific activity of Ag NPs cannot be ignored, which indicates that the mechanism of antibacterial action differs between $\mathrm{Ag}^{+}$and AgNPs. ${ }^{39}$ The most universally accepted hypothesis is that the $\mathrm{Ag}^{+}$released from $\mathrm{Ag}$ NPs interact with cysteine in certain regions of proteins on bacterial membranes, causing $\mathrm{K}^{+}$loss from inside and the disruption of cellular transport systems, which finally leads to bacterial cell death (Figure 2). ${ }^{40,41}$ Other studies show that $\mathrm{Ag}^{+}$interact with proteins of the cell wall and plasma membrane of bacteria. ${ }^{31}$ Combination of $\mathrm{Ag}^{+}$with negatively charged membrane perforates the membrane, thus allowing cytoplasmic contents to flow out of the cell, dissipating the $\mathrm{H}^{+}$gradient across the membrane and sometimes causing cell death. ${ }^{42}$ If the bacteria have not been killed yet, these contacts allow $\mathrm{Ag}^{+}$to move through the cell wall and
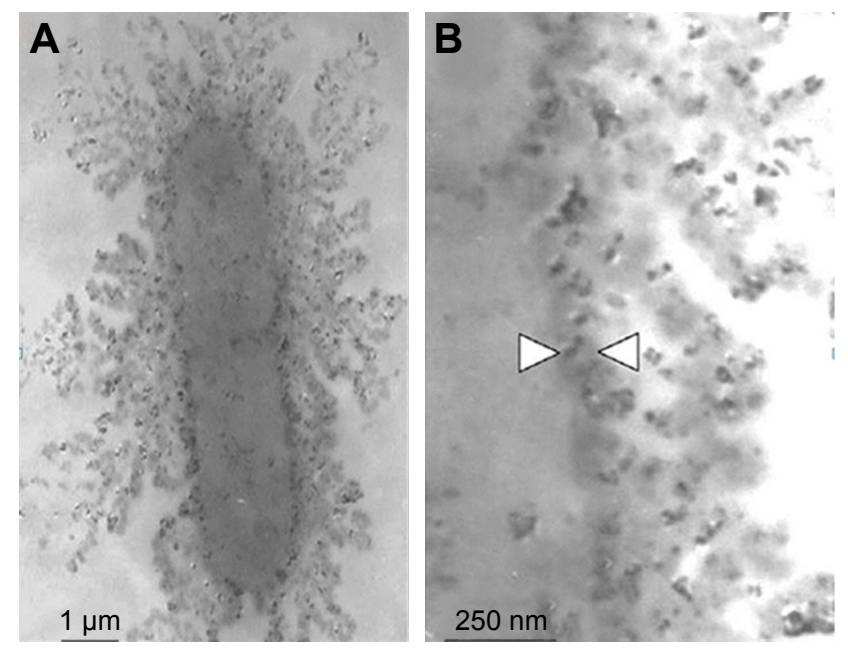

Figure 2 Transmission electron microscope image of Escherichia coli cells treated with silver nanoparticles in liquid Luria-Bertani medium: (A) membrane of $E$. coli; (B) nanoparticles accumulated in the membrane and penetrated the cell (arrows). Note: Reprinted from Adv Drug Deliv Rev. 65(13-14). Pelgrift RY, Friedman AJ, Nanotechnology as a therapeutic tool to combat microbial resistancel803-1815, Copyright (2013), with permission from Elsevier. ${ }^{31}$

the plasma membrane. Finally, $\mathrm{Ag}^{+}$functions as an extra antimicrobial agent in the cytoplasm of the bacterial cell. ${ }^{34}$ Despite widespread use of $\mathrm{Ag}^{+}$, bacterial resistance to $\mathrm{Ag}^{+}$has been found rare and developed slowly, especially compared to resistance to antibiotics, which makes it a potential antimicrobial agent to solve the problem of antibiotic resistance. Again, this is presumably due to the multiple mechanisms of antimicrobial action of Ag described earlier, whereas antibiotics usually have only one mechanism of action. ${ }^{34,36,42}$ As is known to all, Ag NP-based hydrogels have so many merits that they performed better on Gram-negative bacteria than Gram-positive bacteria because Gram-negative bacteria have low resistance of the cellular membranes compared with the peptidoglycan cellular walls of Gram-positive bacteria. ${ }^{40}$ But, it has also been argued that Gram-negative bacteria are less sensitive than Gram-positive bacteria to $\mathrm{Ag}^{+}$, because $\mathrm{Ag}^{+}$ binds to the negatively charged lipopolysaccharide (LPS) of the outer membrane of Gram-negative bacteria more strongly than to the peptidoglycan layer of Gram-positive bacteria. By this argument, $\mathrm{Ag}^{+}$is trapped in the LPS and is less likely to enter a Gram-negative cell than a Gram-positive cell. ${ }^{31,34}$

In this review, we concentrate on the hydrogels that are loaded with Ag NPs. There are mainly two types of hydrogel matrices: one is the natural polymer (including modified natural polymer) and the other is the synthetic polymer. The most common natural polymers are polysaccharides. Polysaccharides mainly include alginate, chitin, chitosan (CS) and carboxymethyl cellulose (CMC). Alginate is a natural derivative linear copolymer that can form 
hydrogel via methods such as $\mathrm{Ca}^{2+}$ ionic interaction. $\mathrm{Ag}$ NPs were incorporated into alginate microbeads through electrochemical synthesis by Stojkovska et al, ${ }^{43,44}$ which showed antibacterial activity against Staphylococcus aureus and Escherichia coli. Although alginate has been already commercially in use for wound dressings, Ag NPs on alginate have high tendency to aggregate. Obradovic et al ${ }^{45}$ optimized the technique for the production of $\mathrm{Ag} /$ alginate microbeads by freezing-thawing based on alginate, poly(vinyl alcohol) (PVA) and poly(N-vinylpyrrolidone) (PVP) to reduce the aggregation. Ghasemzadeh et $\mathrm{a}^{46}$ also attempted to use alginate/PVA as a hydrogel matrix with sodium borohydride as a reducing agent. Madhusudana Rao et $\mathrm{al}^{47}$ went one step further by fabricating sodium alginate-based semi-interpenetrating polymer network (IPN) hydrogels for delivery of Ag NPs, and the hydrogel exhibited good antibacterial activity. The degree of cross-linking and nature of semi-IPN polymer chains are key factors in regulating the size, shape and release of nanoparticles. ${ }^{48}$ Neibert et $\mathrm{al}^{49}$ described a method to enhance mechanical strength of alginate hydrogel loaded with Ag NPs by chemical cross-linking, which is more favorable for epidermal regeneration while maintaining antibacterial properties. ${ }^{50}$ Many animal experiments on alginate hydrogel loaded with Ag NPs have been conducted, which means this kind of antimicrobial hydrogel has been studied thoroughly.

Other important polysaccharides used as antimicrobial hydrogels are chitin and CS. It is notable that both chitin and CS have antimicrobial and metal-binding properties. Chitinor CS-based hydrogels such as CS/2-glycerophosphate/ nanosilver hydrogel and silver molybdate nanoparticle/chitin matrix $\left(\mathrm{Ag}_{2} \mathrm{Mo}_{2} \mathrm{O}_{7} /\right.$ chitin $)$ hydrogel also provide green synthetic process and excellent antibacterial performance against E. coli..$^{51,52}$ The other polysaccharide hydrogels include iota-carrageenan-based Ag NP hydrogel and Ag NP-loaded PVA/gum acacia (GA) hydrogel, ${ }^{53,54}$ both iota-carrageenan and GA are well-known polysaccharides with rich production in nature. Both the hydrogels showed good antibacterial activity against Gram-negative bacterium E. coli. Sodium CMC is another kind of biocompatible and biodegradable polysaccharide polymer which can effectively work as both reducing and stabilizing agents. It has been reported that CMC can be cross-linked by epichlorohydrin as an antimicrobial hydrogel matrix, and it can also be added into CMC and starch-composed hydrogel network as a component, ${ }^{55,56}$ both systems work well as antimicrobial hydrogels. Ranga Reddy et al ${ }^{57}$ demonstrated that the natural polysaccharide gelatin has contributed an excellent property for anchoring and stabilizing the Ag NPs and formulating poly (gelatinacrylamide) silver nanocomposite hydrogels for inactivation of bacteria. The natural hydrogels have weak antimicrobial properties, but they can be good carriers for Ag NPs, and other antibiotic agents. Moreover, they can be extracted from natural materials easily.

As for a synthetic matrix for Ag NP hydrogels, there is a large diversity, but most of them are poly(acrylamide) (PAM), acrylic acid, poly(ethylene glycol) (PEG), PVA, pyrrolidone and their derivatives. The main advantage of using this template is that the morphology and size of the nanoparticles can be easily controlled by changing the amount of cross-linker and monomer of the hydrogel network..$^{48,58,59}$ For example, PAM/ PVA hydrogel-Ag NPs fabricated by Varaprasad et $\mathrm{al}^{60}$ can obtain Ag NPs of 2-3 nm size in gel networks, which exhibit higher antibacterial activity on E. coli compared with Ag NPs alone and $\mathrm{Ag}^{+}$-bonded hydrogels. Styrene sulfonic acid sodium salt was incorporated into hydrogels to form poly(acrylamidestyrene sulfonic acid sodium salt) Ag NP hydrogel, and the most sensitive strain it can deal with was Bacillus subtilis. ${ }^{58}$ PAM is also used to form semi-interpenetrating network hydrogels composed of pluronic and PAM by simultaneous free-radical cross-linking polymerization and served as nanoreactors for the synthesis of Ag NPs. ${ }^{59} \mathrm{PAM}$ mixed with itaconic acid (IA) or starch to form Ag NP-loaded hydrogels was also reported to have good antibacterial properties while providing a green process of synthesis. ${ }^{61,62} \mathrm{Poly}(\mathrm{N}$-isopropylacrylamide) (PNIPAM) is the second commonly used matrix in Ag NP hydrogels. James et al,$^{63}$ Manjula et $a l^{64}$ and Zafar et al ${ }^{65}$ used PNIPAM as a main component to synthesize Ag NP hydrogels. James et $\mathrm{l}^{63}$ synthesized PNIPAM-co-allylamine nanogels and grafted them onto non-woven polypropylene. Hydrogels made by Manjula et $\mathrm{al}^{64}$ were reduced with neem leaf (Azadirachta indica) extracts, providing another green process. During the fabrication, emphasis was placed on green techniques, in order to make it environmentally friendly. Zafar et a ${ }^{65}$ mixed $\mathrm{Ag}$ NPs with N-isopropylacrylamide-based nanogels which had a peak of lower critical solution temperature (LCST) that is close to the human body temperature. This increases the possibility in practical medical application. All these three hydrogels demonstrated conspicuous antibacterial properties. Hydrogels of 2-acrylamido-2-methylpropane sulfonic acid sodium salt containing Ag NPs have been proved to have no cytotoxicity while exhibiting better antimicrobial ability than commercial Acticoat $^{\mathrm{TM}}$ (Smith \& Nephew, London, UK) and PolyMem Silver ${ }^{\circledR}$ (Ferris Mfg. Corp., Fort Worth, TX, US), ${ }^{66,67}$ which can give us more confidence in exploitation of Ag NP hydrogels. However, some researchers would like to try some new 
ways, such as cross-linking fumaric acid (FA) and CMC. These hydrogel-based silver nanocomposites were coated on cotton fabric for antibacterial property, and the result was promising. ${ }^{68}$ Paladini et al ${ }^{69}$ used in situ photochemical reaction to coat Ag NPs on the fibers of hydrogel and demonstrated their antibacterial capabilities by any hydrogel blend on $E$. coli and $S$. aureus.

As for other Ag NP hydrogels, different matrices bring different characteristics and different processes of synthesis, all these creative points offered us a unique view on the way to more advanced antimicrobial biomaterials. Poly(acrylic acid co-poly(ethylene glycol)methyl ether acrylate)/Ag NP composite hydrogels were developed by Lee et al, ${ }^{70}$ offering a novel promising bioadhesive patch or wound dressing materials with their inherent good electrical conductivity. Thermoplastic PEG-polyhedral oligosilsesquioxane (POSS) hydrogels were synthesized from multiblock PEG-POSS polyurethanes by $\mathrm{Wu}$ et al, ${ }^{71}$ and their antimicrobial property lasts over 10 days. PVA/PVP-based hydrogels containing Ag NPs fabricated by Eid et al $^{72}$ were reported to be high, uniformly distributed, and stable. Poly(methacrylic acid) (PMAA) hydrogel reduced with borohydride by Bajpai et $\mathrm{al}^{73}$ and poly(2-hydroxyethyl methacrylate/IA)/Ag NP hydrogels synthesized with gamma irradiation by Micic et $\mathrm{al}^{74}$ showed antimicrobial activity against $E$. coli. The $\mathrm{pH}-$ sensitive poly(methyl methacrylate-methacrylic acid)/Ag NP hydrogels synthesized with free radical cross-linking by Wei et $\mathrm{al}^{75}$ can be potentially smart antimicrobial biomaterials. All the abovementioned hydrogels displayed enhanced antimicrobial ability against E. coli, S. aureus, Pseudomonas aeruginosa and even $B$. subtilis. Some of them even acquired longer antimicrobial duration than antibiotics. ${ }^{76}$ The antimicrobial ability and cytotoxicity can be regulated by diverting the amount of components, which may turn out to be potentially smart antimicrobial biomaterials.

A novel antibacterial coating made of poly(L-lysine)/ hyaluronic acid multilayer films and liposomes loaded with $\mathrm{Ag}^{+}$was designed in 2008. ${ }^{77}$ The strong antibacterial effect was attributed to the diffusion of silver ions from the $\mathrm{AgNO}_{3}$ coating, which resulted in a bactericidal concentration of silver ions aggregated around the membrane of the bacteria. Similarly, other small antimicrobial chemicals such as antibiotics can be loaded in liposomes in hydrogels to reach the aim of delayed drug delivery. Malcher et al opened a new route to modify surfaces with small chemicals which cannot permeate phospholipid membranes. ${ }^{77}$

The most interesting Ag NP hydrogels are hydrogels synthesized with water-soluble PEG polymers, which contain reactive catechol moieties. Synthesis of this hydrogel was inspired by mussel adhesive proteins. This biomimetic material has a strong potential for antibacterial tissue adhesives and biomaterial coatings because of the materialindependent adhesive properties of catechols. ${ }^{78}$ Another new hydrogel with Ag NPs was called reduced graphene oxide (GO)-based Ag NP-containing hydrogel. This composite was fabricated in situ through the simultaneous reduction of GO and noble metal precursors within the GO gel matrix. ${ }^{79}$ This new kind of hydrogel has already been used in waste water cleansing due to its antimicrobial and antifouling properties inspiring the idea of clinical application. For example, this hydrogel can be used to deal with a polluted wound as a wound dressing.

However, serum albumin also reduces the antibacterial effects of Ag NP-embedded hydrogels. ${ }^{80}$ The gene toxicity of Ag NPs has also been reported, and balances between antireactive oxygen species (ROS) response and DNA damage; and mitosis inhibition and chromosome instability, might play significant roles in silver-induced toxicity. ${ }^{81}$ Therefore, the vital issues are: improvement of the antimicrobial ability against Gram-positive bacteria, minimization of gene toxicity, and reduction of serum albumin when designing Ag NP-based hydrogels. More non-toxic and environmentally friendly synthetic processes such as the idea of size-controllable synthesis of Ag NPs with tobacco mosaic virus (TMV) as a biomediator without external reducing agents $^{82}$ should be developed. In recent studies, more hydrogels loaded with Ag NPs have been discovered. Researchers have improved their properties, such as strong antimicrobial properties and prolonged release. All these developments and improvements ensure the clinical potential of the hydrogels. To provide clarity, all the hydrogels with Ag NPs are recorded in Table 1.

\section{Gold nanoparticles (Au NPs)}

Gold is universally considered as biologically inert but $\mathrm{Au}$ NPs have a diversity of biological functions. ${ }^{83}$ Au NPs can be designed into different sizes and be functionalized with desired polymers, thus they are realized as biocompatible materials. ${ }^{84} \mathrm{Au}$ NPs can be attached to the bacterial membrane, which leads to the leakage of bacterial contents or penetration of the outer membrane and the peptidoglycan layer, resulting in bacterial death. ${ }^{85}$ However, compared with Ag NPs, studies on antimicrobial Au NP hydrogels alone are rare. In a recent study by Brown et al, ${ }^{86} \mathrm{Au}$ NPs lack antibacterial activity alone. However, Au NP with ampicillin bound to the surface (Au NP-AMP) killed multiple drug-resistant 


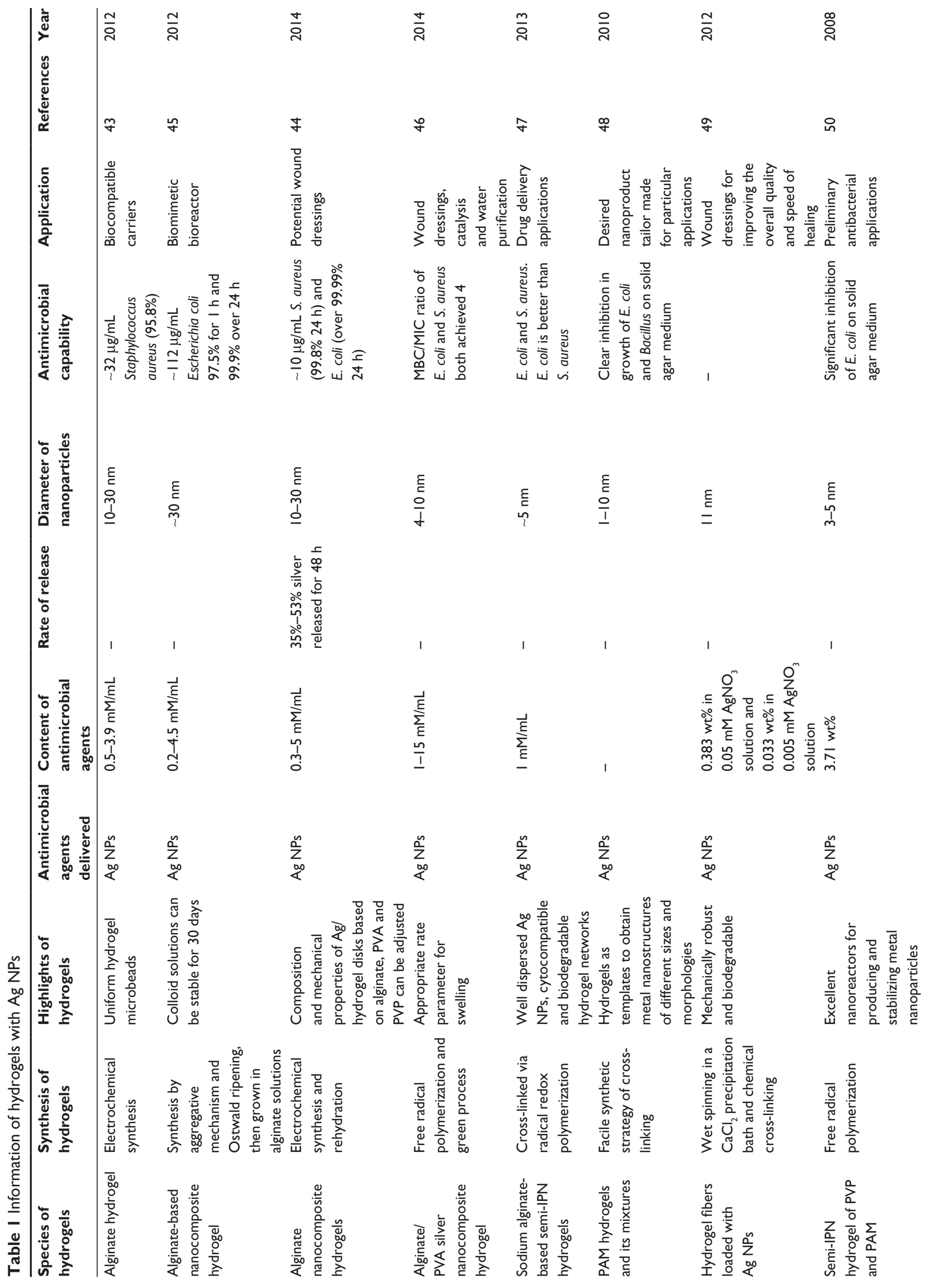




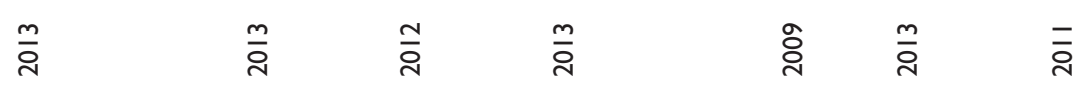

$\overline{\bar{c}}$

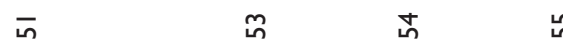

นึ เ

ถิ

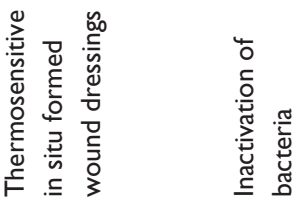

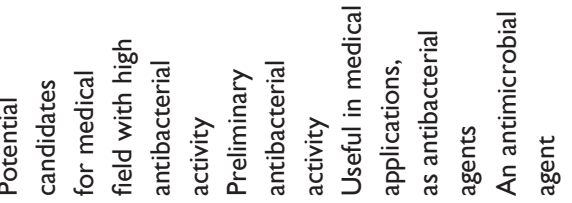

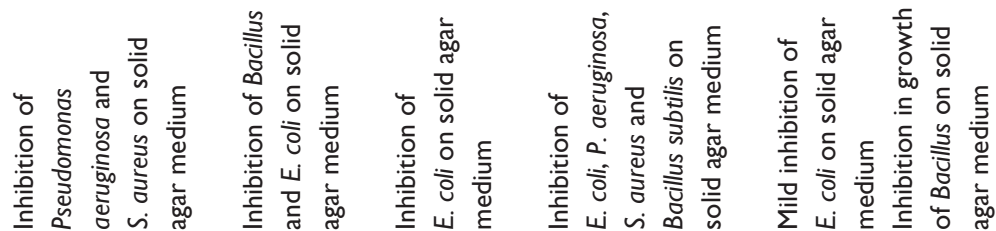

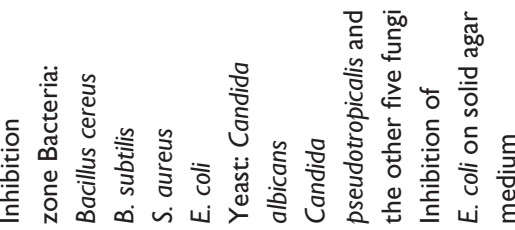

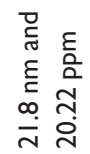

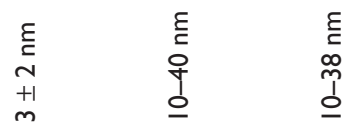

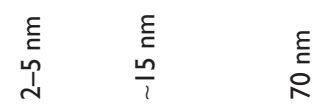

$\frac{\varepsilon}{\frac{\varepsilon}{5}}$

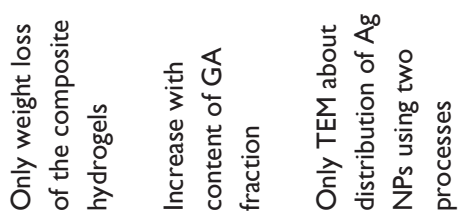

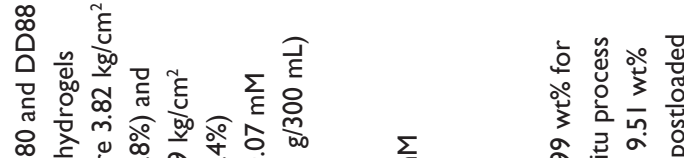

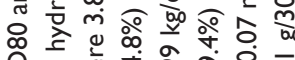

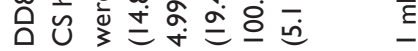

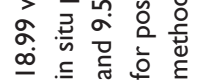

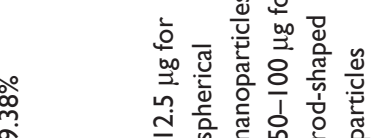

吕

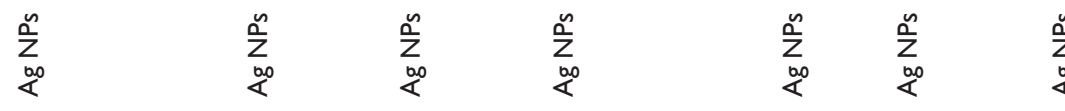

$\underset{\substack{n \\ \gtrless}}{\substack{\infty \\<}}$

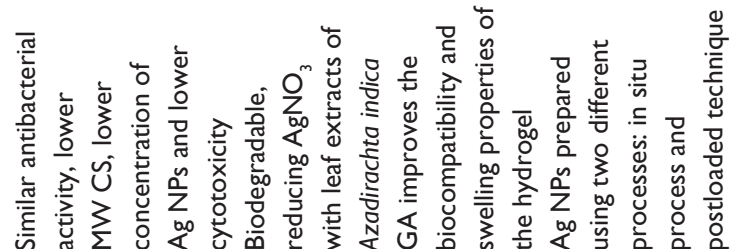

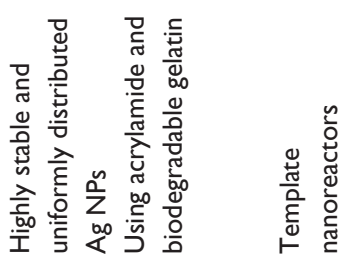

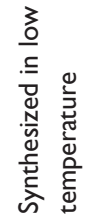
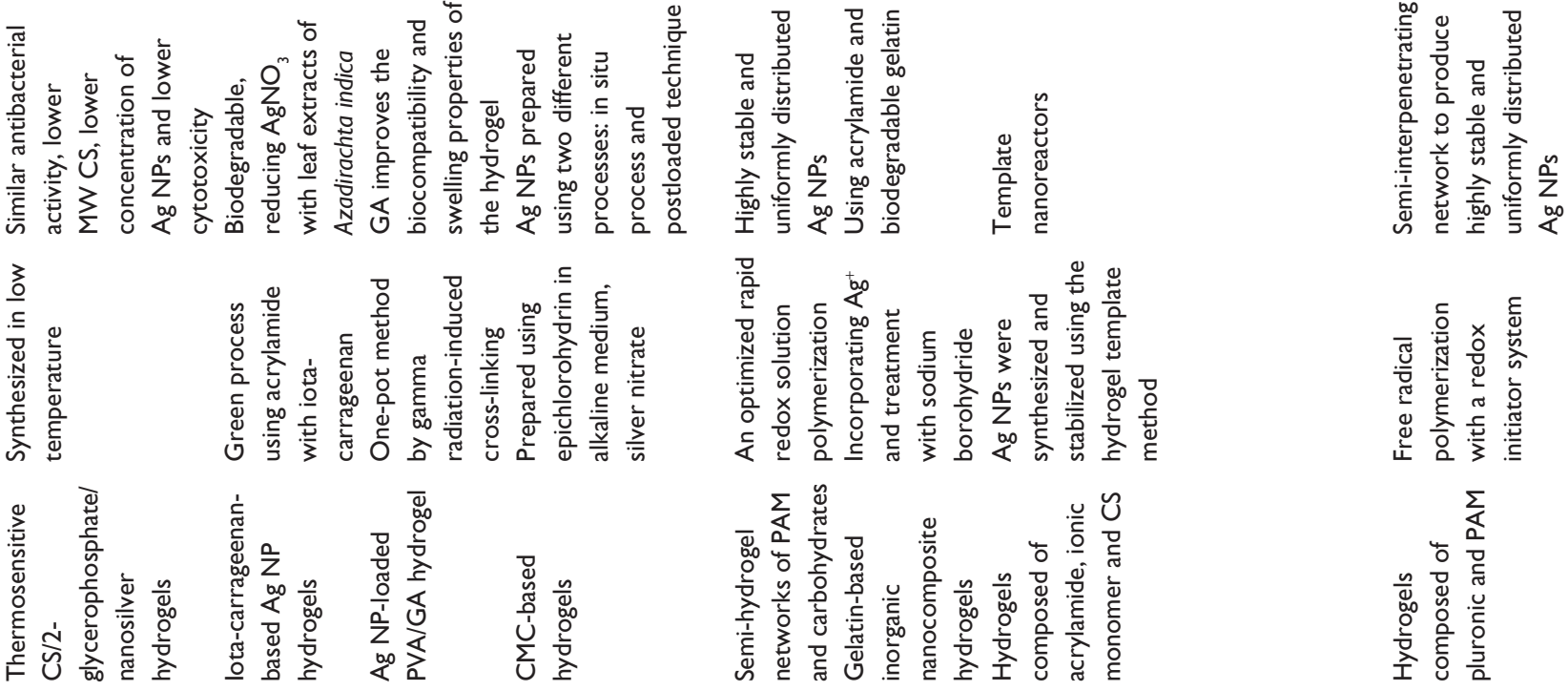


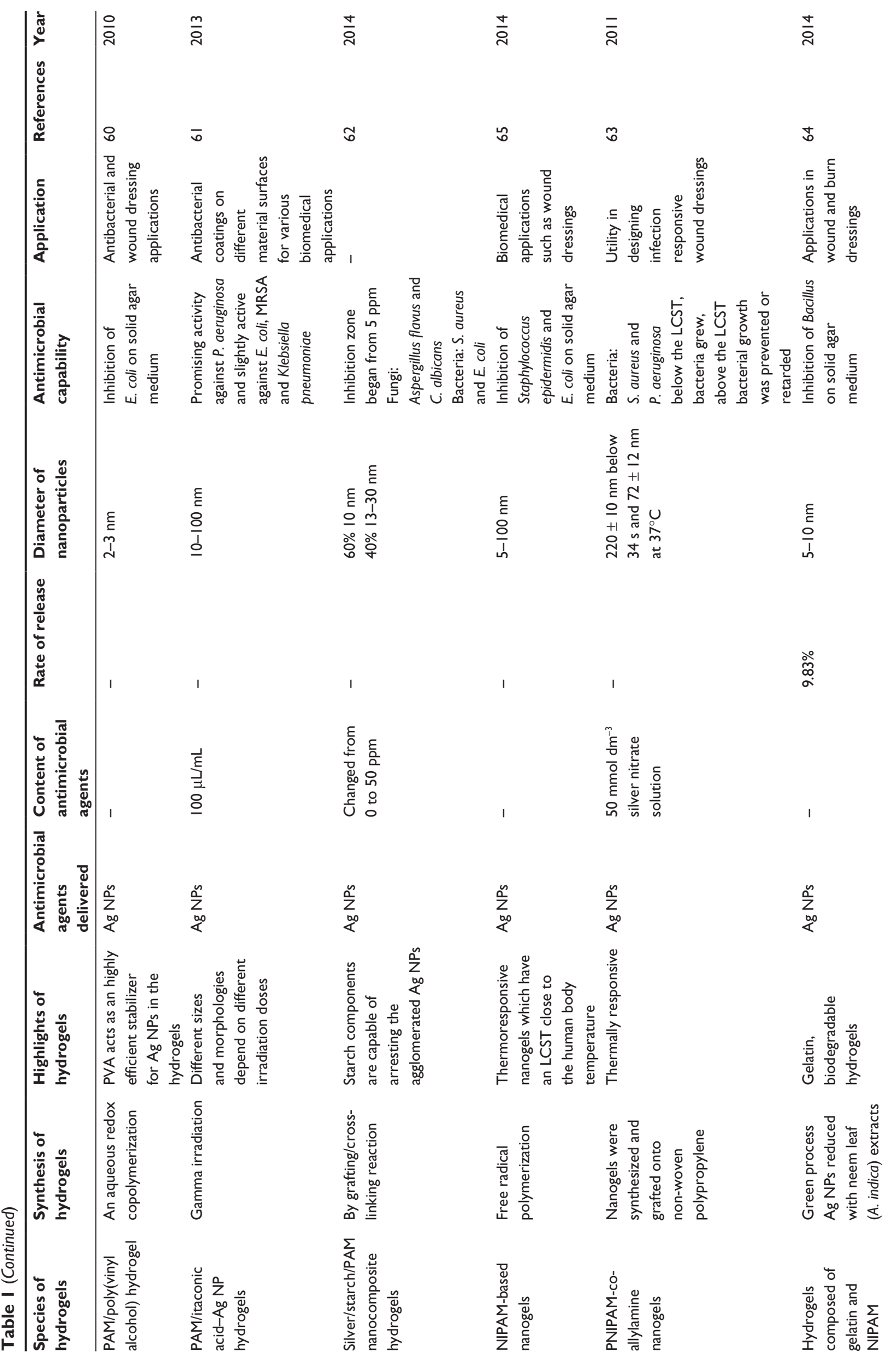




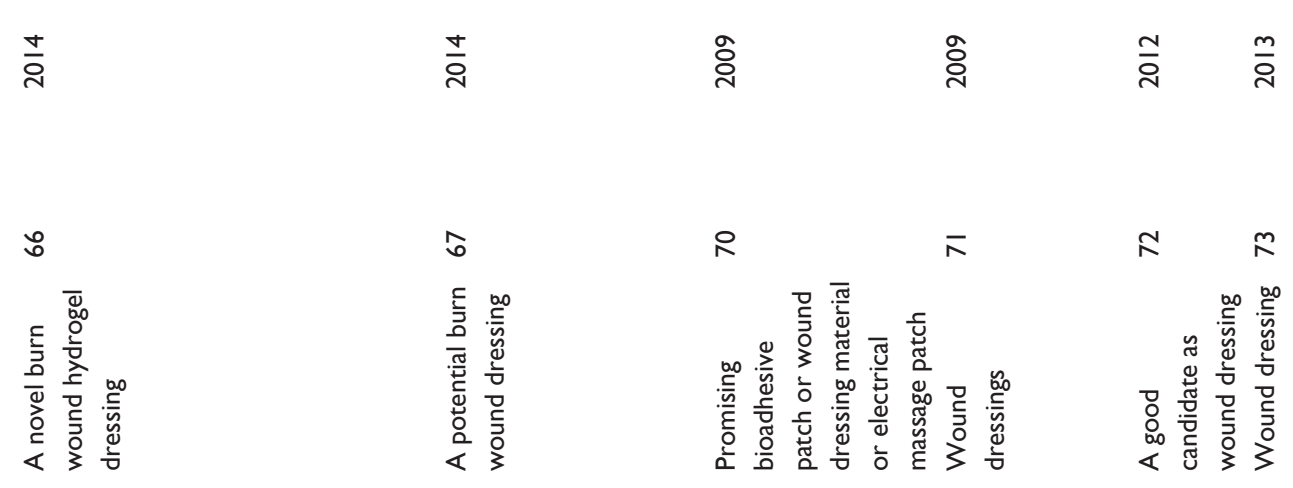

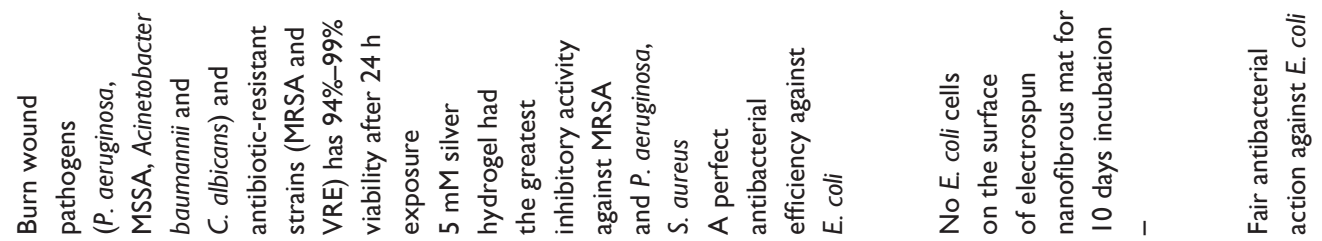
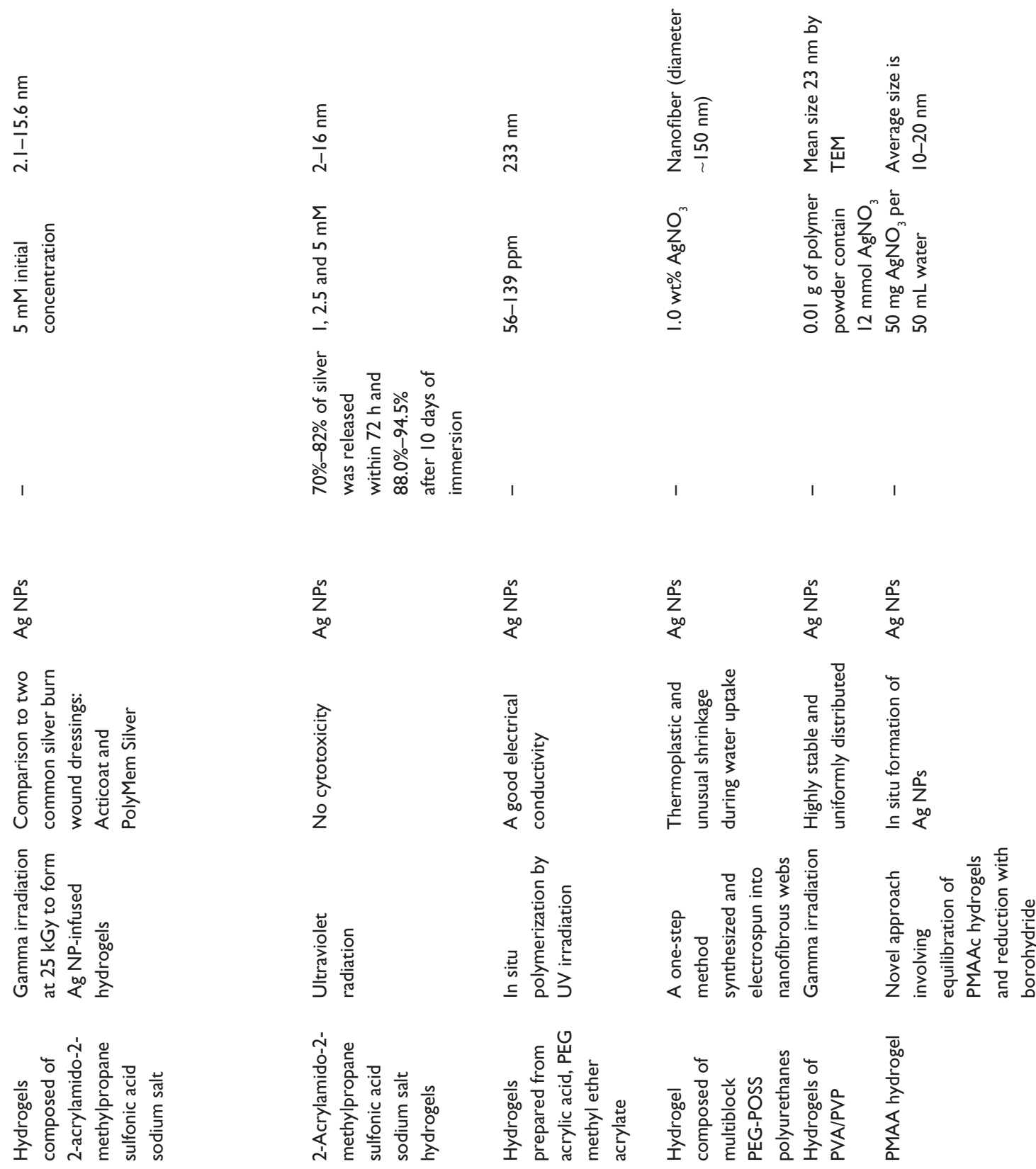


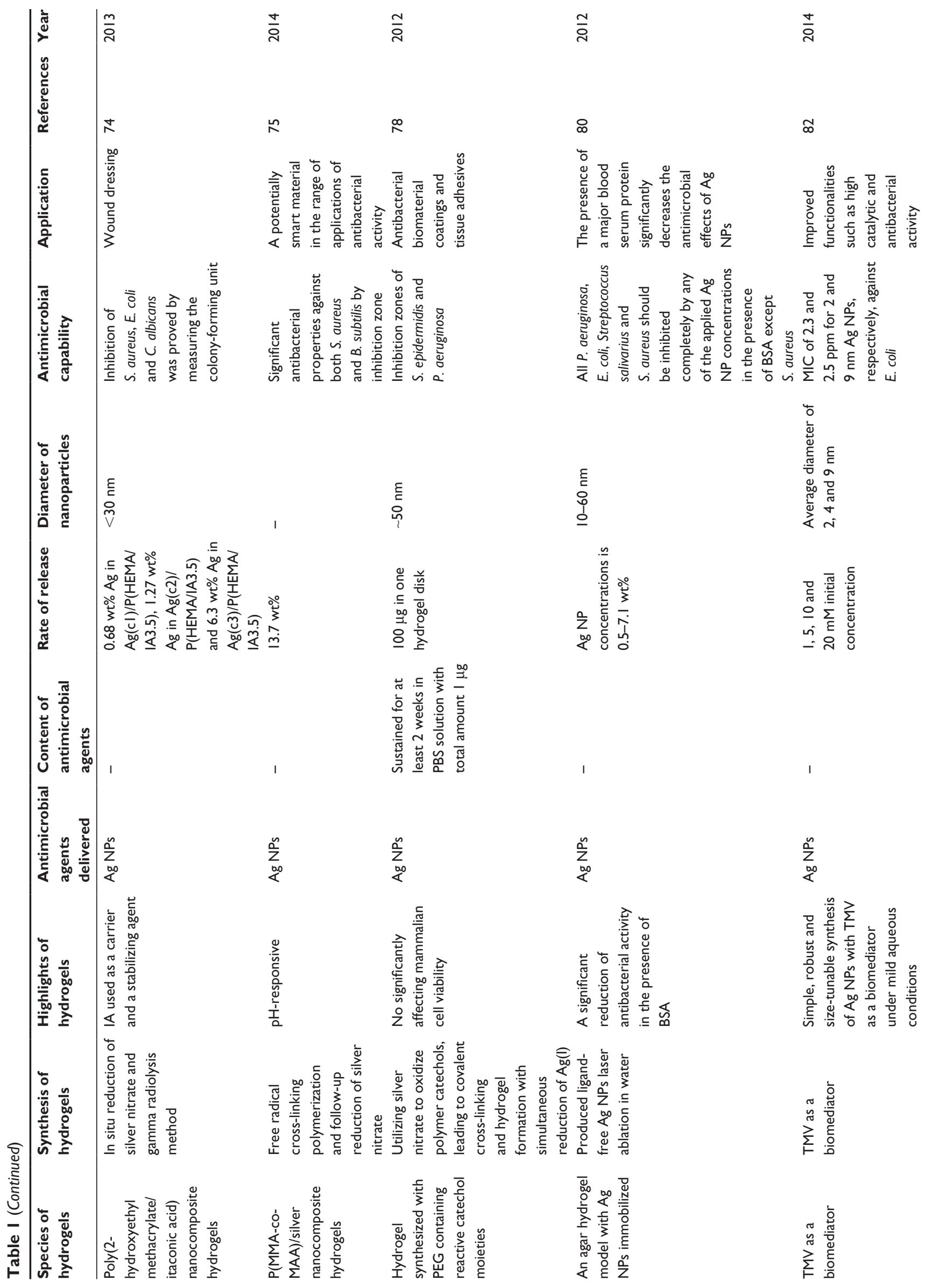


는

는

능

음

는

a

$\stackrel{2}{2}$

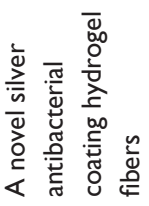

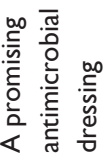

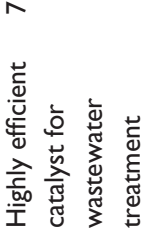

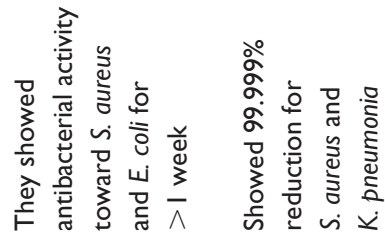

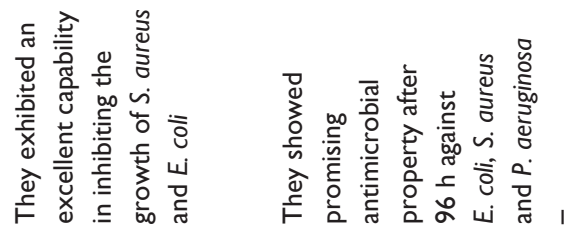

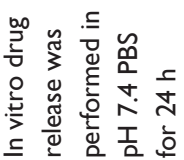

।

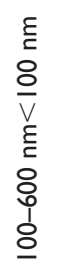

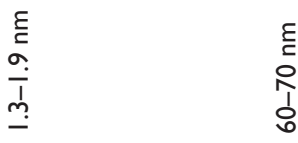

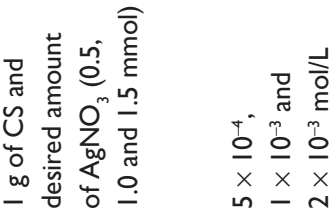

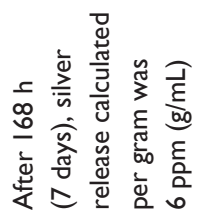

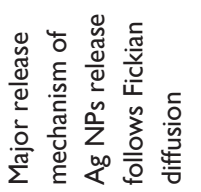

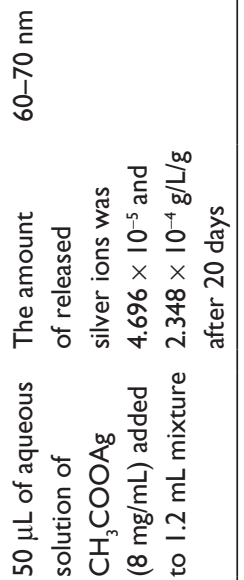

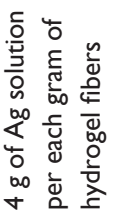

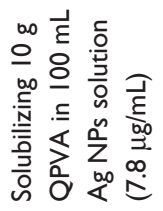

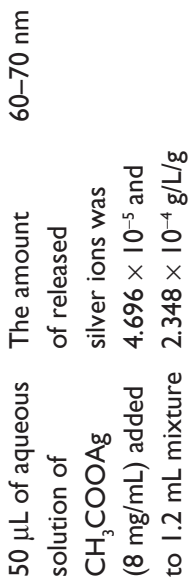

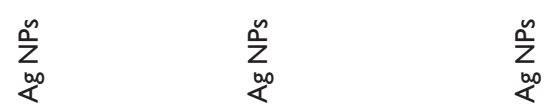

$\sum_{\substack{n \\<}}^{\infty} \sum_{\substack{n \\<}}^{\infty}$

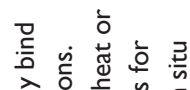

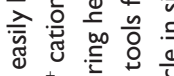

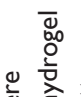

$\overline{\mathrm{d}} . \simeq$

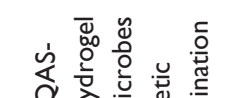

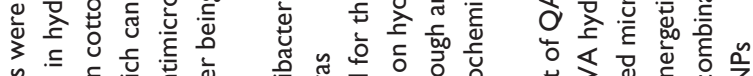

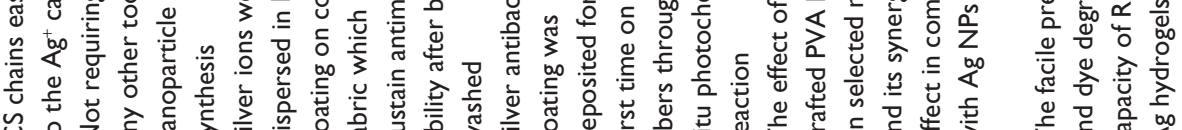

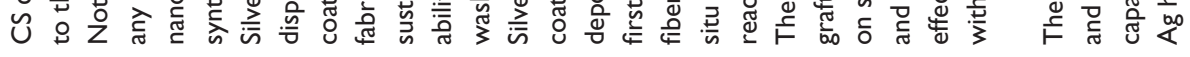

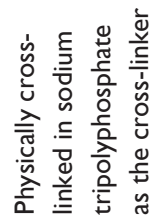

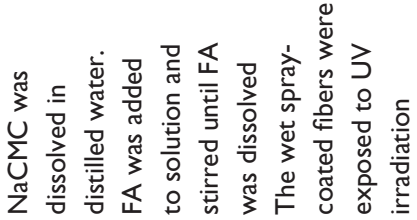

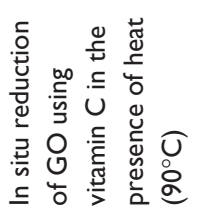
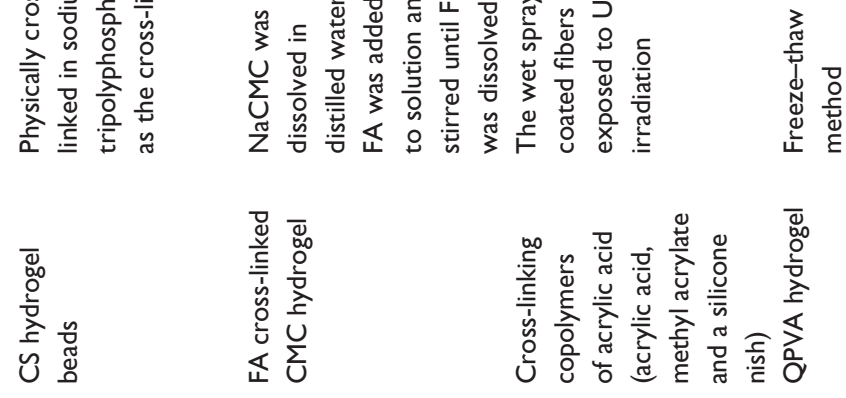

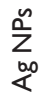

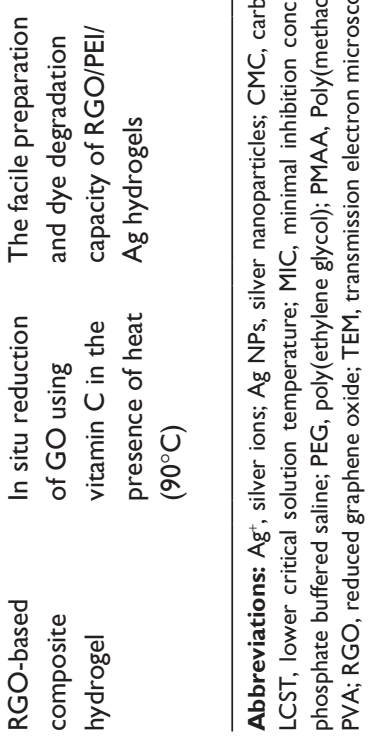


bacteria, including methicillin-resistant $S$. aureus (MRSA), $P$. aeruginosa, Enterobacter aerogenes and E. coli $\mathrm{K}-12$ substrain DH5-alpha (pPCR-Script AMP SK $\left.{ }^{+}\right) .{ }^{86}$ Though Nisopropylacrylamide-based hydrogels containing Au NPs and pH-responsive PMAA hydrogel microcapsules carrying Au NPs had already been reported, ${ }^{87,88}$ their antimicrobial property had not been studied until Gao et al $^{89}$ demonstrated that hydrogel containing Au NP-stabilized liposomes for antimicrobial application displayed excellent antibacterial properties on S. aureus without skin toxicity in a mouse model. In the research of Ribeiro et al, ${ }^{90}$ silk fibroin/nanohydroxyapatite hydrogel modified with in situ-synthesized Au NPs showed antimicrobial activity. Compared with Ag NPs, no toxicity against osteoblastic cells was found, which means Au NPs could be used for bone regeneration..$^{90}$ Moreover, Jayaramudu et al ${ }^{91}$ used acrylamide (AM) and wheat protein isolate (WPI) to develop biodegradable gold nanocomposite hydrogels. The results indicated that these biodegradable gold nanocomposite hydrogels can be used as potential candidates for antibacterial applications. ${ }^{91}$ Through combination of bimetallic (Ag, Au) hydrogel nanocomposites, Ranga Reddy et $\mathrm{al}^{92}$ took it one step further to enhance their antimicrobial activity. Varaprasad et $\mathrm{al}^{93}$ even prepared dual-metallic $\left(\mathrm{Ag}^{0}-\mathrm{Au}^{0}\right)$ nanoparticles via a green process with mint leaf extract, which exhibited significant antibacterial activity against Bacillus and E. coli (Figure 3). Although the antimicrobial ability of Au NPs is weaker than that of Ag NPs, the Au NPs have their own advantages. The antibacterial spectrum of Ag NPs is broad, including MRSA. Moreover, the hydrogels with $\mathrm{Au}$ NPs showed negligible interference to bone regeneration. These properties of hydrogels with Au NPs make them promising materials in clinical orthopedic surgery.

\section{Zinc oxide nanoparticles ( $\mathrm{ZnO}$ NPs)}

There are also many other metal nanoparticles with antimicrobial activities besides silver and gold, ${ }^{94,95}$ but only a few are embedded into hydrogels. Among these, zinc is the most popular antimicrobial agent. ${ }^{96,97} \mathrm{ZnO}$ NPs are used in many cosmetic materials because of their well-known antibacterial activity and non-cytotoxicity at an appropriate concentration. ${ }^{98} \mathrm{ZnO}$ NPs combat microbes through multiple mechanisms. Resistance to $\mathrm{ZnO}$ NPs is rarely reported. ${ }^{31}$ Some of the mechanisms are as follows: 1) ZnO NPs bind to bacterial cell membranes tightly and destroy both the lipids and proteins of the membrane causing increased membrane permeability and cell lysis; and ${ }^{31,33,95}$ 2) ZnO NPs also cause the formation of $\mathrm{Zn}^{2+}$ ions and ROS, including hydrogen peroxide $\left(\mathrm{H}_{2} \mathrm{O}_{2}\right)$, which damage the bacterial cell. ${ }^{33,35}$

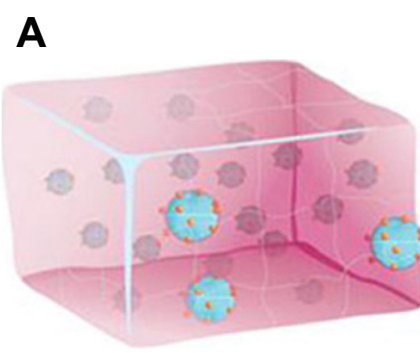

AuC-liposome hydrogel

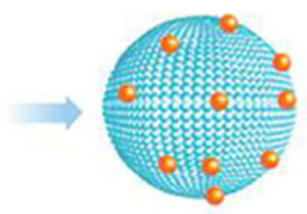

Released AuC-liposomes at $\mathrm{pH}=7.4$

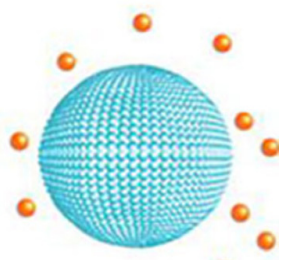

Released liposomes at $\mathrm{pH}=4.5$
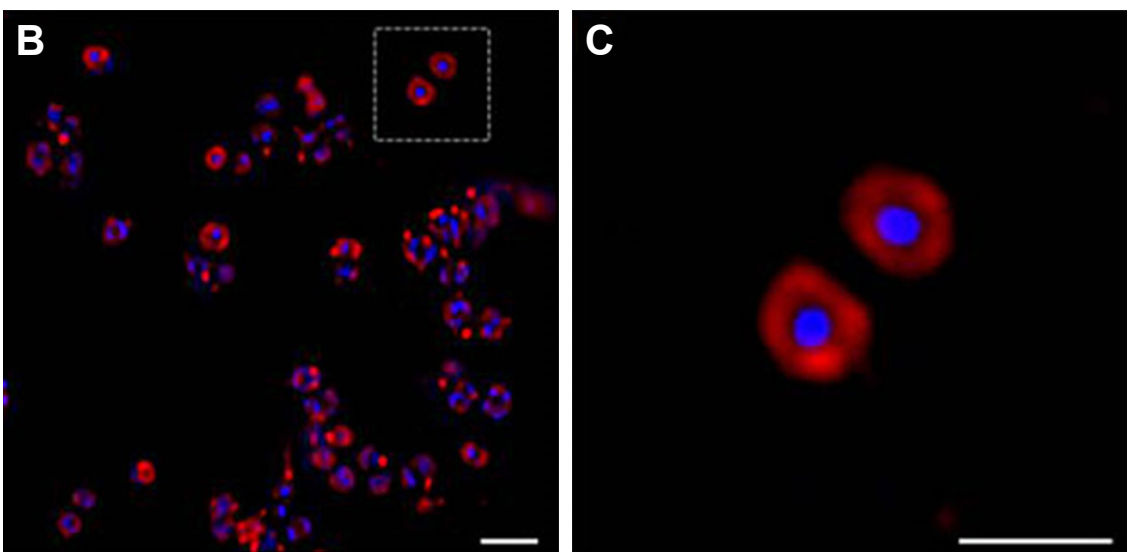

Figure $3 \mathrm{Gao}$ et al synthesized hydrogel containing Au NP-stabilized liposomes for antimicrobial application (A) illustrations of hydrogel containing nanoparticle-stabilized liposomes for topical antimicrobial delivery; (B) bacteria incubated with AuC-liposome hydrogel (PEGDMA 0.8 vol\%) at pH = 4.5; (C) a zoomed-in image of (B). Note: The scale bars in (B and $\mathbf{C}$ ) represent I $\mu \mathrm{m}$. Reproduced from Gao W, Vecchio D, Li J, et al. Hydrogel containing nanoparticle-stabilized liposomes for topical antimicrobial delivery. ACS Nano. 2014;8(3):2900-2907.89 
ZnO NPs are effective against both Gram-positive and Gram-negative bacteria because of their antibacterial activity against high temperature-resistant and high pressure-resistant bacterial spores. ${ }^{99}$ Similar to Ag NPs, ZnO NPs were incorporated into PNIPAM as antimicrobial hydrogel coatings, which was demonstrated to be a promising candidate for novel biomedical device coatings. ${ }^{100,101}$ Yadollahi et al ${ }^{102}$ synthesized $\mathrm{CMC} / \mathrm{ZnO}$ nanocomposite hydrogel through the in situ formation of ZnO NPs within swollen CMC hydrogels which demonstrated their antibacterial effects against E. coli and $S$. aureus bacteria. Nanocomposite hydrogels with IPN structure based on PEG methyl ether methacrylatemodified $\mathrm{ZnO}$ (ZnO-PEGMA) and 4-azidobenzoic agarose (AG-N3) exhibited an increasing anti-adhesive property and bactericidal activity toward Gram-negative E. coli and Gram-positive $S$. aureus. ${ }^{103}$ Moreover, the $\mathrm{ZnO}$ hydrogels showed great potential in drug carrying and wound healing in some recent studies. ${ }^{103-105} \mathrm{CMC}$ and CS hydrogels were also reported to be used as a hydrogel matrix for $\mathrm{ZnO}$ NPs. ${ }^{98,99,106}$ CMC hydrogels exhibited antibacterial activity against both Gram-positive and Gram-negative bacteria, and CS hydrogels were confirmed eligible wound dressing materials. ${ }^{103,107,108}$ Although the antibacterial ability of $\mathrm{ZnO}$ NPs is relatively weak, the low cytotoxicity still indicated that $\mathrm{ZnO}$ NPs have potential in clinical use. Moreover, $\mathrm{ZnO}$ NPs have a positive effect on bone regeneration, ${ }^{109}$ which means $\mathrm{ZnO}$ NPs are promising materials in orthopedic surgery.

\section{Other metal nanoparticle-based antimicrobial hydrogels}

There are many other metal nanoparticles combined with hydrogels, which have been studied in recent years. Their antibacterial mechanisms are shown in Figure $4 .{ }^{31}$ Apart from these commonly used metal nanoparticles, cytocompatible nickel nanoparticle-loaded chitin hydrogels were developed against $S$. aureus, ${ }^{110}$ and antibacterial cobalt-exchanged natural zeolite/PVA hydrogel was proved to have antibacterial activity against $E$. coli. ${ }^{111}$ Although copper-containing NPs $(\mathrm{Cu} \mathrm{NPs} / \mathrm{CuO} \mathrm{NPs})$ have weaker antibacterial effects than Ag NPs, they have a greater range of microbicidal activities against both fungi, especially Saccharomyces cerevisiae, and bacteria, including E. coli, S. aureus and Listeria monocytogenes. ${ }^{112-114} \mathrm{CMC} /$ $\mathrm{CuO}$ nanocomposite hydrogels and CS hydrogel loaded with copper particles demonstrated excellent antibacterial effects against $E$. coli and $S$. aureus without causing any toxicity in recent studies. ${ }^{115,116}$ It was reported recently that magnesium-containing nanoparticles, including magnesium halogen-containing nanoparticles $\left(\mathrm{MgX}_{2} \mathrm{NPs}\right)$ and magnesium oxide-containing nanoparticles (MgO NPs), also combat microbes through multiple mechanisms. ${ }^{17-119}$ Hezaveh and Muhamad ${ }^{120}$ loaded MgO NPs to hydrogels prepared from hydroxyalkyl $\kappa$-carrageenan derivatives, thus controlling the drug delivery in gastrointestinal tract studies. This may enlighten us with the idea that we can load hydrogels with metal nanoparticles or other ingredients to adjust the release of other drugs in the same system. Different from Ag NPs and Au NPs, other metal nanoparticles might need further exploitation as many of these kinds of metals or their alloys appear more in designing and fabricating modern medical biomaterials. The hydrogels with other metal nanoparticles are recorded in Table 2.

Hydrogel with metal nanoparticles might be a way to solve antibiotic resistance. There are several advantages of these antimicrobial materials. First, metal nanoparticles could be good substitutes for antibiotics. Despite widespread use of metal nanoparticles, bacterial resistance has been rarely reported. This is presumably due to the multiple mechanisms of antimicrobial action (Table 3), while antibiotics usually have only one mechanism of action. Second, the small size of particles allows them to pass through peptidoglycan cell walls and cell membranes, getting into the cytoplasm of bacterial cells easily. Third, metal nanoparticles are stable in quality, which means they could go on to kill other microbial cells after being released from dead cells. Metal nanoparticles could bring sustainable antimicrobial effect in this way. Finally, hydrogels can offer delivery system for local application. Antibacterial property improves with increasing concentration of nanoparticles. The concentration of metal nanoparticles could be high at the infection zone. All the abovementioned advantages indicate that hydrogels with nanoparticles can help to solve the present-day challenges of antimicrobial medicine.

\section{Hydrogel loaded with micromolecular drugs}

Micromolecular drugs include various antibiotic agents, such as antibiotics, biological extracts and synthetic antimicrobial drugs. All these drugs have been used for their great antimicrobial properties clinically. Usually, they are systematically used in the hospital. Once carried by hydrogels, they can be used locally around the focus, and are a good way to reduce the dosage and the appearance of resistance.

\section{Antibiotics}

Though antibiotics were discovered later than metal antimicrobial agents in human history, they are undoubtedly the most 


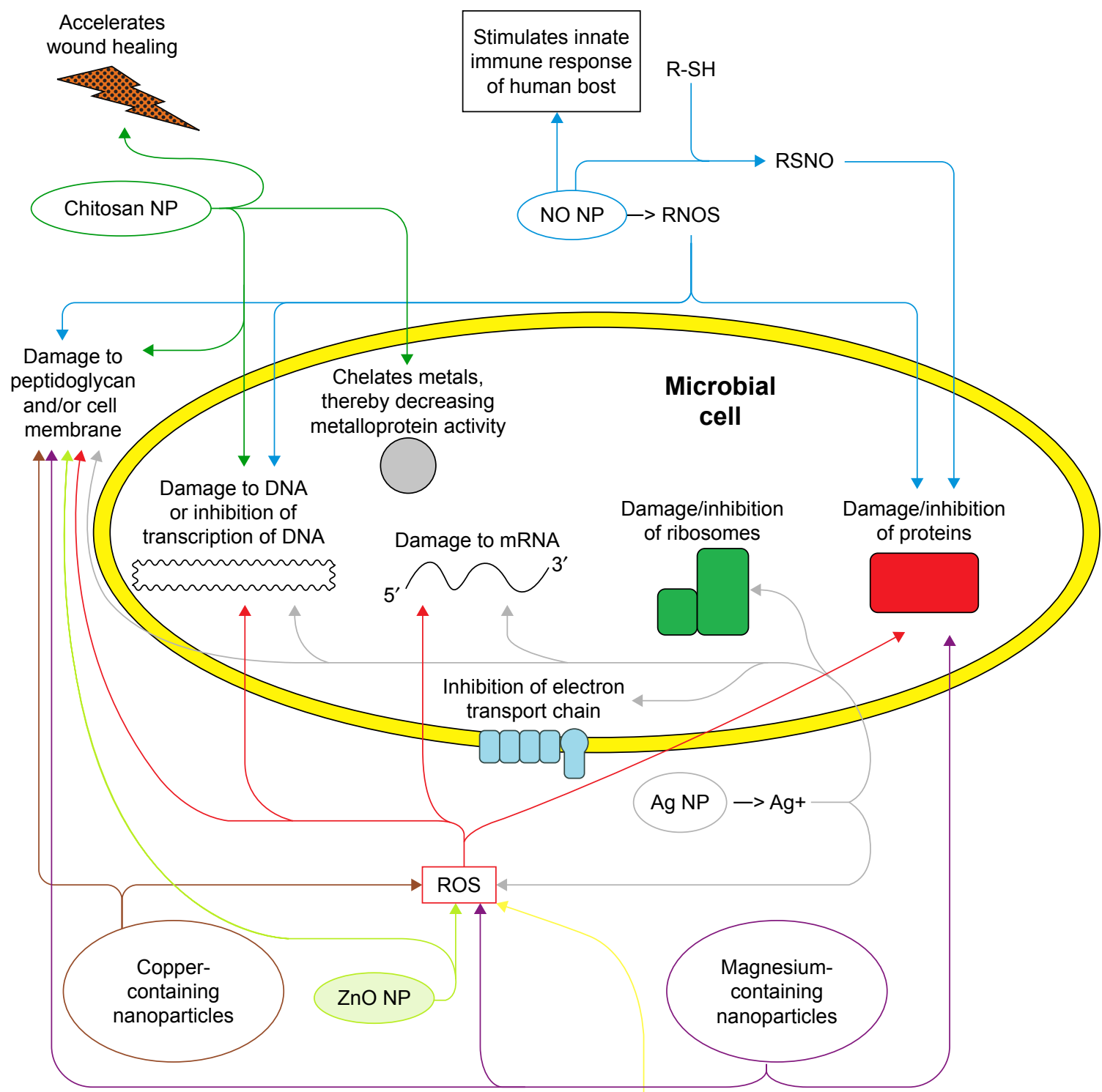

Near-UV or UVA radiation $\longrightarrow \mathrm{TiO}_{2} \mathrm{NP}$

Unknown antimicrobial mechanisms

Figure 4 Multiple mechanisms of antimicrobial action of Ag NPs, ZnO NPs, copper-containing nanoparticles and Mg NPs are separately exhibited.

Note: Reprinted from Adv Colloid Interface Sci. I66(I-2). Dallas P, Sharma VK, Zboril R, Silver polymeric nanocomposites as advanced antimicrobial agents: classification, synthetic paths, applications, and perspectives, I19-135, Copyright 20II, with permission from Elsevier. ${ }^{37}$

Abbreviations: Ag NPs, silver nanoparticles; Mg NPs, magnesium-containing nanoparticles; NP, nanoparticle; ROS, reactive oxygen species; UV, ultraviolet; ZnO NPs, zinc oxide nanoparticles.

commonly used, and the most effective antimicrobial agents until now. ${ }^{121}$ The drug-resistant effect of antibiotics becomes the biggest obstacle on the development and application of antibiotics. In recent years, there have been several new antibiotic approvals as well as renewed interest in second- and third-line antibiotics because of the concerns mentioned earlier. ${ }^{9}$ Almost all recent antibiotic resistance appeared in the year when the resistant bacterium were discovered (Figure 5). In recent studies, only one antibiotic, teixobactin, has no resistant bacteria strains. ${ }^{122}$ It is very effective to Gram-positive bacteria. However, the antibacterial spectrum of teixobactin does not include Gram-negative bacteria. ${ }^{123}$ Moreover, the lack of selection of resistance to teixobactin in vitro should be viewed with great caution before large scale of clinical use. ${ }^{124}$ Although the Governments of US and European Union tried to make it attractive, most pharmaceutical companies have stopped, or severely limited, investments to discover or develop new antibiotics to treat the increasing prevalence of infections caused by multidrug-resistant bacteria. ${ }^{125}$ The 


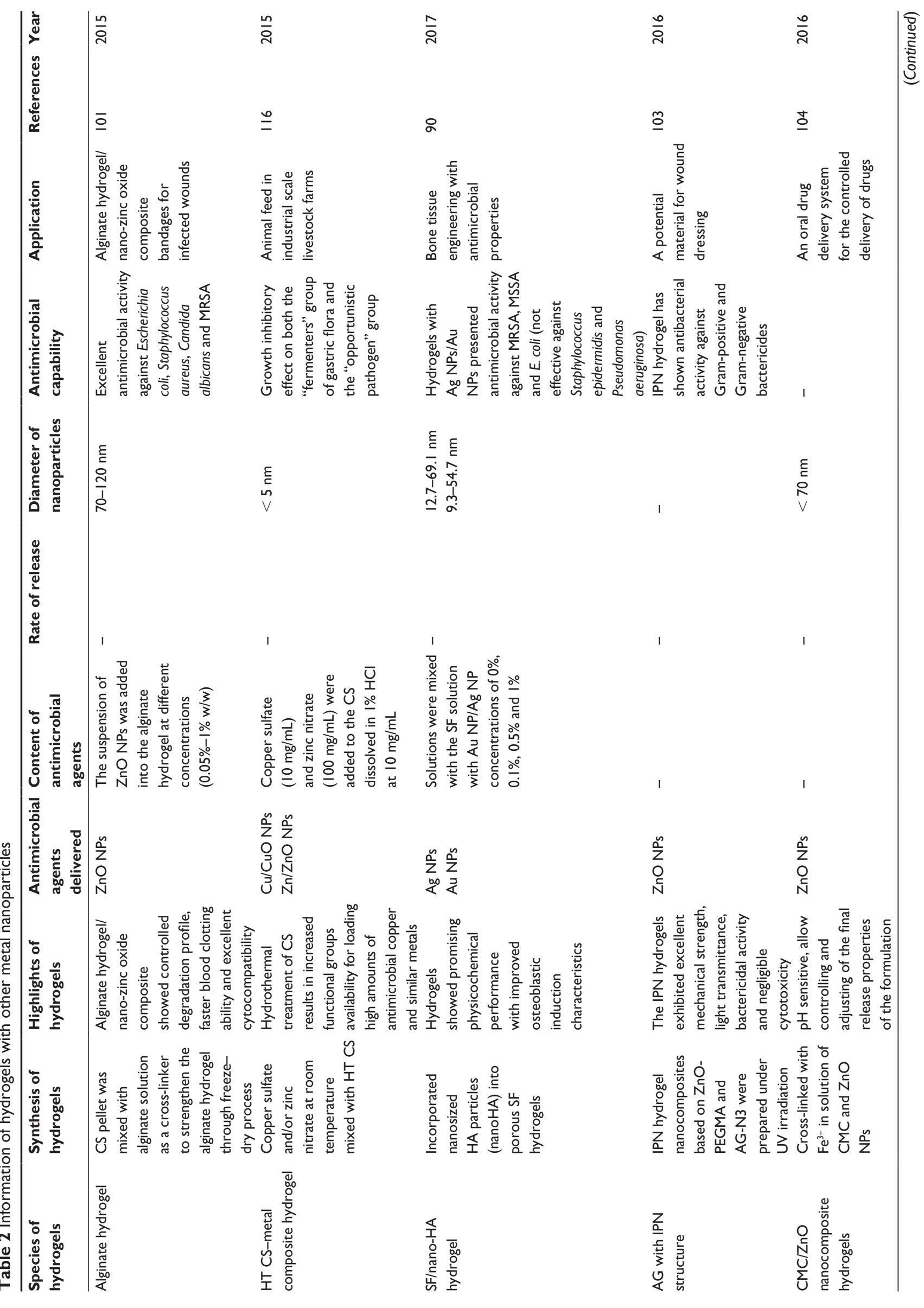




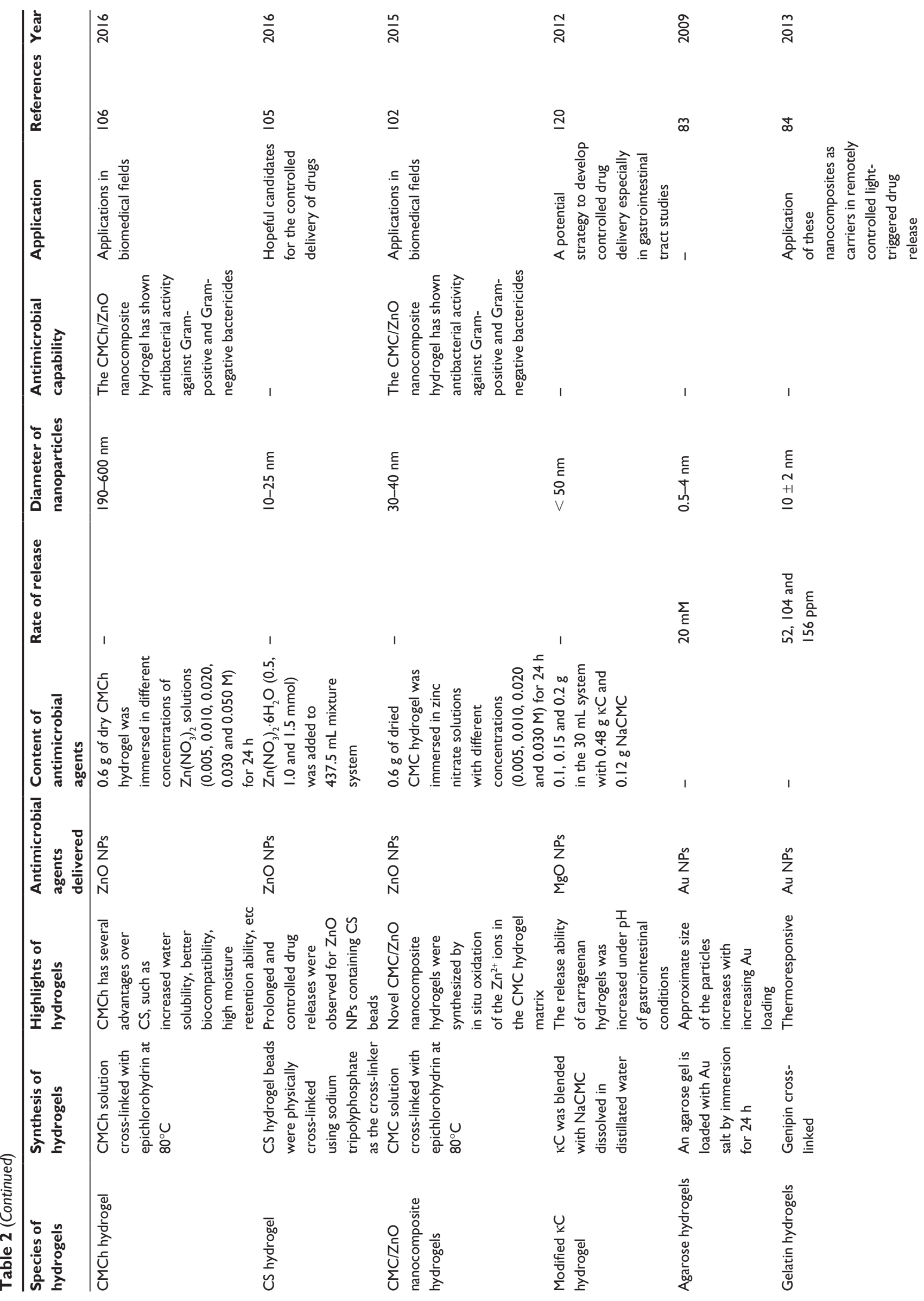


ڤัे

$\infty$

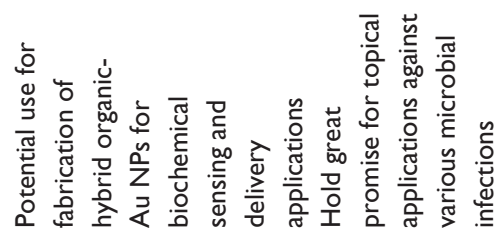

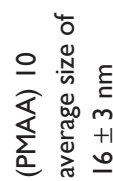

1

$\frac{n}{z}$

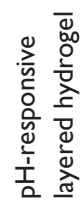

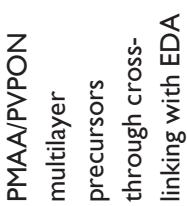

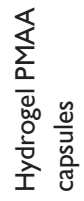
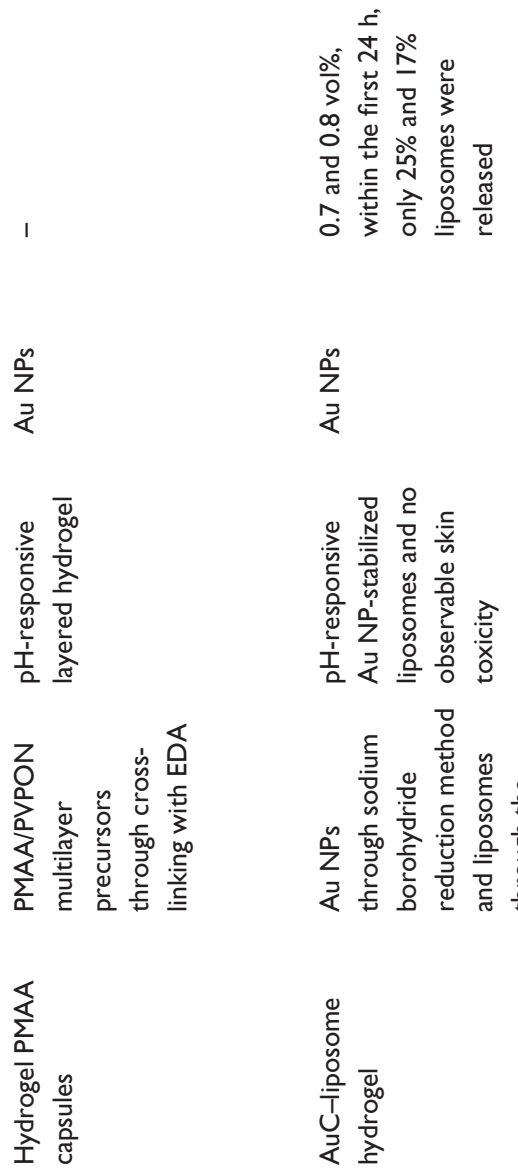

$\infty$

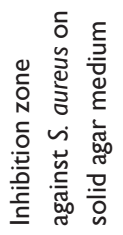

$\frac{4}{2}$

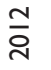

2
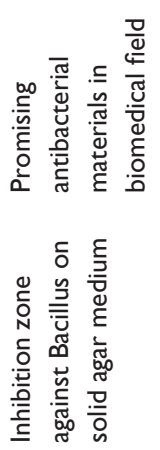

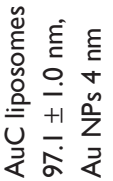

نั

疋

돈

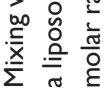

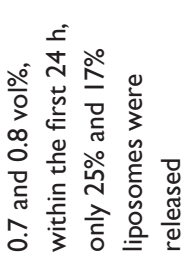

$\sum_{z}^{n}$

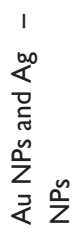

호

$\overline{\bar{N}}$

ำ

ล

$\stackrel{\infty}{\circ}$
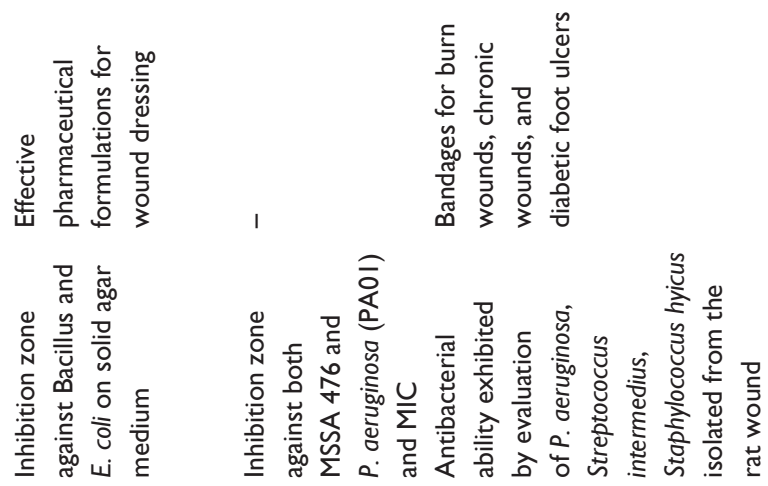

$E$
$m$
$m$
+1
$n$

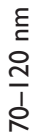

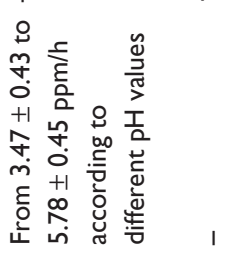

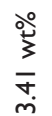

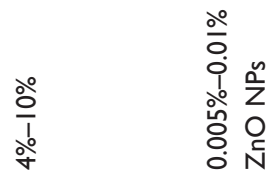

$\sum_{\substack{0 \\ 0}}^{\infty 00}$

$\sum_{z}^{n} \frac{n}{z}$

零岕

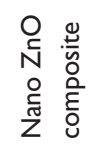
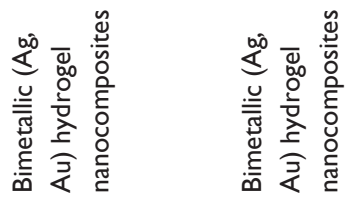

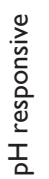
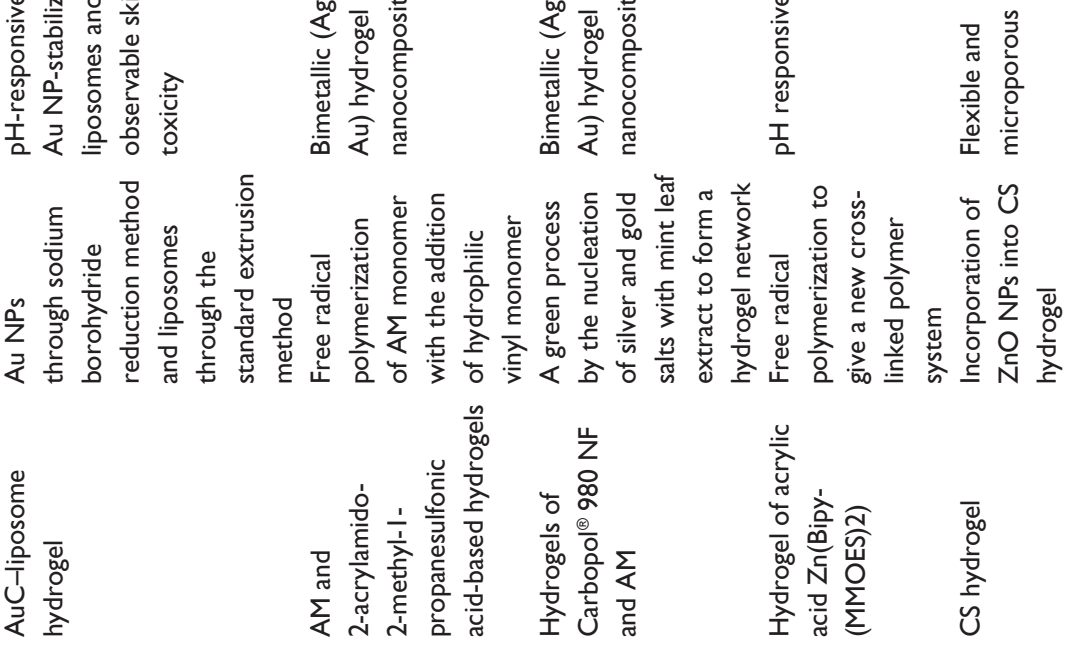

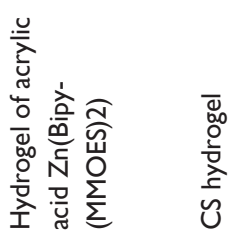




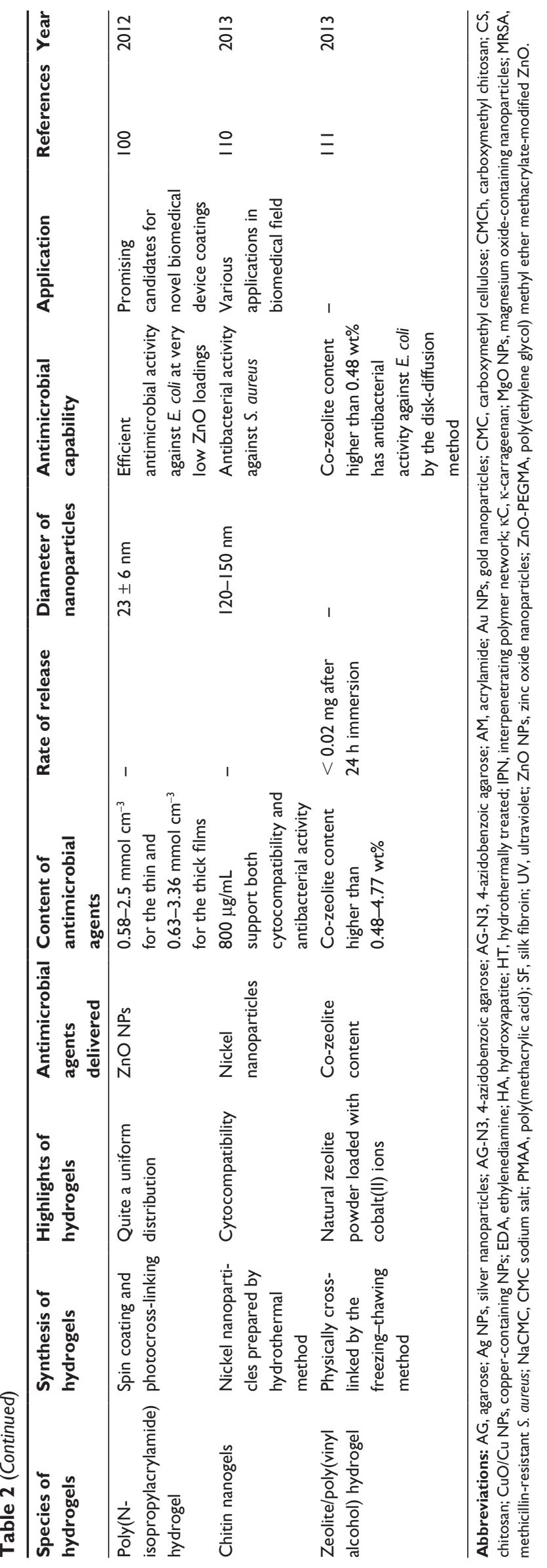

reason is that return on investment has been mostly negligible for antibiotics with US Food and Drug Administration (FDA) certification in the last few decades. ${ }^{126}$ There are two main ways to overcome antibiotic resistance, one is manufacture of novel antibiotics, and the other is minimizing the dosage to decrease antibiotic resistance. ${ }^{127}$ To achieve the second aim, local antibiotic administration has drawn increasing attention in recent years to improve the treatment effects. Antibioticloaded systems can deliver an adequate local bactericidal dose directly to the infected site, without significantly overtaking the systemic toxicity level. ${ }^{128}$ Hydrogels, as a kind of local administration matrix, offer high surface area to volume ratio and the capacity to design their physical properties such as porosity to match natural tissue. Recent studies have shown that a combination of synthetic antimicrobial polymers and antibiotics could potentially evade problems of drug resistance by taking advantages of the polymer's membrane-lytic mechanism. Meanwhile, polymer toxicity is mitigated as the co-usage of antibiotics allows for a smaller amount of polymer in use. ${ }^{2}$ So, it is easy for hydrogels to selectively load drug molecules with controlled release at the desirable site and to offer accurate prolonged release..$^{31,129-131}$ The antibiotics in common use for antimicrobial hydrogels are as follows.

\section{Ciprofloxacin}

Ciprofloxacin is a fluoroquinolone antibacterial agent, which is active against a broad spectrum of Gram-positive and Gram-negative bacteria. ${ }^{136}$ It is the gold standard for various topical applications, such as eye and skin infections. ${ }^{137}$ Ciprofloxacin is also a recommended treatment for Shigella infections. However, ciprofloxacin-resistant Shigella sonnei are being increasingly isolated in Asia and sporadically reported on other continents. ${ }^{138,139}$ The mechanism of ciprofloxacin depends upon blockage of bacterial DNA duplication by binding itself to DNA gyrase, thereby causing double-stranded ruptures in the bacterial chromosomes, so resistance to this drug develops slowly. ${ }^{140}$ Minimal toxicity of ciprofloxacin is related to dosage, and excessive doses can cause damages to tissues, whereas hydrogels can solve this problem as a local delivery system.

Ciprofloxacin can be self-assembled with a tripeptide into an antimicrobial nanostructured hydrogel to enable abundant drug to be carried along with prolonged release. ${ }^{129,137}$ Modified hydrogel coatings were reported to prevent titanium implantassociated infections. ${ }^{128} \mathrm{~A}$ hydrogel generated by polymerizing aminophenyl boronic acid in PVA with ciprofloxacin was reported to treat wound healing in diabetes patients. ${ }^{141}$ It has been reported that diseases associated with the colon 
Table 3 Antimicrobial mechanism of nanoparticles

\begin{tabular}{|c|c|c|}
\hline Nanoparticles & Antimicrobial mechanisms & References \\
\hline $\mathrm{Ag} N P s$ & $\begin{array}{l}\text { I. Ag dissolved from } \mathrm{Ag} \mathrm{NPs} \text { interact with sulfur-containing and phosphorus-containing groups of proteins of } \\
\text { the cell wall and plasma membrane of bacteria. Binding to negatively charged parts of the membrane creates } \\
\text { holes in the membrane, allowing plasma contents (including } \mathrm{K}^{+} \text {) to flow out of the cell, dissipating the } \mathrm{H}^{+} \\
\text {gradient across the membrane. } \\
\text { 2. Inside the microbial cell, } \mathrm{Ag} \mathrm{NPs} \text { exert several antimicrobial effects: I) inhibiting cytochromes of the electron } \\
\text { transport chain of microbes; 2) causing damage to DNA and RNA of microbes; } 3 \text { ) inducing formation of } \\
\text { ROS, which are also toxic to host cells; and 4) inhibiting cell wall synthesis in Gram-positive bacteria. } \\
\text { 3. After the } \mathrm{Ag} \mathrm{NPs} \text { are leaked from the dead microbes, } \mathrm{Ag} \mathrm{NPs} \mathrm{could} \mathrm{go} \mathrm{on} \mathrm{to} \mathrm{kill} \mathrm{other} \mathrm{microbial} \mathrm{cells.}\end{array}$ & $34,36,39-42$ \\
\hline Au NPs & $\begin{array}{l}\text { Au NPs can be attached to bacterial membrane, which leads to leakage of bacterial contents or penetration of } \\
\text { the outer membrane and peptidoglycan layer, resulting in bacterial death. }\end{array}$ & 85 \\
\hline Au NP-Amp & $\begin{array}{l}\text { First, the presence of multiple Amp molecules on the surface of Au NP allows the Au NP-Amp to overwhelm } \\
\text { high concentrations of beta-lactamase expressed by these bacteria. Second, Au NP-Amp inhibits the } \\
\text { transmembrane pump that catalyzes drug efflux from the bacterial cell. }\end{array}$ & 86 \\
\hline $\mathrm{ZnO} N P s$ & $\begin{array}{l}\text { I. } \mathrm{ZnO} N P s \text { bind to bacterial cell membranes and destroy the lipids and proteins on them. } \\
\text { 2. } \mathrm{ZnO} \text { NPs could cause formation of } \mathrm{Zn}^{2+} \text { ions and ROS, which damage the bacterial cell. } \\
\text { 3. When coated with PVA, ZnO NPs increase membrane permeability and enter the cytoplasm of the bacterial cell. }\end{array}$ & $\begin{array}{l}31,33,35 \\
95,98\end{array}$ \\
\hline $\mathrm{CuO} / \mathrm{Cu} \mathrm{NPs}$ & $\begin{array}{l}\text { I. } \mathrm{Cu} \text { interacts with amine and carboxyl groups on the surfaces of microbial cells. Therefore, microbes with } \\
\text { higher density of the two groups have higher sensitivity to } \mathrm{CuO} / \mathrm{Cu} \text { NPs. } \\
\text { 2. } \mathrm{Cu}+\text { ions induce formation of ROS. }\end{array}$ & $112-114$ \\
\hline $\mathrm{MgO} / \mathrm{MgX}{ }_{2} \mathrm{NPs}$ & $\begin{array}{l}\text { I. } \mathrm{MgO} / \mathrm{MgX}{ }_{2} \mathrm{NPs} \text { inhibit certain enzymes of microbial cells. } \\
\text { 2. } \mathrm{MgX}_{2} \mathrm{NPs} \text { may induce formation of ROS. } \\
\text { 3. } \mathrm{MgX}_{2} \mathrm{NPs} \text { inhibit growth and biofilm formation. } \\
\text { 4. Unlike any other metal, the antimicrobial activity of } \mathrm{MgO} \text { works by adsorbing halogen molecules onto the } \\
\text { surface of the } \mathrm{MgO} \text {. }\end{array}$ & $117-120$ \\
\hline
\end{tabular}

Abbreviations: Ag NPs, silver nanoparticles; Amp, ampicillin; Au NPs, gold nanoparticles; CuO/Cu NPs, copper-containing NPs; MgO NPs, magnesium oxide-containing nanoparticles; $\mathrm{MgX}_{2} \mathrm{NPs}$, magnesium halogen-containing nanoparticles; PVA, polyvinyl alcohol; ROS, reactive oxygen species; ZnO NPs, zinc oxide nanoparticles.

such as constipation may be treated with hydrogels containing laxative psyllium and ciprofloxacin. ${ }^{142}$ Hosny $^{136}$ demonstrated that a liposomal hydrogel containing ciprofloxacin improved maximum ocular availability through albino rabbit cornea.
In the research of Zhou et al, ${ }^{143}$ porous scaffolds of PVA were prepared by quenching in liquid nitrogen and the freeze drying method, from different concentration aqueous solutions loaded with ciprofloxacin were fabricated. Complete inhibition of

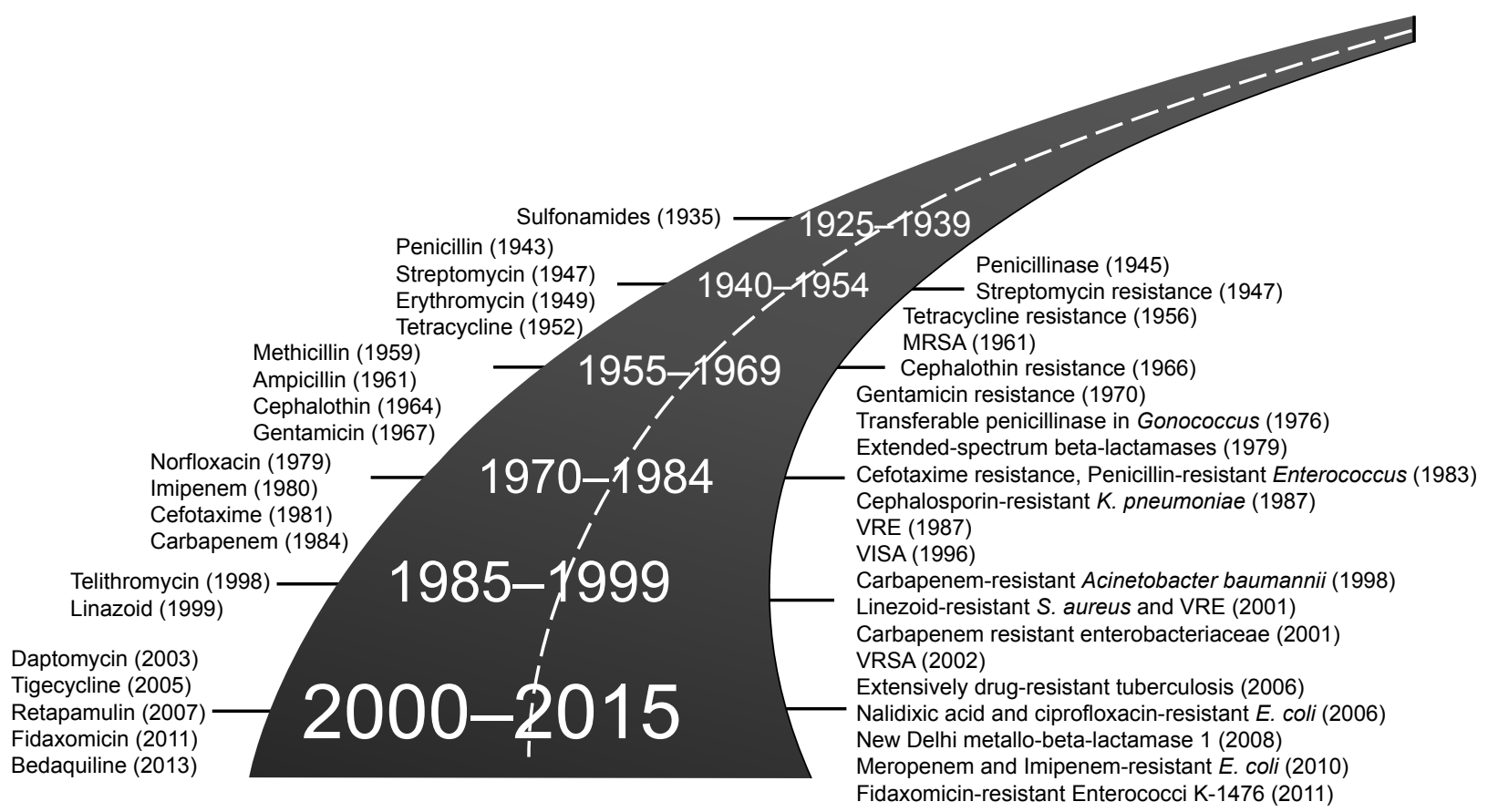

Figure 5 Development of antibiotics and appearance of drug resistance are summarized chronologically referring to Huh and Kwon, ${ }^{35}$ Andersson and Hughes, ${ }^{132}$ RodriguezRojas et al, ${ }^{133}$ van Hoek et al, ${ }^{134}$ Molton et al. ${ }^{135}$

Abbreviations: E. coli, Escherichia coli; K. pneumoniae, Klebsiella pneumoniae; MRSA, methicillin resistant S. aureus; S. aureus, Staphylococcus aureus; VISA, vancomycin intermedicate resistant S. auereus; VRE, vancomycin-resistant Enterococcus; VRSA, vancomycin-resistant S. aureus. 
microorganism growth revealed the sustaining release of ciprofloxacin. Other researchers used dextrin and poly-based hydrogel as a carrier for ciprofloxacin, and the results suggest that hydrogel was a promising candidate for controlled release of ciprofloxacin. ${ }^{144,145}$ These studies indicate that the hydrogels loaded with ciprofloxacin have great potential of clinical administration, especially for infectious diseases due to their excellent antimicrobial properties and prolonged effect.

\section{Gentamicin}

Gentamicin is a traditional broad spectrum antibiotic used for the treatment of skin and soft tissue infections. However, systemic toxicity, especially for kidney, and low plasma concentration hinder its application. ${ }^{146}$ To avoid the side effects, gentamicin is often used locally nowadays. ${ }^{147,148}$ Local administration of functional gentamicin hydrogels offers an efficient solution. Gentamicin-loaded PVA and PVA-AAm hydrogels cross-linked by sterculia have many biomedical properties such as blood compatibility, tensile strength, burst strength, water vapor permeability and oxygen diffusion. It can be a kind of potent antimicrobial wound dressings. ${ }^{149,150}$ Superabsorbent polysaccharide gentamicin hydrogels based on pullulan derivatives also brought a broadened view about antimicrobial hydrogels. It may become one of the important applications in the future with the ability to expand to $4,000 \%$ of its volume. ${ }^{151}$ Phospholipid-modified solid lipid microparticles encapsulating gentamicin were loaded into three polymeric hydrogels. Poloxamer 407 microgels were proved to have the most desirable properties in terms of fast antibacterial activity, in vitro diffusion-dependent permeation, spread ability, $\mathrm{pH}$ and viscosity. ${ }^{152}$ This implied that the same drug can reach different diffusion speeds on hydrogels of different matrices. Hydrogel based on the copolymer poly(Nisopropylacrylamide-co-dimethyl- $\gamma$-butyrolactoneacrylateco-Jeffamine ${ }^{\circledR}$ M-1000 acryl amide) (PNDJ) with delivery in $>6$ weeks was loaded with gentamicin. This hydrogel might decrease treatment failure for orthopedic infection. ${ }^{153}$ Inspiringly, Wu et al ${ }^{154}$ found that gentamicin sulfate (GS)-loaded carboxymethyl-chitosan (CMCh) hydrogel cross-linked by genipin was an effective and simple approach to achieve combined antibacterial efficacy and excellent osteoblastic cell responses, which has great potential in orthopedic applications. In open orthopedic surgeries, gentamicin-loaded thermosetting composite hydrogels, which were prepared combining CS with bovine bone substitutes (Orthoss ${ }^{\circledR}$ granules, Orange, CA, USA), beta-glycerophosphate as a cross-linker and lyophilized to obtain moldable composite scaffolds (moldable composite scaffold loaded with gentamicin [mCSG]), were considered to reduce the infection risks. ${ }^{155}$
The hydrogels have broken the limit of gentamicin application since the effective dosage can be decreased. Other antibiotics with serious side effects can also be used with hydrogels.

\section{Vancomycin}

Vancomycin, a macromolecular glycopeptide antibiotic, is considered as the last defense of infection clinically, especially for methicillin-resistant Staphylococcus. ${ }^{156,157}$ But now even vancomycin-resistant Enterococcus (VRE) has been found in different regions. ${ }^{158-160}$ As mentioned earlier, hydrogels as a delivery system are able to protect and enhance the validity of vancomycin. Syringeable pluronic- $\alpha$-cyclodextrin (CD) supramolecular gels, ${ }^{161}$ hydrogel of thiolated CS cross-linked with maleic acid-grafted dextrin, ${ }^{162}$ thermosensitive hydrogel of CS/gelatin/ $\beta$-glycerol phosphate, ${ }^{163}$ hydrogel of oligo(PEG fumarate)/sodium methacrylate (OPF/SMA) charged copolymers as biocompatible matrices, ${ }^{164} \operatorname{poly}(\beta$-amino ester $)$ (PBAE) hydrogels mixed with PEG $(\mathrm{MW}=400)$ diacrylate (PEGDA) and diethylene glycol diacrylate (DEGDA) ${ }^{165}$ and hydrogels achieved by photo cross-linking of methacrylated dextran and poly(L-glutamic acid)-g-hydroxyethyl methacrylate are all studied, and they exhibited excellent antimicrobial properties and desirable release capacity. ${ }^{166}$ The most common pathogen of osteomyelitis is S. aureus, especially MRSA. Vancomycin is always used in the treatment of osteomyelitis because it is the most effective antibiotic against MRSA. The combination of hydrogels and vancomycin is a good material, which can prevent osteomyelitis clinically.

\section{Synthetic antimicrobial drugs}

Here, synthetic antimicrobial drugs refer to the nitroimidazoles, sulfanilamide groups and other frequently used antibiotics through de novo synthesis, not including semi-synthetic antibiotics or biological extract. Synthetic drugs have many advantages because of their special chemical structures, but they bring risks and damage to normal tissue for the same reason too. So, stable and safe delivery systems become necessary. ${ }^{167}$ Nitroimidazoles can have an effect on anaerobic bacteria and amoeba, so they are often used for the digestive system. ${ }^{168}$ Ornidazole has been loaded on hydrogels composed of CMCh for colon-targeted delivery, and its release can be controlled by a change in $\mathrm{pH} \cdot{ }^{163,169}$ Das et al ${ }^{130,144,170}$ used dextrin and poly-based hydrogel as a carrier for ornidazole, and the result suggests that the hydrogel was a promising vehicle. Hydrogels based on dextrin grafted with poly(2hydroxyethyl methacrylate) by embedding N,N-methylene bisacrylamide as a cross-linker can also be a good candidate for an orally administered drug delivery system for the colon region. ${ }^{130}$ Metronidazole (MTZ) containing PMAA nanogel 
as an oral dosage form for gastrointestinal infection ${ }^{171}$ and tinidazole containing hydrogels based on CS have also been studied. ${ }^{172}$ Moreover, floating $\mathrm{pH}$-sensitive CS hydrogels containing MTZ were more effective against Helicobacter pylori than the commercially available oral MTZ tablets. ${ }^{173}$ $\mathrm{CS} /$ gelatin/ $\beta$-glycerol phosphate hydrogels could maintain sustained release of MTZ in concentrations that are effective for eliminating pathogenic bacteria over time. ${ }^{163}$ Chlorhexidine is considered a promising antimicrobial agent and possesses a broad spectrum of activity against bacteria. ${ }^{174}$ Chlorhexidine thermosensitive hydroge ${ }^{175}$ and chlorhexidine diacetate containing thermoresponsive hydrogel copolymers exhibit novel application of this traditional sterilization agent. ${ }^{176}$ In recent research studies, the micrometer-sized $\beta$-CD-based hydrogel (bCD-Jef-MPs) system also achieved sustained release of chlorhexidine digluconate, thus treating periodontitis lesions became effective. ${ }^{177}$ The prolonged release has made it possible to decrease its dosage. Therefore, its side effects were reduced. Octenidine, as an external application, has become active wound dressings with minimized side effects after being loaded on bacterial nanocellulose. ${ }^{178}$ Thiosemicarbazone, an antimicrobial drug used in ophthalmic diseases, was loaded on poly(2-hydroxyethyl methacrylate)conjugated beta-CD or directly cross-linked hydroxypropylbeta-CD to explore novel materials for fabrication of soft contact lenses. ${ }^{179}$ In the study by Sittiwong et al, ${ }^{180}$ the drug release rate of sulfanilamide-loaded PVA hydrogels could be controlled through the drug size, matrix pore size, electrode polarity and applied electric field. As for wound therapy, immobilization of cetylpyridinium chloride to PVA hydrogels offers suppressed release; ${ }^{181}$ chloramine-T and sulfadiazine sodium salt-loaded hydrogels composed of PVA, PVP and glycerin showed an excellent swelling capacity; ${ }^{182}$ a novel polyvinyl-pyrrolidone-iodine hydrogel in wound therapy was found to be able to enhance epithelialization and reduce loss of skin grafts; ${ }^{183}$ poly(N-hydroxyethyl acrylamide)/ salicylate hydrogels provide both antimicrobial and antifouling functions; ${ }^{184}$ and isothiazolinones delivered in alginate hydrogel sphere achieved long-term antibacterial activity by improvement of the alkali and heat resistances. ${ }^{185}$ All these evidence showed that novel applications of synthetic drugs and hydrogels can avoid risks and side effects. The combination of synthetic drugs and hydrogels offers us a an effective clinical antimicrobial method.

\section{Other antibiotics}

Besides the aforementioned most commonly used antibiotics, there are many other antibiotics loaded in hydrogels, such as amoxicillin, ampicillin, cephalosporin etc. Each of them has its own antibacterial spectrum and advantages. Amoxicillin trihydrate, a common treatment for peptic or gastric ulcers caused by $H$. pylori infection, ${ }^{186}$ loaded in $\kappa$-carrageenan hydrogels containing $\mathrm{CaCO}_{3}$ and $\mathrm{NaHCO}_{3}$ or CS/polygamma-glutamic acid nanoparticle $\mathrm{pH}$-sensitive hydrogels was well protected from the gastric juice, thus facilitating drug effects specifically at the site of infection. ${ }^{187,188}$ The similar results of in vivo studies by Moogooee et al ${ }^{189}$ showed that the amoxicillin-loaded hydrogels enhance drug concentration at the topical site than powder amoxicillin, meaning that therapeutic concentration can be achieved at a much lower dose which may reduce the adverse effects of amoxicillin in high doses. Ampicillin sodium-loaded PVAalginate physically cross-linked hydrogel exhibited both Gram-positive and Gram-negative antimicrobial properties and improved hemolysis. ${ }^{190}$ Cephalosporin belongs to betalactamase, and it is a widely used $\beta$-lactamase-resistant and broad spectrum antibiotic. ${ }^{191}$ Cefixime (CFX)-loaded CS/ PEG hydrogel exhibited controlled release of drug and antibacterial activity against Gram-negative bacteria (E. coli) and Gram-positive bacteria (S. aureus). ${ }^{192}$ Cefditoren pivoxil hydrogels with gastroretentive effect were achieved, ${ }^{193}$ and cefazolin containing methoxy PEG-co-poly(lactic acidco-aromatic anhydride) hydrogels offered a stable release without initial burst. ${ }^{194}$ Levofloxacin-loaded hyaluronic acid hydrogels were reported to be able to chase bacteria within the cells for both $S$. aureus and $P$. aeruginosa strains. ${ }^{127}$ In order to eradicate bacterial biofilm and avoid possible intestinal obstructions, Islan et a ${ }^{195}$ reported a smart autodegradable hydrogel containing alginate lyase (AL) and levofloxacin, which induced the reduction of drug toxicity and enhancement of drug bioavailability. A hydrogel based on (-)-menthol, which is a traditional cooling compound tailed by an amino acid derivate through an alkyl chain, can provide innoxious environment to living cells and deliver lincomycin to the local infection site. ${ }^{196}$ O-Carboxymethyl CS (O-CMCS) hydrogels synthesized from CS and monochloroacetic acid were reported as a promising carrier for antibiotics, which showed significant antibacterial activities against $E$. coli and $S$. aureus while loaded with lincomycin. ${ }^{197}$ Doxycycline was also loaded on an in situ thermally sensitive hydroxypropyl- $\beta-C D$ hydrogel for ophthalmic delivery. ${ }^{198}$ Controlled release of doxycycline from CS-gelatin hydrogels cross-linked with transglutaminase was observed in other research, indicating that it is a potential carrier for cell delivery. ${ }^{199}$ Mupirocin appears to be one of the promising antimicrobials, as it is well tolerated in topical administration with very few side effects. Liposomes-in-hydrogel delivery system for mupirocin solved the problem of controlled and 
prolonged release of mupirocin, which offered an improved burn therapy, and substantial efforts have been devoted in the literature to prove its antibiofilm activity against $S$. aureus biofilms and non-toxicity against keratinocytes. ${ }^{200,201}$ The methoxypoly(ethylene glycol)-co-poly(lactic-co-glycolic acid) (mPEG-PLGA) hydrogel containing teicoplanin was reported effective for treating osteomyelitis in rabbits. ${ }^{202}$ There are a plenty of reports about different antibiotics loaded in hydrogels, but the three mentioned earlier are the mostly used ones. However, other antibiotics and hydrogel offered us with more choices when facing different bacterial infections. Meanwhile, it decreases the risk of antibiotic resistance. The controlled release of antibiotics is another advantage of hydrogels. The stable and continuous release without initial burst would ensure prolonged antimicrobial effect which can satisfy clinical demand. To offer an easier query, most of the hydrogels with antibiotics are recorded in this review (Table 4).

\section{Biological extracts}

Biological extracts include extracts from vegetations and animals, some of these extracts have a long history of application, and others were discovered in recent years. ${ }^{203}$ For example, the therapeutic efficiency of herbal extracts and ingredients has been limited by various factors, including the lack of targeting capacity and poor bioavailability. Hydrogel is a promising carrier for the extracts of herbal medicine in recent studies. ${ }^{204}$ Following are reports of hydrogels loaded with various natural extracts. Seaweed extract-based hydrogel was reported as a novel antimicrobial wound dressing, and no seaweed-derived antimicrobials have been used in wound dressings ever before. ${ }^{205}$ Combinations of agar and carrageenan-PVA hydrogel wound dressing have been proved to be useful in treating burns, other external wounds and non-healing ulcers of diabetes. ${ }^{206}$ Hydrogels extracted and assembled from dermis samples containing basement membrane proteins vital to skin regeneration, including laminin $\beta 3$, collagen IV and collagen VII, were applied as a barrier against bacteria in wound healing. ${ }^{207}$ Though according to some research studies alginate does not display antimicrobial properties, it can be an ideal wound dressing due to its morphology, fiber size, porosity, degradation and swelling ratio. ${ }^{205-208}$ Allicin-CS complexes were proved to have antibacterial activity against spoilage bacteria, and they may be used as an antimicrobial agent in foods. ${ }^{209}$ CS-based hydrogel film loaded with ethyl acetate Salix alba leaves extract showed no cytotoxicity and excellent antibacterial ability against Salmonella typhi and Candida guilliermondii. ${ }^{210}$ Achyrocline satureioides is a medicinal plant widely used in South America, which exhibits a welldocumented antioxidant activity against Gram-positive and Gram-negative bacteria, as well as a set of yeast molds. ${ }^{211}$ Curcumin is non-toxic and bioactive agent with multifunction; it is found in turmeric and has been applied for centuries as a remedy to various ailments. ${ }^{212}$ However, low aqueous solubility and poor bioavailability limit the application of curcumin, and thus curcumin nanoparticles and hydrogels were developed. Ag NPs-curcumin hydrogels for wound dressing were also reported, exhibiting good antibacterial properties and sustained release, which indicate enormous prolonged therapeutic value. ${ }^{213,214}$ A polysaccharide extracted from Aloe vera, Acemannan, has various medical properties, such as antibacterial property, and it can accelerate healing of lesions. ${ }^{215}$ Some studies demonstrated its antibacterial activity against both susceptible and resistant $H$. pylori strains. ${ }^{216}$ Alginate hydrogels containing Aloe vera were applied in clinical wound care treatment due to their antimicrobial and anti-inflammation capacity. ${ }^{217}$ Essential oils, such as lavender, thyme oil, peppermint, tea tree, rosemary, cinnamon eucalyptus, lemongrass and others, have been found to possess particular antimicrobial properties, mainly in response to the overwhelming concern of consumers over the safety of synthetic food additives. ${ }^{218,219}$ Essential oils encapsulated in sodium alginate were reported to be qualified as disposable wound dressings. ${ }^{220}$ For those extracts from animals, honey was the most easily acquired; a Malaysian honey, Gelam honey, was incorporated into a hydrogel system to produce a functional wound dressing. ${ }^{221}$ Besides honey, bee propolis loaded into hydrogels has good antibacterial ability, making it a good wound dressing for skin wound healing. ${ }^{217}$ Another bee derivative is bee venom peptide, namely melittin, and its copolymer interactions on thermosensitive PLGA-PEGPLGA hydrogel can be used as delivery systems for peptide drugs. ${ }^{222}$ Lysozymes, derived from normal tears with their inherent antibacterial properties, were deposited on hydrogel contact lenses that exhibit marked activity. ${ }^{223}$ Vitamin $\mathrm{E}$ is also an important antioxidant, biodegradable hydrogel from vitamin E-functionalized polycarbonates for antimicrobial applications; it displayed excellent compatibility with human dermal fibroblast loaded with cationic polymers and/or fluconazole at minimum biocidal concentrations. ${ }^{224}$ Lignins and lignin-derived compound model polymer, dehydrogenate polymer (DHP) in alginate hydrogel, have shown strong antimicrobial and wound healing activity. ${ }^{225}$ These biological extracts are easier to get and more readily accepted. Excellent biocompatibility and good antibacterial properties also make them promising antimicrobial biomaterials in the future. However, with the studies ongoing, 


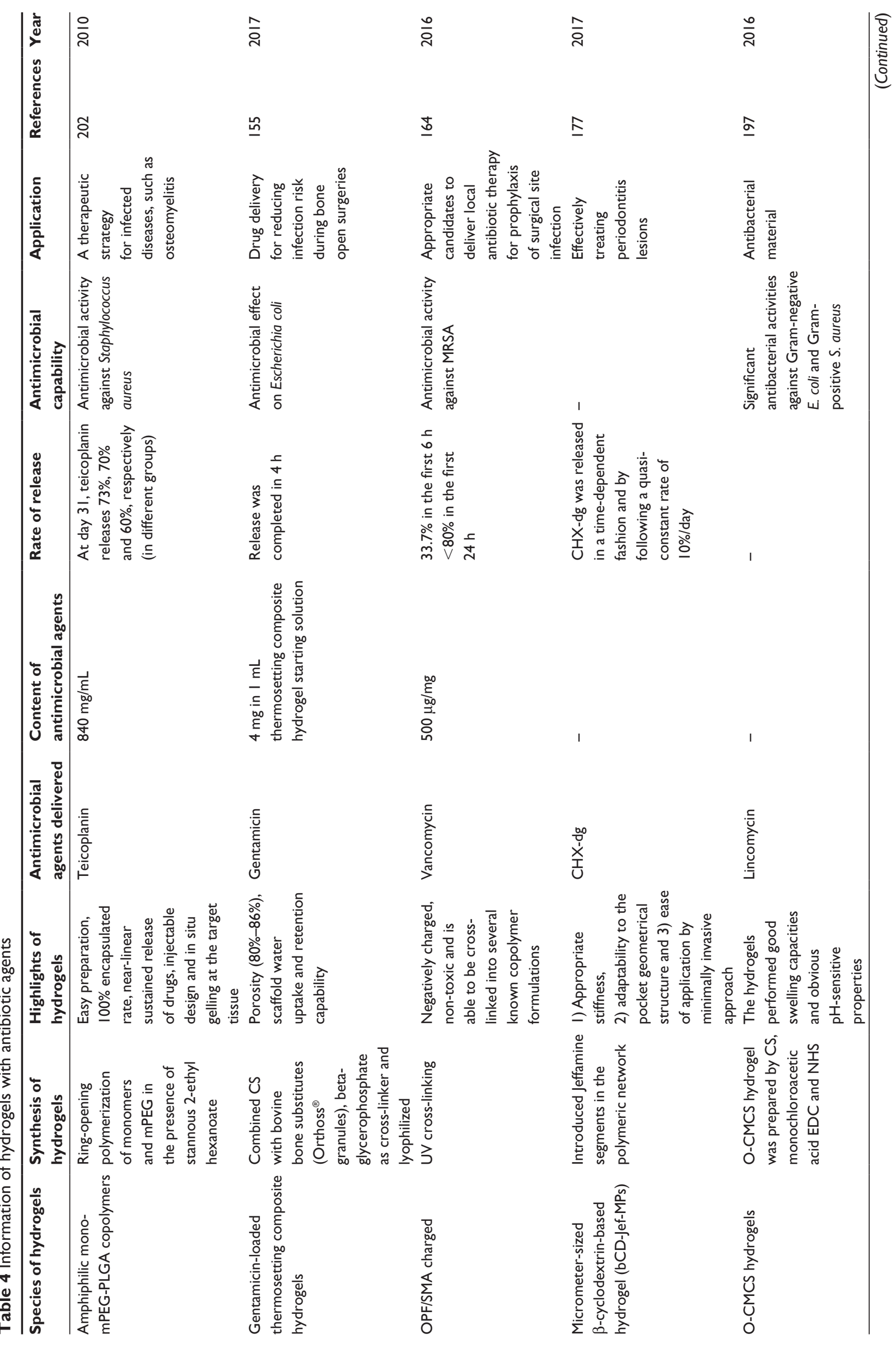




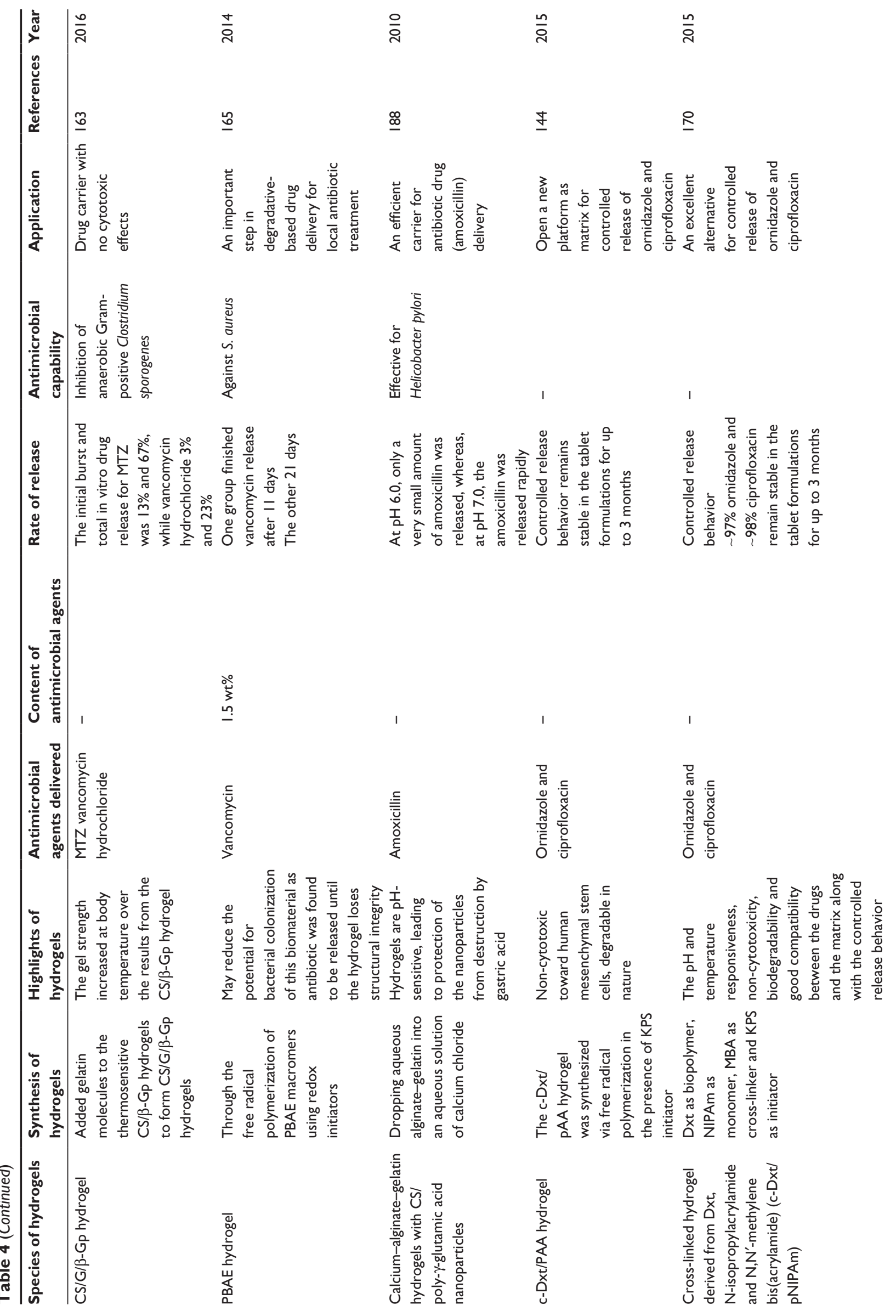




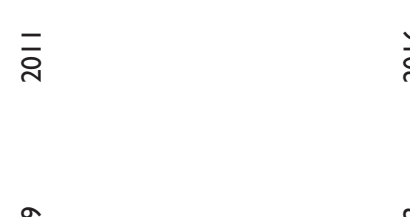

@

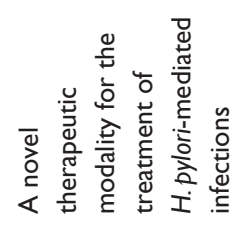

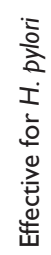

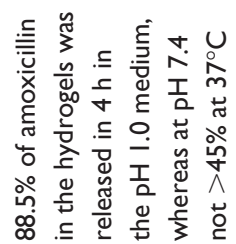

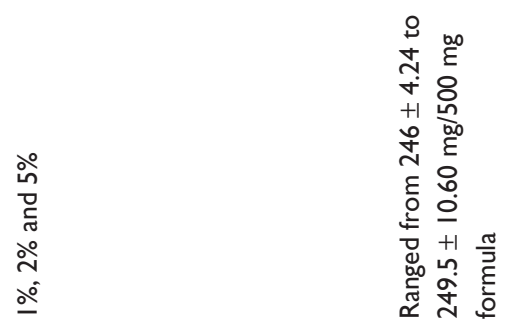

$\stackrel{m}{\underline{1}}$
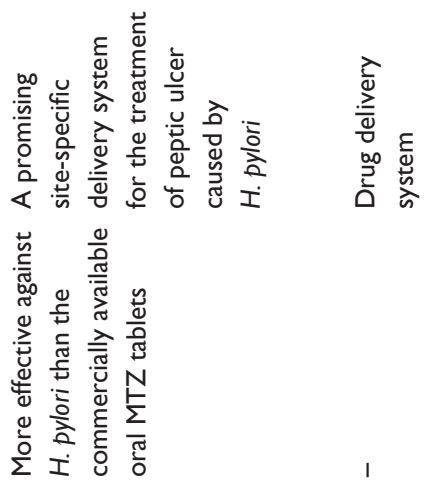

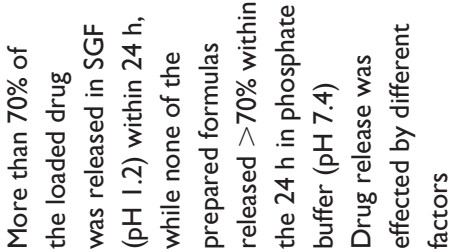

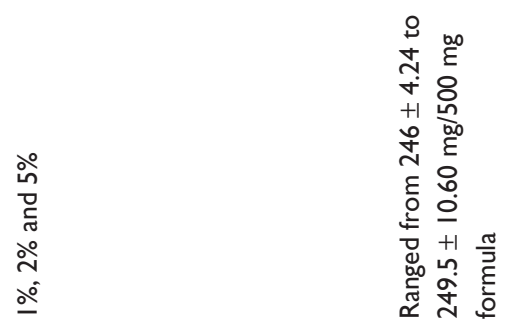

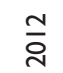

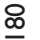

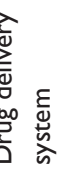

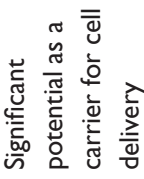

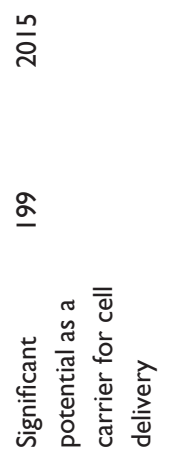

$\stackrel{\sigma}{2}$

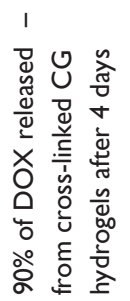

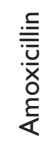

$\stackrel{N}{\Sigma}$

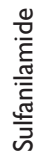

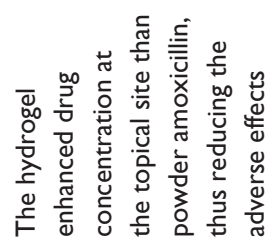

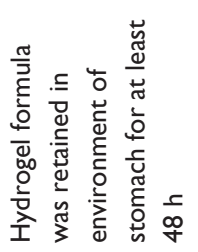

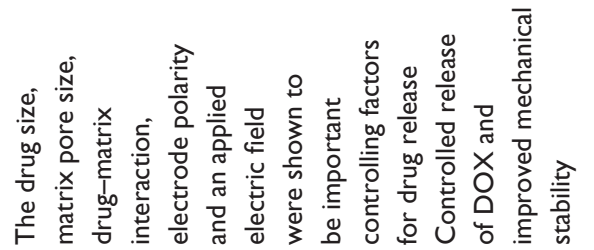
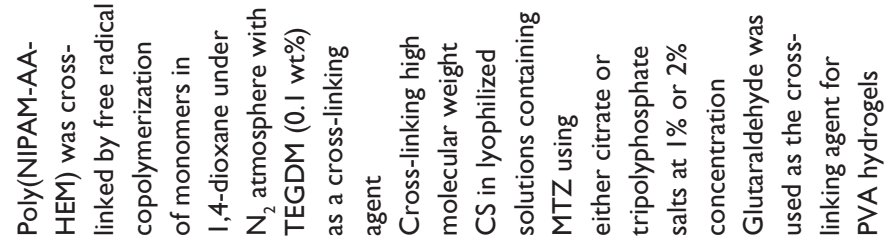

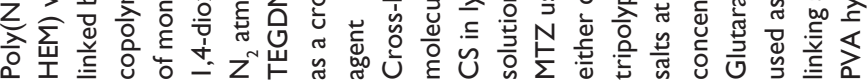
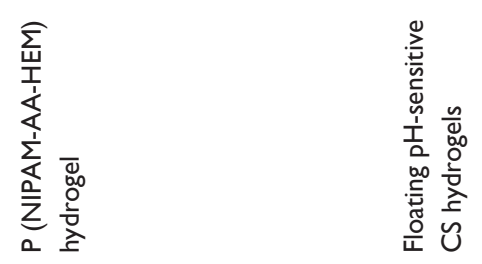

$\overline{\mathrm{d}}$
$\mathrm{o}$
$\frac{0}{\mathrm{~d}}$
$\mathrm{~d}$
$\frac{1}{\mathrm{a}}$
a

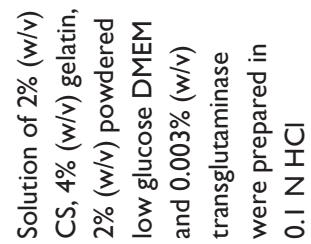

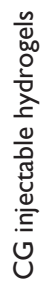




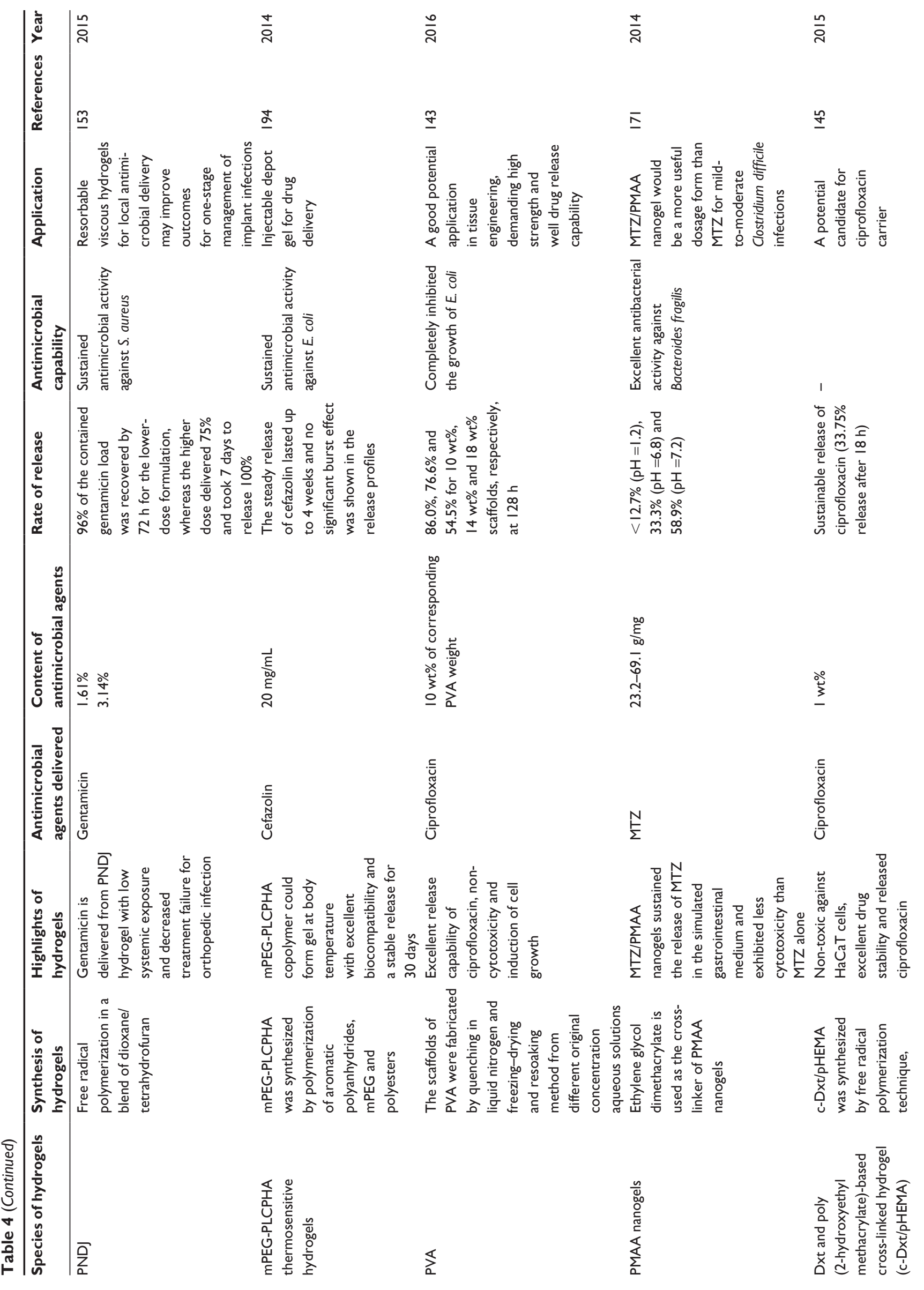



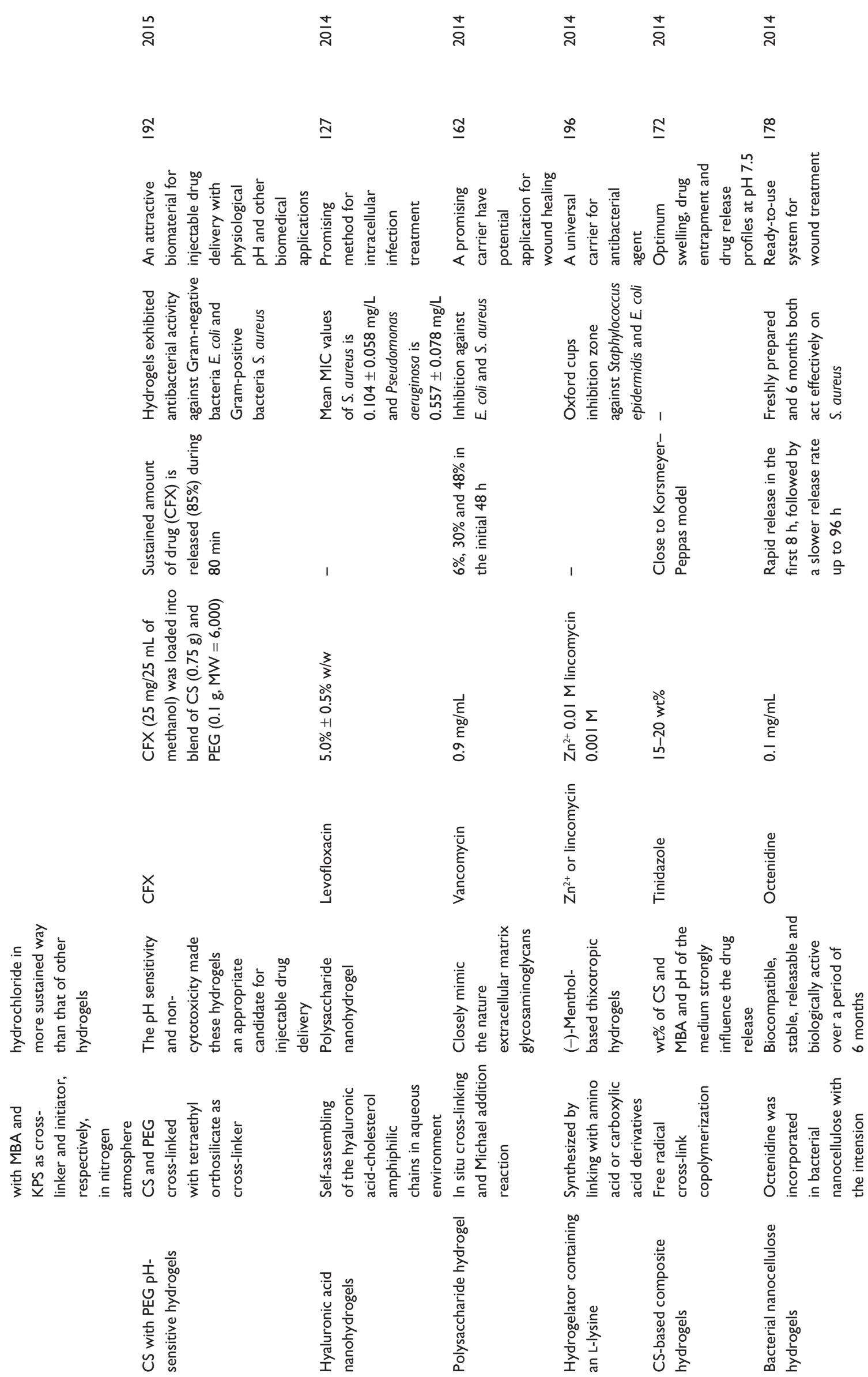

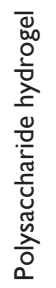
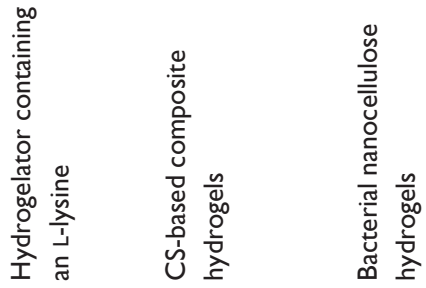


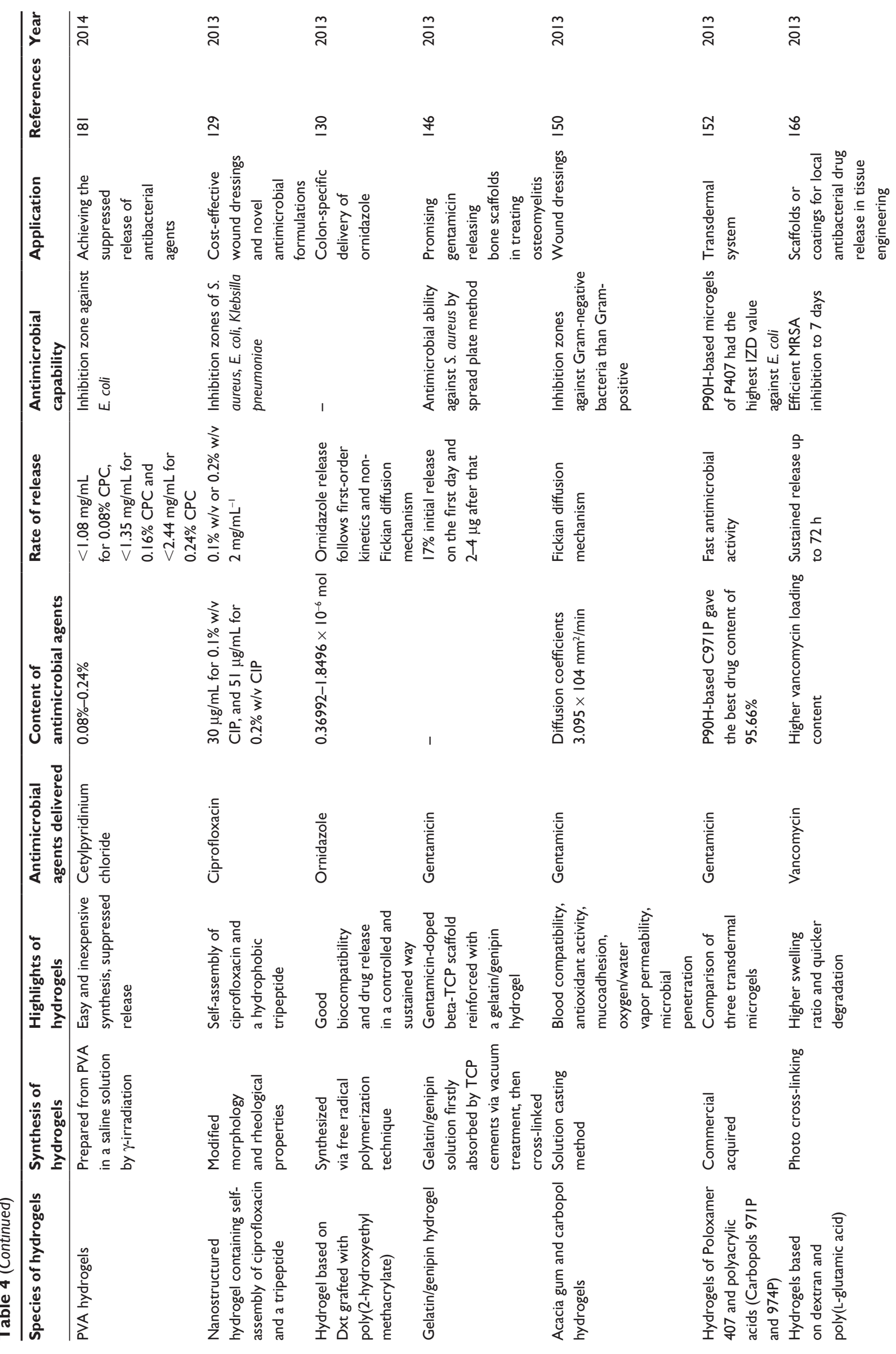




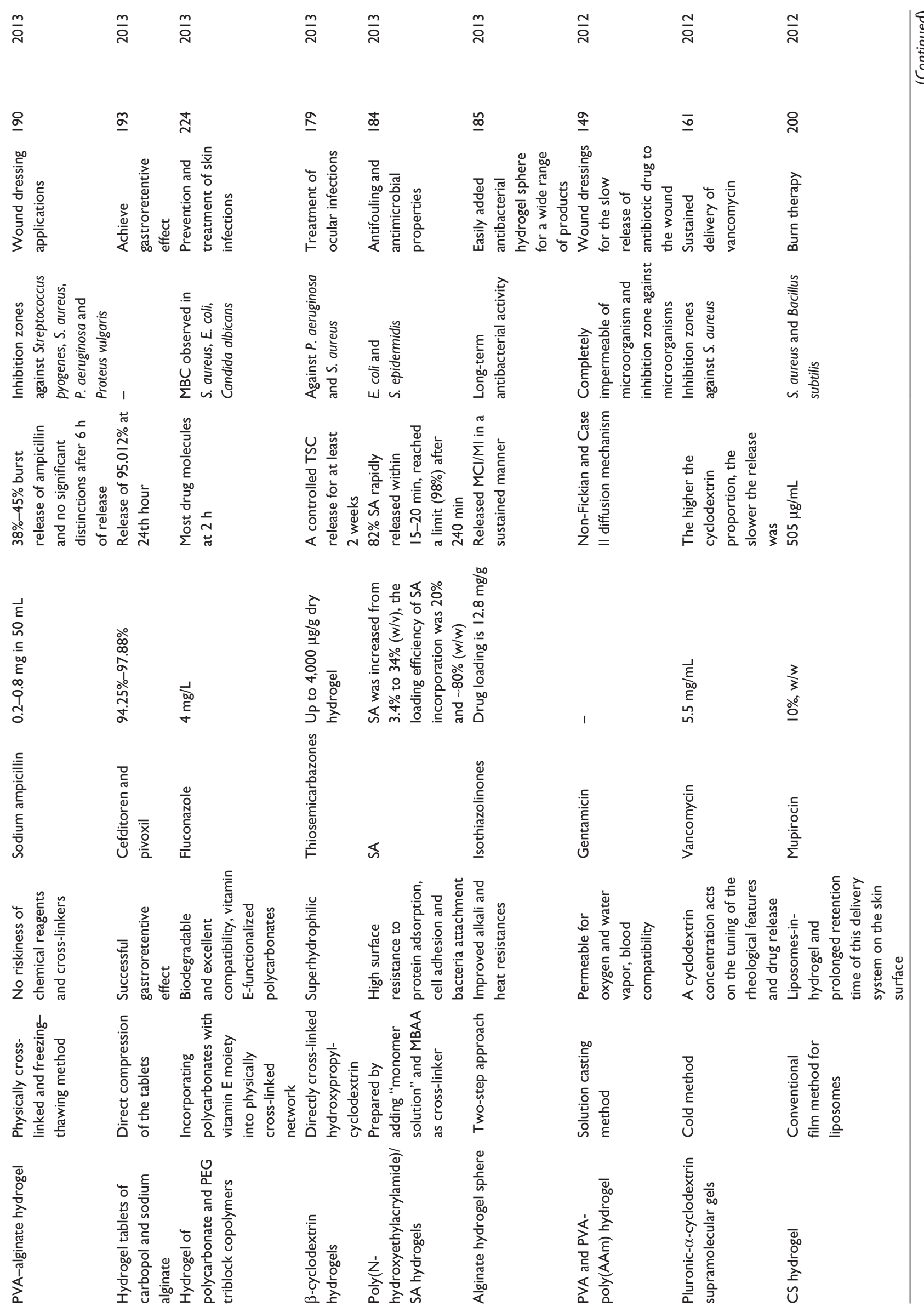




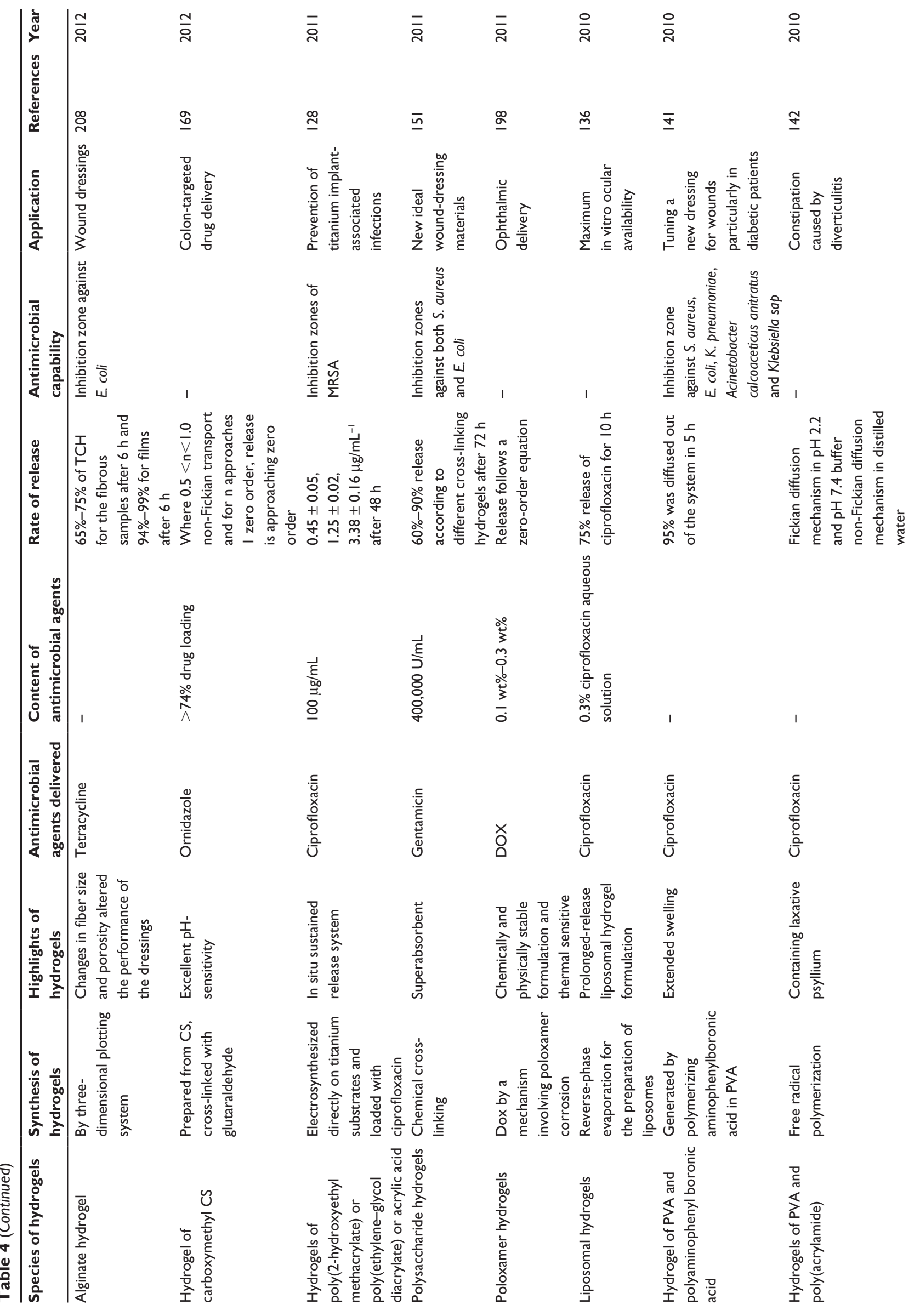




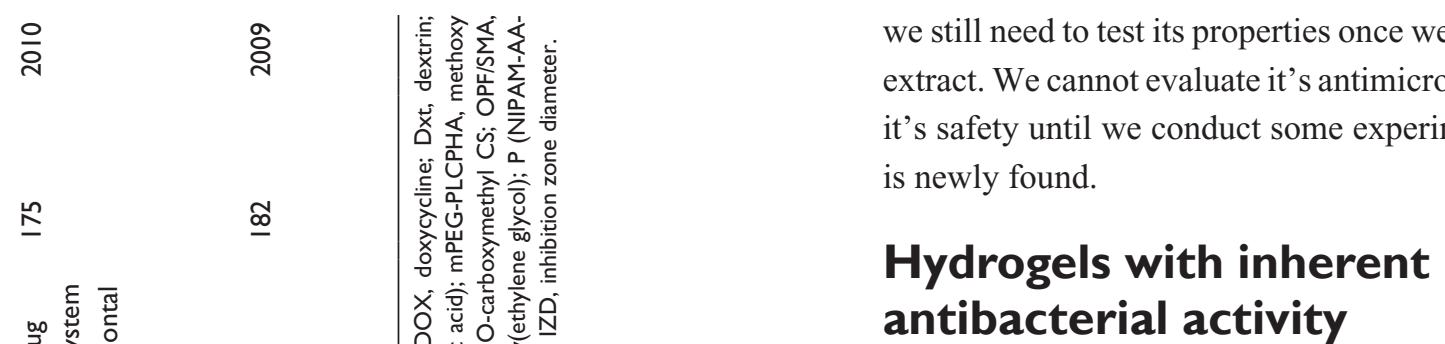

Here, hydrogels with inherent antibacterial activity refer to polymers of these hydrogels that exhibit antimicrobial activity by themselves or those whose biocidal activity is conferred through their chemical modification, not including hydrogels that incorporate antimicrobial organic compounds or active inorganic systems. ${ }^{6,15,226}$ These hydrogels developed in recent years can be regarded as novel antimicrobial agents without traditional defects. ${ }^{7}$ The main types of these hydrogels are as follows.

\section{Antimicrobial polymers}

Antimicrobial polymers are non-stimulated or potential antimicrobials. Some of the antimicrobial polymers can form hydrogels. For non-stimulated polymers, most commonly there are certain components in the chemical structures which can play a role in antimicrobial activity. These polymers could be prepared by several routes such as in situ synthesis within a hydrogel to obtain antimicrobial activities. ${ }^{227}$ Novel hydrogels composed of thermoresponsive PNIPAM and redox-responsive poly(ferrocenylsilane) (PFS) macromolecules exhibited strong antimicrobial activity while maintaining a high biocompatibility with cells. ${ }^{228}$ Jiang et al ${ }^{229}$ synthesized the quaternary ammonium salt of gelatin using 2,3-epoxypropyl trimethylammonium chloride (EPTAC) as the antimicrobial polymer ingredient of the hydrogel. $\mathrm{pH}$-sensitive and temperature-sensitive hydrogels based on 2-hydroxyethyl methacrylate (HEMA) and IA copolymers were proved to have great potential for biomedical applications, especially for skin treatment and wound dressings with excellent results of microbe penetration test. ${ }^{230}$ Antimicrobial property of an antifouling hydrogel prepared by the photopolymerization of PEGDA and a monomer containing ammonium salt ( $\mathrm{RNH} 3 \mathrm{Cl}$ ) in the presence of a photoinitiator was also demonstrated by a study employing E. coli. ${ }^{231}$ As for potential antimicrobial polymers, light is one of the most important factors. Photodynamic porphyrin anionic hydrogel copolymers were reported and showed great promise to the prevention of intraocular lens-associated infectious endophthalmitis. ${ }^{232}$ Another photodynamic pHEMA-based hydrogels exhibit light-induced bactericidal effect via release of NO. ${ }^{233}$ All mechanisms of these antimicrobial polymers provide not only novel antimicrobial materials but also novel delivery and release methods, 
which can be a turn on-off switch. Although not all the ingredients can be used as antibacterial agents, they provide us with the reference. In further research studies, we may design the antimicrobial hydrogels with some functional structures or ingredients that are able to function with bacteria. As for the other parts, we shall keep them for some other properties, such as anti-inflammation or antifouling.

\section{Antimicrobial polypeptides}

AMPs are an abundant and diverse group of molecules produced by multicellular organisms as a defense mechanism against competing pathogenic microbes. ${ }^{234}$ They are recognized as a possible source of panacea for the treatment of antibiotic-resistant bacterial infections, ${ }^{13,235}$ because AMPs have strong antimicrobial activity against a very broad spectrum of microorganisms, including Grampositive and Gram-negative bacteria, fungi and virus., 5,236 Although agreement about the specific mechanism of AMPs has not been reached until now, it is known that AMPs work with membranes and finally lead to bacteria killing (Figure 6). ${ }^{235}$ However, AMPs have their own disadvantages. They are not stable and easy to degrade. Moreover, antimicrobial properties of natural AMPs are not as good as antibiotics. To overcome all these disadvantages, researchers have designed some recombinant AMPs with short chains, which have improved antibacterial property. The hydrogels can also be good media for AMPs to prevent self-degradation.

At first, relatively simple AMPs were loaded on hydrogels, and then AMPs with certain structures or even self-assembled AMPs were developed. Mitra et al developed dipeptide-based amphiphile hydrogel with good antibacterial activities and greater cell specificities. ${ }^{14}$ Peptide-based hairpin hydrogels were reported, respectively, by Salick et al with MAX1 peptides and Veiga et al with arginine-rich peptides; both of them are self-assembly peptides exhibiting potent antibacterial activity. ${ }^{237,238}$ A Gram-positive antibacterial activity possessing peptide (KIGAKI)3-NH2 with hairpin and self-assembly structure was incorporated with hydrogels by Liu et al. ${ }^{239}$ Highly active AMP CKRWWKWIRW-NH2 was immobilized to the surface of poly(ethylene terephthalate) hydrogel, thus establishing bactericidal activity against $S$. aureus and S. epidermidis. ${ }^{240}$ Poly-lysine, a popular AMP that has been reported by Zhou et al, was applied in photopolymerized antimicrobial hydrogels, which can be promising coatings for medical devices and implants (Figure 7). ${ }^{241,242}$ In the research

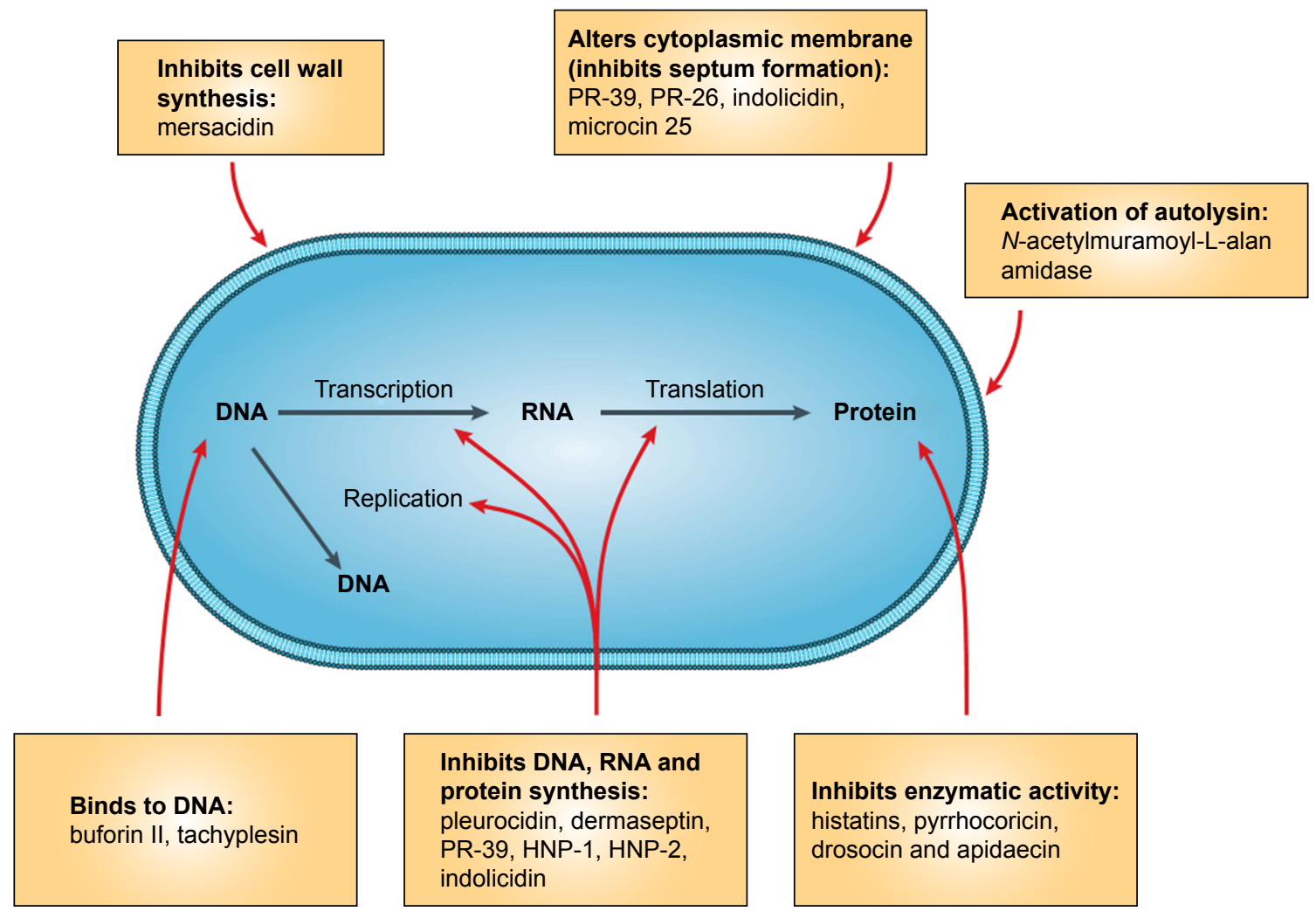

Figure 6 Mode of action for intracellular antimicrobial peptide activity. In this figure Escherichia coli was shown as the target microorganism from Brogden.

Note: Reprinted by permission from Springer Nature, Nat Rev Microbiol, Brogden KA, Antimicrobial peptides: pore formers or metabolic inhibitors in bacteria? 2005;3(3): 238-250, Copyright 2005. ${ }^{235}$ 
A0
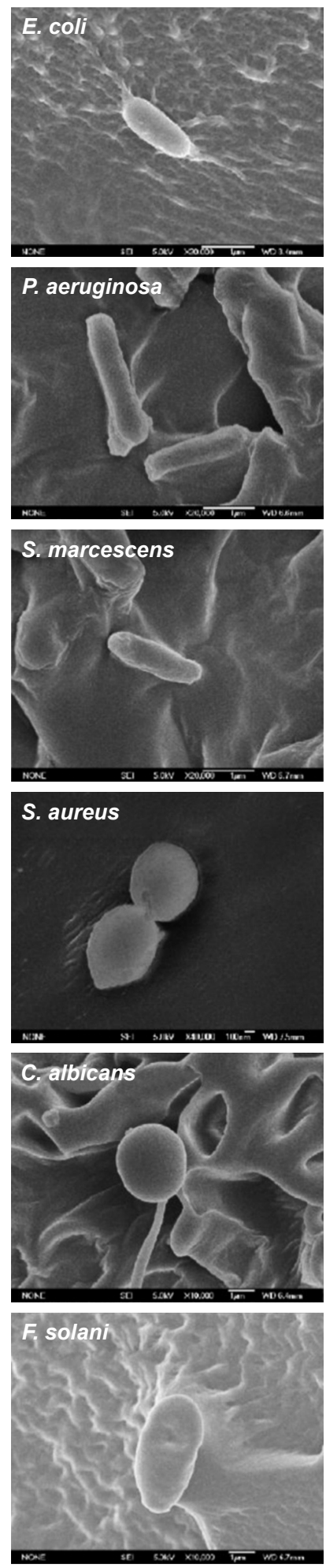

Figure 7 Morphological observation of various microorganisms seeded on hydrogels by scanning electron microscope. Left columns (control), right columns (antimicrobial hydrogels).

Note: Reprinted from Biomaterials. 32(II). Zhou C, Li P, Qi X, et al, A photopolymerized antimicrobial hydrogel coating derived from epsilon-poly-l-lysine, 2704-2712, Copyright 201 I, with permission from Elsevier. ${ }^{242}$

Abbreviations: C. albicans, Candida albicans; E. coli, Escherichia coli; F. solani, Fusarium solani; P. aeruginosa, Pseudomonas aeruginosa; S.aureus, Staphylococcus aureus; S. marcescens, Serratia marcescens. studies conducted by Jiang et al, ${ }^{243}$ cationic multidomain peptides (MDPs) demonstrated a better antimicrobial activity in hydrogels than in solution. AMP maximin-4-loaded poly (2-hydroxyethyl methacrylate) hydrogels, ${ }^{244} \mathrm{~L}$-cysteine- and silver nitrate-loaded hydrogels were proved to have qualified antibacterial activity. ${ }^{245}$

Although AMPs still have disadvantages, such as tissue toxicity and hemolysis, ${ }^{246,247}$ they also exhibited a higher antimicrobial biocompatibility index value compared with synthetic drugs with similar structures, ${ }^{248,249}$ and a lot of studies have attempted to improve the biocompatibility. ${ }^{234-236} \mathrm{~A}$ cell adhesive polypeptide and PEG hydrogel with inherent antibacterial activity was developed by Song et al as a potential scaffold for cutaneous wound healing. ${ }^{250}$ Moreover, a protein anchor developed to immobilize functional protein to PEGDA microspheres by Buhrman et al demonstrated a novel method to maintain therapeutic efficacy without toxicity. ${ }^{251}$ In the study of Xie et al, ${ }^{252}$ in situ forming biodegradable hydrogel (iFBH) system conjugated and functionalized with AMPs offered excellent bacteria inhibition and promoted wound healing without cytotoxicity. Interestingly, nanostructured hydrogels with D-amino acids for peptide self-assembling demonstrated better antimicrobial activity without cytotoxicity. ${ }^{253}$ These studies have brought us the possibility of applying the AMPs as antibiotic agents in the hospital. However, there is still a long way to go due to the fact that AMPs are not stable and they degrade easily. Whether AMPs can be kept in the hydrogels for a long time still needs further studies.

\section{Amphoteric ion hydrogels}

Amphoteric ion hydrogels work in the similar way to AMPs. They are synthetic mimics (polymers) of AMPs; the feature of the mechanisms includes electrostatic interactions that facilitate binding of polymers with anionic bacterial membrane. The resulting amphiphilic interactions physically destroy the membrane structure, leading to cell death. ${ }^{254}$ This is also the mechanism of some types of drugs. However, we concentrate on novel amphoteric hydrogels functioning in the same way. A plethora of antimicrobial synthetic cationic polymers have been reported, including poly(acrylate) and poly(norbornene) systems, poly(arylamide)s poly- $\beta$-lactams and polycarbonates. ${ }^{255-262}$ Jiang and $\mathrm{CaO}^{263,264}$ are the frontrunners in this area and have published several works and reviews on zwitterionic polymers such as poly(carboxybetaine) (pCB) and poly(sulfobetaine) $(\mathrm{pSB})$ in the construction of antimicrobial hydrogels. Mi and Jiang ${ }^{265}$ reported a new antimicrobial and non-fouling zwitterionic hydrogel through using the antibacterial salicylate 
anion with the negative charge to initialize its zwitterionic state. Quaternary ammonium group was one of the most famous antimicrobial materials; an in situ antimicrobial and antifouling hydrogel was fabricated from polycarbonate and PEG through Michael addition by Liu et al. ${ }^{266}$ When combined with hydrogels, amphiphiles work as effectively as AMPs. Polyampholytic hydrogels with high antibacterial activity exhibited water absorbency, making them a good carrier for water-soluble agents. ${ }^{267}$ Potent antimicrobial hydrogels were formed with anti-inflammatory N-fluorenyl-9methoxycarbonyl (Fmoc) amino acid/peptide-functionalized cationic amphiphiles and exhibited efficient antibacterial activity against both Gram-positive and Gram-negative bacteria. $^{268}$ To achieve the bifunctional aim of antibacteria and antifouling, a zwitterionic hydrogel is conjugated with an antimicrobial agent salicylate. This hydrogel can reach onesalicylate-per-monomer drug delivery while still maintaining non-fouling property at protein and bacteria levels. ${ }^{265}$ For amphiphiles, biocompatibilities may be an obstacle to overcome. Dutta et $\mathrm{al}^{269}$ developed cholesterol-based amino acid containing hydrogels with the aim to improve the biocompatibility of these amphiphilic molecules. In their studies, Ag NPs were synthesized in situ. The amphiphile-Ag NP soft nanocomposite exhibited notable antimicrobial property. Apart from disinfection of normal Gram-positive and Gramnegative bacteria, an antimycobacterial supramolecular hydrogel based on amphiphiles was developed by Bernet et al, ${ }^{270}$ which retains specific, chain length-dependent antimicrobial and antimycobacterial activity, while showing practically negligible antiproliferative cytotoxic effects. With good antibacterial properties and negligible cytotoxicity, the clinical application of amphoteric ion hydrogel still needs to be developed. These hydrogels may be a promising material to solve the problem of antibiotic resistance.

\section{Antimicrobial polysaccharides}

Antimicrobial polysaccharides are usually natural polymer or its derivatives such as starch and CS, which are being recently used for the preparation of hydrogels because of their nontoxicity, biodegradability, biocompatibility and abundance in nature. ${ }^{271,272}$ Some of these polysaccharides have inherent antimicrobial activity, the most popular one is CS. CS has wide antibacterial spectrum of activity and high killing rate against Gram-positive and Gram-negative bacteria and low toxicity toward mammalian cells. ${ }^{16}$ As for bacteria, polysaccharide capsule plays a key role in dampening the effects of environment on bacteria. In particular, the capsule protects bacteria from osmotic stress, ensuring the cells maintain viable cytoplasmic turgor. ${ }^{273} \mathrm{CS}$ can be dissolved in weakly acidic solution and release $\mathrm{NH}_{2}^{+}$, which could bind with negative charge to achieve bacteria stasis. ${ }^{274}$ As for the polymers composed mainly of $\mathrm{CS}$, semi-interpenetrating $\mathrm{CMCh} /$ poly(acrylonitrile) hydrogels were reported to have clearly better antibacterial activity with more $\mathrm{CMCh}$, and hydrogel coating by electrophoretic co-deposition of CS/alkynyl CS exhibited better antibacterial activities than pure CS hydrogel. ${ }^{19,275}$ In the study by Straccia et al, ${ }^{276}$ alginate hydrogels coated with CS hydrochloride showed intrinsic antimicrobial activity against E. coli. Quaternary ammonium CS/PVA/polyethylene oxide (PEO) hydrogels were reported to exhibit a pronounced inhibitory effect against S. aureus and E. coli. ${ }^{277}$ As for the polymers containing CS which is just an antibacterial modification, PNIPAM/ polyurethane copolymer hydrogel after CS modification exhibited good antibacterial activity. ${ }^{278} \mathrm{CS}$-grafted hydrogels containing mica nanocomposite produced a rougher surface while maintaining antibacterial activity. ${ }^{279}$ The CS hydrogels have already been used clinically as wound dressings due to their good antihemorrhagic properties. The antibacterial ability suggests that the clinical usage of CS hydrogels can be further developed in the future.

\section{Peptide-based hydrogels}

Several notable peptide-based antimicrobial hydrogels have also been reported in recent years. Different from hydrogels loaded with AMPs, peptide-based hydrogels refer to those hydrogels that were synthesized with amino acid or peptides as ingredients in their structure. For example, Salick et $\mathrm{al}^{237}$ designed a $\beta$-hairpin hydrogel scaffold based on the self-assembling 20-residue peptide for tissue regeneration purposes, whereby the hydrogel itself possessed intrinsic broad-spectrum antibacterial activity. Two years after the development of the $\beta$-hairpin hydrogel, the same group reported another injectable $\beta$-hairpin hydrogel based on a different 20 -residue peptide, which is capable of killing MRSA on contact. ${ }^{280}$ In the work of Schneider et $\mathrm{al}^{238}$ the role of arginine in the structure of antibacterial peptide was highlighted which worked as instructions for the following research studies. Moreover, recently, Liu et al ${ }^{239}$ also designed a Gram-positive antibacterial peptide-containing hydrogel material which can self-assemble in response to external stimuli such as $\mathrm{pH}$, ionic strength and heat. Debnath et $\mathrm{a}^{268}$ reported a class of Fmoc-protected peptide hydrogelators that contained terminal pyridinium moieties, known as possessing antibacterial properties due to their propensity for penetrating cell membranes. All of the peptide hydrogels tested were effective at killing both Gram-positive and Gram-negative bacteria. ${ }^{268}$ 
A related AMP hydrogel was designed by Hughes et al. ${ }^{281}$ They exploited enzymatic hydrolysis mechanisms inside E. coli cells to trigger an intracellular molecular self-assembly of amphiphilic peptide hydrogelators. ${ }^{281}$ Song et al ${ }^{250}$ developed all-synthetic polypeptide hydrogels with antibacterial activity by cross-linking poly(Lys)x(Ala)y copolymers with six-armed N-hydroxysuccinimide (NHS)-terminated PEG. Zhou et $\mathrm{al}^{242}$ modified epsilon-poly-L-lysine (EPL), an AMP produced by Streptomyces albulus, with methacrylamide moieties, and it was then cross-linked with PEGDA to form antibacterial hydrogels. Besides their antibacterial applications, these peptide-based hydrogels have offered inspiration of hydrogel design for us in the future. We can design antimicrobial hydrogels according to the different active structures of antimicrobial drugs. Therefore, the hydrogels would have excellent antimicrobial capacity. The hydrogels with inherent antibacterial activity are in Table 5.

\section{Hydrogels with synergistic effect}

Hydrogels with synergistic effect refer to hydrogels containing two or more antimicrobial agents combined to reach more powerful antimicrobial effect. There are two main types of antimicrobial biomaterials that are commonly reported to be incorporated into hydrogels with synergistic effect: metal nanoparticles group and antibiotics group. Those containing both metal nanoparticles and antibiotics are assigned to the antibiotics group because antibiotics feature prominently in clinical practice.

\section{Synergistic effective hydrogels containing metal nanoparticles}

Metal nanoparticles in synergistic effective hydrogels were mainly Ag NPs. Ag NPs can be loaded on synthetic amphiphilic or amino acid-based hydrogels, and they can also be loaded with biological extracts. ${ }^{282}$ Reithofer et al ${ }^{283}$ synthesized sizecontrolled, stable Ag NPs within ultrashort peptide hydrogels with great potential for applications in wound healing due to their low silver content, sustained Ag NP release and biocompatibility. Novel Ag NP composite systems are more suitable for biomedical applications because of their good biocompatibility with biological molecules, cells, tissues and so on. ${ }^{284}$ In situ-synthesized Ag NPs on amphiphilic hydrogels by Dutta et $\mathrm{al}^{285}$ exhibited improved biocompatibility and antimicrobial efficacy, which has promising applications in biomedicine and tissue engineering. The same laboratory also reported in situ-synthesized Ag NP in self-assemblies of amino acid-based amphiphilic hydrogel in the same year, exhibiting normal growth of mammalian cells on its surface while being lethal toward both Gram-positive and Gram-negative bacteria. ${ }^{286}$ Some researchers synthesized antimicrobial Ag NPs and impregnated them into antifouling zwitterionic hydrogels, thus getting mussel-inspired, antifouling, antibacterial hydrogels with great potential in wound healing applications (Figure 8). ${ }^{287}$ Both bactericidal hydrogels based on L-cysteine and silver nitrate and $\mathrm{Ag}(\mathrm{I})$-glutathione hydrogel which exhibited improved cytocompatibility were reported in 2011, ${ }^{245,288}$ offering more possibilities on potential application in biomedical field such as burn wound dressings. For other combinations, Ag NP-curcumin composite hydrogels demonstrated that incorporation of curcumin into these hydrogel nanocomposites would further enhance their antibacterial efficacy. The entrapped Ag NPs and curcumin molecules proved sustained release, which could be exerted in enormous prolonged therapeutic values. ${ }^{213}$ Anjum et al ${ }^{289}$ reported a composite hydrogel for wound dressing containing nanosilver along with aloe vera and curcumin. It showed better antimicrobial nature, wound healing and infection control compared with the control group. ${ }^{289}$ Synergistic effective hydrogels containing metal nanoparticles show great antibacterial ability and large antibacterial spectrum. According to distinct antimicrobial pathways, it is impossible to develop antimicrobial resistance. These materials are promising for hospital application in the future.

\section{Synergetic effective hydrogels containing antibiotics}

Hydrogels containing antibiotics exhibit more potent antimicrobial properties and biocompatibility when combined with other antimicrobial materials. As for traditional gentamicin, a novel controlled release zinc oxide/gentamicin-CS composite gel with potential application in wounds care was reported. $\mathrm{ZnO}$, gentamicin and CS are all antimicrobial agents, but the composite gel can significantly improve minimal inhibition concentrations (MICs) of Gram-positive and Gram-negative bacteria compared with only gentamicin (Figure 9). ${ }^{290}$ Bacterial cellulose polymers functionalized by RGDC (R: arginine; G: glycine; D: aspartic acid; C: cysteine)-grafting groups and gentamicin offer a creative method for novel antimicrobial composite though it was not hydrogel. ${ }^{291}$ To cure keratitis, Paradiso et $\mathrm{al}^{292}$ added levofloxacin and chlorhexidine to vitamin E-loaded silicone hydrogel contact lenses and found that drug loaded in the lenses can be controlled to achieve a daily release in vivo. Ciprofloxacin is one of the most effective antibiotics used clinically, and it has become the gold standard for various topical applications such as skin and eye infections. It was reported to be able to be combined with different materials 


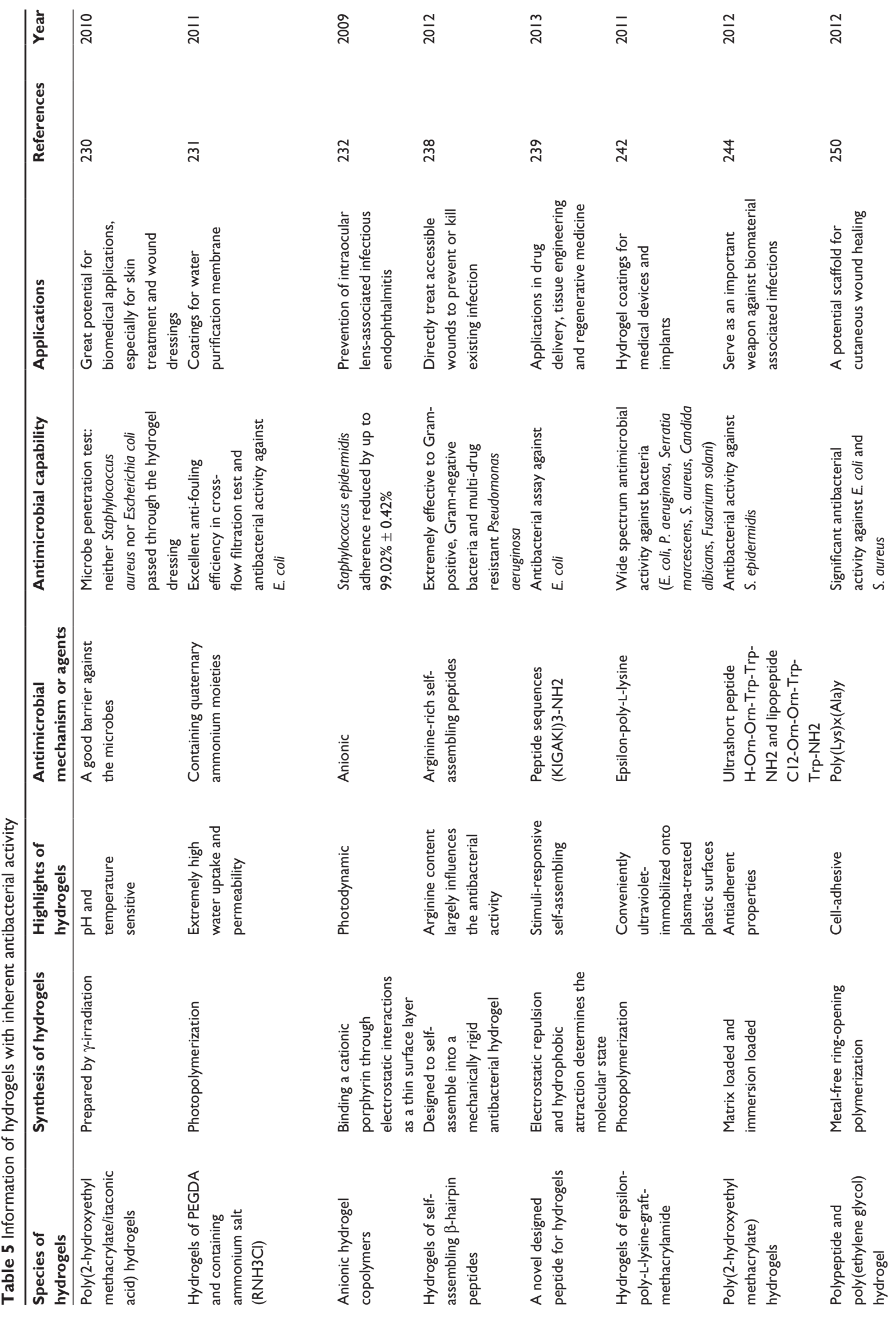



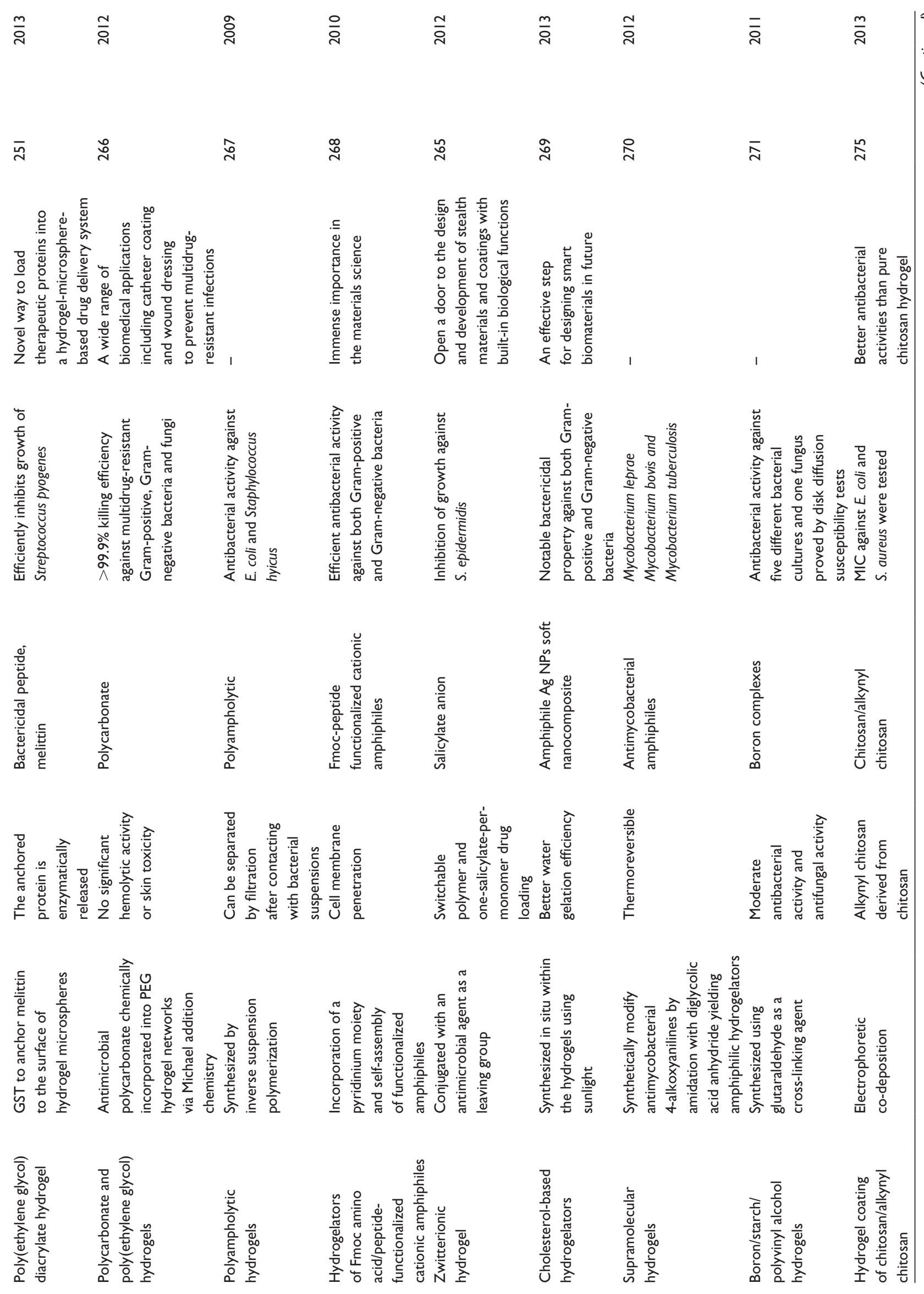


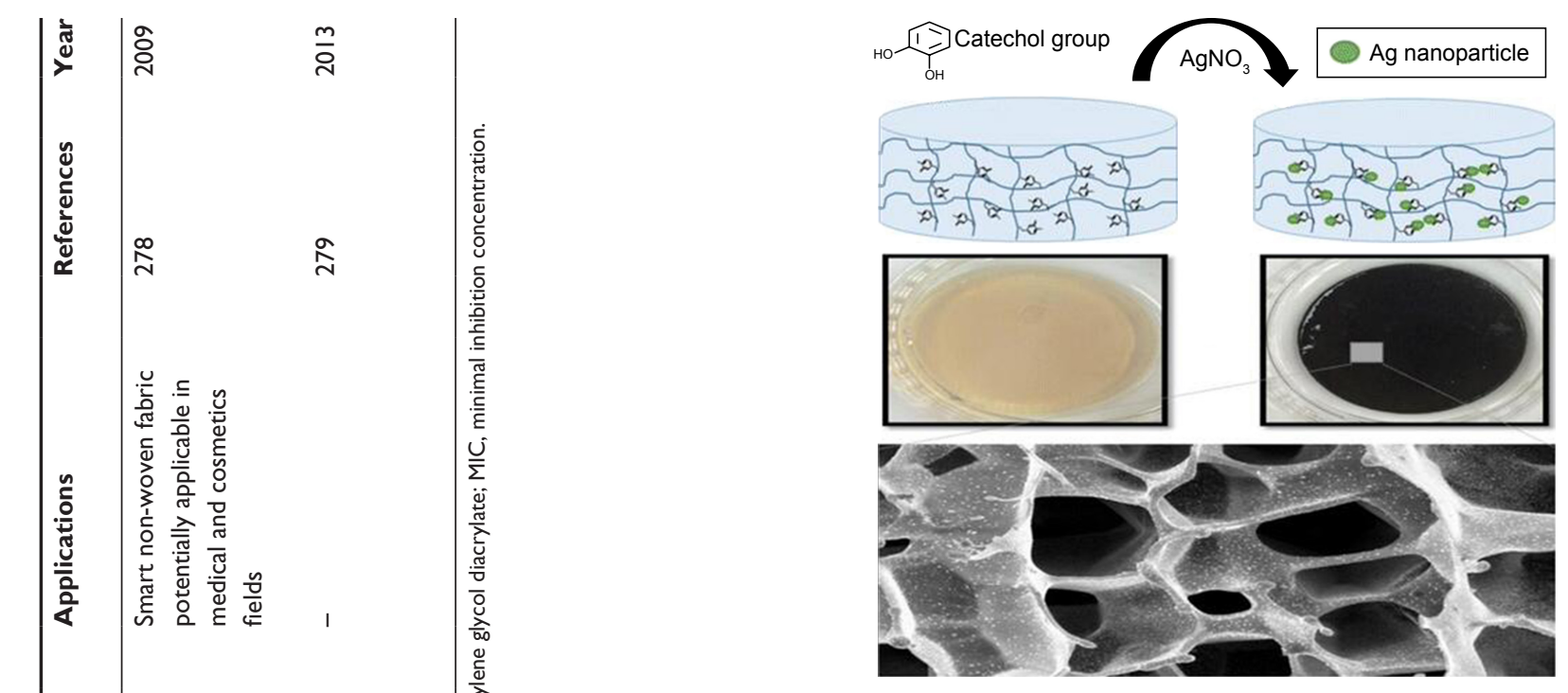

Figure $8 \mathrm{~A}$ new strategy that uses catecholic chemistry to synthesize antimicrobial silver nanoparticles impregnated into antifouling zwitterionic hydrogels.

Notes: On the top is the schematic illustration of the combination of AgNPs and antifouling hydrogel.In the middle, Photographs show the changes in color of hydrogels by changing the $\mathrm{pH}$ because of reaction that converts the $\mathrm{Ag}+$ into solid AgNPs. The bottom section shows the surface structure and the morphology of hydrogel via scanning electron microscopy. Reprinted with permission from GhavamiNejad A, Park $\mathrm{CH}$, Kim CS. In situ synthesis of antimicrobial silver nanoparticles within antifouling zwitterionic hydrogels by catecholic redox chemistry for wound healing application. Biomacromolecules. 2016;17(3):1213-1223. Copyright (2016), American Chemical Society. ${ }^{287}$

from metal nanoparticles to amphiphiles. ${ }^{137}$ Ciprofloxacin loaded into an antimicrobial nanostructured self-assembly tripeptide hydrogel was reported by Marchesan et al, ${ }^{129}$ which is meaningful to the design of cost-effective nanomaterials.

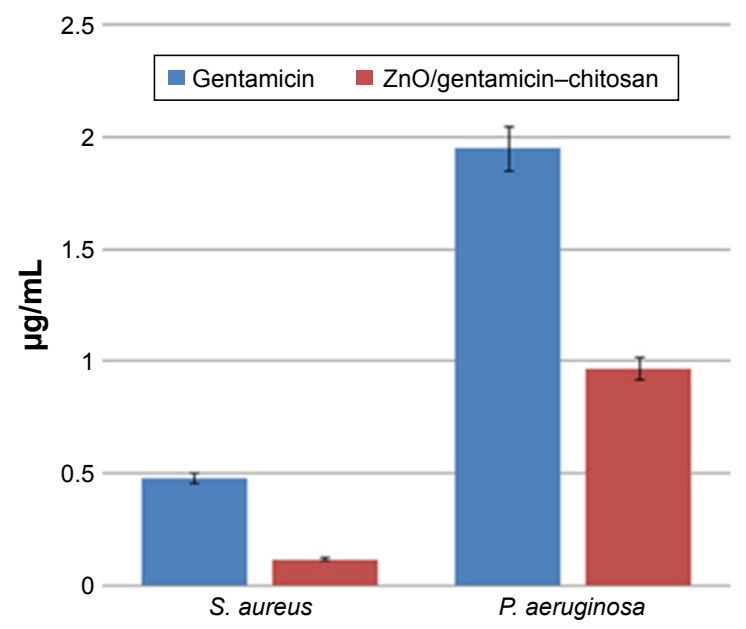

Figure 9 Graphical representation of MICs obtained after growing S. aureus and $P$. aeruginosa in the presence of different concentrations of gentamicin and $\mathrm{ZnO} /$ gentamicin-chitosan.

Note: Reprinted from Int J Pharm. 463(2). Vasile BS, Oprea O, Voicu G, et al, Synthesis and characterization of a novel controlled release zinc oxide/gentamicinchitosan composite with potential applications in wounds care, 161-169, Copyright 2014, with permission from Elsevier. ${ }^{290}$

Abbreviations: MICs, minimal inhibition concentrations; S. aureus, Staphylococcus aureus; $P$. aeruginosa, Pseudomonas aeruginosa. 
In their design, drug incorporation in the delivery could lead to prolonged release and novel antimicrobial formulations. ${ }^{129}$ Release of ciprofloxacin loaded on PVA-based super paramagnetic nanocomposites can be magnetically mediated, which provides novel approach of release though no hydrogel formation was studied in this article. ${ }^{140}$ In in vivo studies, dextrin polymer hydrogels impregnated with amikacin and clindamycin were applied in dogs whose tibial plateau leveling osteotomy implants were removed due to suspected surgical site infection, and no signs of inflammation or infection in any dog were found at the 12th week. ${ }^{293}$ Quaternized gellan gum-based particles for controlled release of ciprofloxacin demonstrated another potential dermal application. ${ }^{294}$ Besides, tetracycline hydrochloride Ag NP composite hydrogels were developed to inhibit bacteria in simulated colon environment. ${ }^{295}$ All these synergetic effective composite hydrogels offer possible approaches for minimum of antibiotics dosage. Combination with other antibacterial ingredients can be a good way to solve the antibiotic resistance and side effects. Meanwhile, the antibacterial spectrum is enlarged, indicating that synergetic effective composite hydrogels have great potential clinically. However, synergistic effects occur when two or more drugs work together to form a stronger response than individually, known as $1+1>2$ effect. In most of the abovementioned studies, researchers were more likely to describe additive effect. When the different antimicrobial ingredients were put together in hydrogel, the antibacterial spectrum was boarder and the antimicrobial effect became better compared with hydrogels loaded with one agent separately, whereas we could not tell if the overall effect was synergistic. We would like to see whether the two antimicrobial ingredients would exhibit synergistic effect or only additive effect in further study.

\section{Summary and prospect}

Recent advances in natural and synthetic hydrogels have either intrinsic antimicrobial properties or act as carriers for antibiotics. Hydrogels as antimicrobial biomaterials can be an alternative and amendable solution other than the traditional antibiotic treatment since too many drug-resistant bacteria were developed due to misuse of antibiotics and other antimicrobial drugs. Controlled and prolonged release, local administration, stimulated switch on-off release, enhanced mechanical strength and improved biocompatibility are important advantages which a broad diversity of hydrogels can bring. Antimicrobial hydrogels can be applied to a broad spectrum such as wound dressings, urinary tract coatings, contact lens, treatment of osteomyelitis, catheter-associated infections, gastrointestinal infections and so on, finally conquer formidable problems in traditional therapy. Novel antimicrobial biomaterials, novel combination of these materials and novel approaches will bring us brand new prospects and promising further in anti-infection treatment.

For treating microbial infections, it is crucial that antimicrobial components can be released from gels to enter immune cells and kill the pathogenic microbes from inside. Hydrogels loaded with antibiotics, metal nanoparticles, antimicrobial polymers and peptides can release the antimicrobial agents in a sustained manner, which is important to treat infections effectively and prevent biofilm formation. Biodegradable antimicrobial polymer-loaded or peptide-loaded gels are more attractive than gels encapsulated with antibiotics or metal nanoparticles because antibiotics easily develop drug resistance, and it is relatively more difficult to mitigate toxicity of metal nanoparticles due to their non-degradability.

Antimicrobial hydrogels could help to solve the presentday challenges of antimicrobial medicine, including antibiotic resistance. The mechanisms are as follows: 1) the antimicrobial hydrogels could be used locally, which would avoid the side effect of systemic application; 2) the hydrogels, as a novel drug delivery system providing sustainable release of antimicrobial drugs, could offer prolonged antimicrobial effect and avoid screening of resistant bacteria; 3 ) according to the multiple mechanisms of nanoparticles and other antibacterial ingredients, it is difficult for bacteria to develop resistance aiming at only one target; and 4) different ingredients might exhibit synergistic effect. This would bring broader antibacterial spectrum and better antimicrobial effect.

Hydrogels have offered us a new way to fight against antibiotic resistance in clinical application. However, the controlled release of drugs cannot be accurate in the existing hydrogels. Some of the hydrogels degrade too fast to prolong the effect. Moreover, the antibacterial property of hydrogels is usually weak. Most of them cannot be used as antimicrobial materials alone. Some hydrogels would react with drugs they load, thus limiting their practical application. In the future, these problems still call for more research studies to be solved.

As for the antimicrobial spectrum of antimicrobial hydrogels, lots of them were determined by the antimicrobial ingredients they carried. Some of the materials were only tested with specific bacteria. Some of the hydrogels were examined with both Gram-positive (usually $S$. aureus) and Gram-negative bacteria (E. coli). The result indicated that the antimicrobial properties of the materials was different against various bacteria. Rarely, researchers have reported the entire antimicrobial spectrum of antibacterial hydrogels in their articles. We hope that researchers could carry out more 
studies about the antibacterial properties of materials against different bacteria. This will help us to find out if activity against one particular bacterium is limited in scope or that nanomaterial might have broader utility.

For future clinical applications, it is critical to test antimicrobial hydrogels against clinically isolated microbes, especially multidrug-resistant strains and evaluate the in vitro and in vivo biocompatibility of hydrogels and encapsulated cargo. With rational design, synthetic polymer chemistry and comprehensive in vitro and in vivo evaluation, hydrogel systems with broad-spectrum antimicrobial activity against multidrug-resistant microbes, high selectivity and negligible toxicity would find great potential in the prevention and treatment of infections.

\section{Disclosure}

The authors report no conflicts of interest in this work.

\section{References}

1. Stone PW, Pogorzelska-Maziarz M, Herzig CT, et al. State of infection prevention in US hospitals enrolled in the National Health and Safety Network. Am J Infect Control. 2014;42(2):94-99.

2. Ng VW, Chan JM, Sardon H, et al. Antimicrobial hydrogels: a new weapon in the arsenal against multidrug-resistant infections. Adv Drug Deliv Rev. 2014;78:46-62.

3. Global Burden of Disease Study 2013 Collaborators. Global, regional, and national incidence, prevalence, and years lived with disability for 301 acute and chronic diseases and injuries in 188 countries, 1990-2013: a systematic analysis for the Global Burden of Disease Study 2013. Lancet. 2015;386(9995):743-800.

4. García-Barrasa J, López-de-Luzuriaga JM, Monge M. Silver nanoparticles: synthesis through chemical methods in solution and biomedical applications. Cent Eur J Chem. 2010;9(1):7-19.

5. Aoki W, Kuroda K, Ueda M. Next generation of antimicrobial peptides as molecular targeted medicines. J Biosci Bioeng. 2012;114(4): 365-370.

6. Malmsten M. Antimicrobial and antiviral hydrogels. Soft Matter. 2011;7(19):8725.

7. Martinez JL, Fajardo A, Garmendia L, et al. A global view of antibiotic resistance. FEMS Microbiol Rev. 2009;33(1):44-65.

8. Martinez JL, Rojo F. Metabolic regulation of antibiotic resistance. FEMS Microbiol Rev. 2011;35(5):768-789.

9. Mazer-Amirshahi M, Pourmand A, May L. Newly approved antibiotics and antibiotics reserved for resistant infections: implications for emergency medicine. Am J Emerg Med. 2017;35(1):154-158.

10. Ramesh S, Govender T, Kruger HG, de la Torre BG, Albericio F. Short AntiMicrobial Peptides (SAMPs) as a class of extraordinary promising therapeutic agents. J Pept Sci. 2016;22(7):438-451.

11. Scorciapino MA, Serra I, Manzo G, Rinaldi AC. Antimicrobial dendrimeric peptides: structure, activity and new therapeutic applications. Int J Mol Sci. 2017;18(3):E542.

12. Kang HK, Kim C, Seo CH, Park Y. The therapeutic applications of antimicrobial peptides (AMPs): a patent review. J Microbiol. 2017; 55(1):1-12.

13. Dasgupta A, Mondal JH, Das D. Peptide hydrogels. RSC Adv. 2013; 3(24):9117.

14. Mitra RN, Shome A, Paul P, Das PK. Antimicrobial activity, biocompatibility and hydrogelation ability of dipeptide-based amphiphiles. Org Biomol Chem. 2009;7(1):94-102.

15. Muñoz-Bonilla A, Fernández-García M. Polymeric materials with antimicrobial activity. Prog Polym Sci. 2012;37(2):281-339.
16. Kong M, Chen XG, Xing K, Park HJ. Antimicrobial properties of chitosan and mode of action: a state of the art review. Int J Food Microbiol. 2010;144(1):51-63.

17. Jamil B, Imran M. Factors pivotal for designing of nanoantimicrobials: an exposition. Crit Rev Microbiol. 2018;44(1):79-94.

18. Cavalieri F, Tortora M, Stringaro A, Colone M, Baldassarri L. Nanomedicines for antimicrobial interventions. J Hosp Infect. 2014;88(4): 183-190.

19. Mohamed RR, Seoudi RS, Sabaa MW. Synthesis and characterization of antibacterial semi-interpenetrating carboxymethyl chitosan/poly (acrylonitrile) hydrogels. Cellulose. 2012;19(3):947-958.

20. Hamidi M, Azadi A, Rafiei P. Hydrogel nanoparticles in drug delivery. Adv Drug Deliv Rev. 2008;60(15):1638-1649.

21. Zhang S, Ermann J, Succi MD, et al. An inflammation-targeting hydrogel for local drug delivery in inflammatory bowel disease. Sci Transl Med. 2015;7(300):300ra128.

22. Noimark S, Dunnill CW, Wilson M, Parkin IP. The role of surfaces in catheter-associated infections. Chem Soc Rev. 2009;38(12):3435-3448.

23. Hetrick EM, Schoenfisch MH. Reducing implant-related infections: active release strategies. Chem Soc Rev. 2006;35(9):780-789.

24. Shea LD, Woodruff TK, Shikanov A. Bioengineering the ovarian follicle microenvironment. Annu Rev Biomed Eng. 2014;16:29-52.

25. Ghobril C, Grinstaff MW. The chemistry and engineering of polymeric hydrogel adhesives for wound closure: a tutorial. Chem Soc Rev. 2015; 44(7):1820-1835.

26. Sahiner N, Sagbas S, Sahiner M, Silan C, Aktas N, Turk M. Biocompatible and biodegradable poly(Tannic Acid) hydrogel with antimicrobial and antioxidant properties. Int J Biol Macromol. 2016;82:150-159.

27. Tsao CT, Chang CH, Lin YY, et al. Antibacterial activity and biocompatibility of a chitosan-gamma-poly(glutamic acid) polyelectrolyte complex hydrogel. Carbohydr Res. 2010;345(12):1774-1780.

28. Hemeg HA. Nanomaterials for alternative antibacterial therapy. Int $J$ Nanomedicine. 2017;12:8211-8225.

29. Sahiner N. Soft and flexible hydrogel templates of different sizes and various functionalities for metal nanoparticle preparation and their use in catalysis. Prog Polym Sci. 2013;38(9):1329-1356.

30. Hu R, Li G, Jiang Y, et al. Silver-zwitterion organic-inorganic nanocomposite with antimicrobial and antiadhesive capabilities. Langmuir. 2013;29(11):3773-3779.

31. Pelgrift RY, Friedman AJ. Nanotechnology as a therapeutic tool to combat microbial resistance. Adv Drug Deliv Rev. 2013;65(13-14): 1803-1815.

32. Skladanowski M, Golinska P. Evaluation of cytotoxicity, immune compatibility and antibacterial activity of biogenic silver nanoparticles. Med Microbiol Immunol. 2016;205(6):603-613.

33. Blecher K, Nasir A, Friedman A. The growing role of nanotechnology in combating infectious disease. Virulence. 2011;2(5):395-401.

34. Lara HH, Ayala-Núñez NV, Padilla CR. Bactericidal effect of silver nanoparticles against multidrug-resistant bacteria. World J Microbiol Biotechnol. 2010;26(4):615-621.

35. Huh AJ, Kwon YJ. "Nanoantibiotics": a new paradigm for treating infectious diseases using nanomaterials in the antibiotics resistant era. $J$ Control Release. 2011;156(2):128-145.

36. Hindi KM, Ditto AJ, Panzner MJ, et al. The antimicrobial efficacy of sustained release silver-carbene complex-loaded L-tyrosine polyphosphate nanoparticles: characterization, in vitro and in vivo studies. Biomaterials. 2009;30(22):3771-3779.

37. Dallas P, Sharma VK, Zboril R. Silver polymeric nanocomposites as advanced antimicrobial agents: classification, synthetic paths, applications, and perspectives. Adv Colloid Interface Sci. 2011;166(1-2): 119-135.

38. Patil MP, Kim GD. Eco-friendly approach for nanoparticles synthesis and mechanism behind antibacterial activity of silver and anticancer activity of gold nanoparticles. Appl Microbiol Biotechnol. 2017; 101(1):79-92.

39. Ivask A, Elbadawy A, Kaweeteerawat C, et al. Toxicity mechanisms in Escherichia coli vary for silver nanoparticles and differ from ionic silver. ACS Nano. 2014;8(1):374-386. 
40. Taglietti A, Diaz Fernandez YA, Amato E, et al. Antibacterial activity of glutathione-coated silver nanoparticles against Gram Positive and Gram Negative bacteria. Langmuir. 2012;28(21):8140-8148.

41. Guo L, Yuan W, Lu Z, Li CM. Polymer/nanosilver composite coatings for antibacterial applications. Colloids Surf A Phys Eng Aspects. 2013;439:69-83.

42. Knetsch MLW, Koole LH. New strategies in the development of antimicrobial coatings: the example of increasing usage of silver and silver nanoparticles. Polymers. 2011;3(1):340-366.

43. Jovanović Ž, Stojkovska J, Obradović B, Mišković-Stanković V. Alginate hydrogel microbeads incorporated with Ag nanoparticles obtained by electrochemical method. Mater Chem Phys. 2012;133(1): 182-189.

44. Stojkovska J, Kostić D, Jovanović Ž, Vukašinović-Sekulić M, MiškovićStanković V, Obradović B. A comprehensive approach to in vitro functional evaluation of Ag/alginate nanocomposite hydrogels. Carbohydr Polym. 2014;111:305-314.

45. Obradovic B, Stojkovska J, Jovanovic Z, Miskovic-Stankovic V. Novel alginate based nanocomposite hydrogels with incorporated silver nanoparticles. J Mater Sci Mat Med. 2012;23(1):99-107.

46. Ghasemzadeh H, Ghanaat F. Antimicrobial alginate/PVA silver nanocomposite hydrogel, synthesis and characterization. J Polym Res. 2014;21(3):355.

47. Madhusudana Rao K, Krishna Rao KSV, Ramanjaneyulu G, Chowdoji Rao K, Subha MCS, Ha C-S. Biodegradable sodium alginate-based semi-interpenetrating polymer network hydrogels for antibacterial application. J Biomed Mater Res A. 2013;102(9):3196-3206.

48. Murali Mohan Y, Vimala K, Thomas V, et al. Controlling of silver nanoparticles structure by hydrogel networks. J Colloid Interface Sci. 2010;342(1):73-82.

49. Neibert K, Gopishetty V, Grigoryev A, et al. Wound-healing with mechanically robust and biodegradable hydrogel fibers loaded with silver nanoparticles. Adv Healthc Mater. 2012;1(5):621-630.

50. Murthy PS, Murali Mohan Y, Varaprasad K, Sreedhar B, Mohana Raju K. First successful design of semi-IPN hydrogel-silver nanocomposites: a facile approach for antibacterial application. J Colloid Interface Sci. 2008;318(2):217-224.

51. Chang HW, Lin YS, Tsai YD, Tsai ML. Effects of chitosan characteristics on the physicochemical properties, antibacterial activity, and cytotoxicity of chitosan/2-glycerophosphate/nanosilver hydrogels. J Appl Polym Sci. 2013;127(1):169-176.

52. Tang H, Lu A, Li L, Zhou W, Xie Z, Zhang L. Highly antibacterial materials constructed from silver molybdate nanoparticles immobilized in chitin matrix. Chem Eng J. 2013;234:124-131.

53. Jayaramudu T, Raghavendra GM, Varaprasad K, Sadiku R, Ramam K, Raju KM. Iota-Carrageenan-based biodegradable Ag0 nanocomposite hydrogels for the inactivation of bacteria. Carbohydr Polym. 2013; 95(1):188-194.

54. Juby KA, Dwivedi C, Kumar M, Kota S, Misra HS, Bajaj PN. Silver nanoparticle-loaded PVA/gum acacia hydrogel: synthesis, characterization and antibacterial study. Carbohydr Polym. 2012;89(3):906-913.

55. Hebeish A, Hashem M, El-Hady MM, Sharaf S. Development of CMC hydrogels loaded with silver nano-particles for medical applications. Carbohydr Polym. 2013;92(1):407-413.

56. Vimala K, Samba Sivudu K, Murali Mohan Y, Sreedhar B, Mohana Raju K. Controlled silver nanoparticles synthesis in semi-hydrogel networks of poly(acrylamide) and carbohydrates: a rational methodology for antibacterial application. Carbohydr Polym. 2009;75(3):463-471.

57. Reddy PR, Varaprasad K, Sadiku R, et al. Development of gelatin based inorganic nanocomposite hydrogels for inactivation of bacteria. J Inorg Organometal Polym Mater. 2013;23(5):1054-1060.

58. El-Sherif H, El-Masry M, Kansoh A. Hydrogels as template nanoreactors for silver nanoparticles formation and their antimicrobial activities. Macromol Res. 2011;19(11):1157-1165.

59. Park S, Murthy PSK, Park S, Mohan YM, Koh W-G. Preparation of silver nanoparticle-containing semi-interpenetrating network hydrogels composed of pluronic and poly(acrylamide) with antibacterial property. J Ind Eng Chem. 2011;17(2):293-297.
60. Varaprasad K, Mohan YM, Ravindra S, et al. Hydrogel-silver nanoparticle composites: a new generation of antimicrobials. J Appl Polym Sci. 2010;115(2):1199-1207.

61. Eid M, Araby E. Bactericidal effect of poly(acrylamide/itaconic acid)-silver nanoparticles synthesized by gamma irradiation against Pseudomonas aeruginosa. Appl Biochem Biotechnol. 2013;171(2): 469-487.

62. Abdel-Halim ES, Al-Deyab SS. Antimicrobial activity of silver/starch/ polyacrylamide nanocomposite. Int J Biol Macromol. 2014;68:33-38.

63. James C, Johnson AL, Jenkins AT. Antimicrobial surface grafted thermally responsive PNIPAM-co-ALA nano-gels. Chem Commun. 2011; 47(48):12777-12779.

64. Manjula B, Varaprasad K, Sadiku R, Ramam K, Reddy GVS, Raju KM. Development of microbial resistant thermosensitive Ag nanocomposite (gelatin) hydrogels via green process. J Biomed Mater Res A. 2014; 102(4):928-934.

65. Zafar M, Shah T, Rawal A, Siores E. Preparation and characterisation of thermoresponsive nanogels for smart antibacterial fabrics. Mater Sci Eng C. 2014;40:135-141.

66. Boonkaew B, Kempf M, Kimble R, Supaphol P, Cuttle L. Antimicrobial efficacy of a novel silver hydrogel dressing compared to two common silver burn wound dressings: acticoat and PolyMem Silver((R)). Burns. 2014;40(1):89-96.

67. Boonkaew B, Suwanpreuksa P, Cuttle L, Barber PM, Supaphol P. Hydrogels containing silver nanoparticles for burn wounds show antimicrobial activity without cytotoxicity. J Appl Polyme Sci. 2014;131:40215.

68. Bozaci E, Akar E, Ozdogan E, Demir A, Altinisik A, Seki Y. Application of carboxymethylcellulose hydrogel based silver nanocomposites on cotton fabrics for antibacterial property. Carbohydr Polym. 2015; 134:128-135.

69. Raho R, Paladini F, Lombardi FA, Boccarella S, Zunino B, Pollini M. In-situ photo-assisted deposition of silver particles on hydrogel fibers for antibacterial applications. Mater Sci Eng C Mater Biol Appl. 2015; 55:42-49.

70. Lee W-F, Tsao K-T. Effect of silver nanoparticles content on the various properties of nanocomposite hydrogels by in situ polymerization. J Sci Mater. 2009;45(1):89-97.

71. Wu J, Hou S, Ren D, Mather PT. Antimicrobial properties of nanostructured hydrogel webs containing silver. Biomacromolecules. 2009; 10(9):2686-2693.

72. Eid M, El-Arnaouty MB, Salah M, Soliman E-S, Hegazy E-SA. Radiation synthesis and characterization of poly(vinyl alcohol)/poly(Nvinyl-2-pyrrolidone) based hydrogels containing silver nanoparticles. J Polym Res. 2012;19(3):

73. Bajpai S, Chand N, Mahendra M. In situ formation of silver nanoparticles in poly (methacrylic acid) hydrogel for antibacterial applications. Polym Eng Sci. 2013;53(8):1751-1759.

74. Micic M, Milic TV, Mitric M, Jokic B, Suljovrujic E. Radiation synthesis, characterisation and antimicrobial application of novel copolymeric silver/poly (2-hydroxyethyl methacrylate/itaconic acid) nanocomposite hydrogels. Polym Bull. 2013;70(12):3347-3357.

75. Wei Q-B, Fu F, Zhang Y-Q, Tang L. Preparation, characterization, and antibacterial properties of $\mathrm{pH}$-responsive $\mathrm{P}(\mathrm{MMA}-\mathrm{co}-\mathrm{MAA}) /$ silver nanocomposite hydrogels. J Polym Res. 2014;21(2):349.

76. Bhowmick S, Mohanty S, Koul V. Fabrication of transparent quaternized PVA/silver nanocomposite hydrogel and its evaluation as an antimicrobial patch for wound care systems. J Mater Sci Mater Med. 2016; 27(11): 160 .

77. Malcher M, Volodkin D, Heurtault B, et al. Embedded silver ionscontaining liposomes in polyelectrolyte multilayers: cargos films for antibacterial agents. Langmuir. 2008;24(18):10209-10215.

78. Fullenkamp DE, Rivera JG, Gong YK, et al. Mussel-inspired silver-releasing antibacterial hydrogels. Biomaterials. 2012;33(15): 3783-3791.

79. Jiao T, Guo H, Zhang Q, et al. Reduced graphene oxide-based silver nanoparticle-containing composite hydrogel as highly efficient dye catalysts for wastewater treatment. Sci Rep. 2015;5:11873. 
80. Grade S, Eberhard J, Neumeister A, et al. Serum albumin reduces the antibacterial and cytotoxic effects of hydrogel-embedded colloidal silver nanoparticles. RSC Adv. 2012;2(18):7190.

81. Xu L, Li X, Takemura T, Hanagata N, Wu G, Chou LL. Genotoxicity and molecular response of silver nanoparticle (NP)-based hydrogel. J Nanobiotechnol. 2012;10(16):1-11.

82. Yang C, Jung S, Yi H. A biofabrication approach for controlled synthesis of silver nanoparticles with high catalytic and antibacterial activities. Biochem Eng J. 2014;89(8):10-20.

83. Faoucher E, Nativo P, Black K, et al. In situ preparation of network forming gold nanoparticles in agarose hydrogels. Chem Commun. 2009; (43):6661

84. Daniel-da-Silva AL, Salgueiro AM, Trindade T. Effects of Au nanoparticles on thermoresponsive genipin-crosslinked gelatin hydrogels. Gold Bull. 2013;46(1):25-33.

85. Zhao Y, Jiang X. Multiple strategies to activate gold nanoparticles as antibiotics. Nanoscale. 2013;5(18):8340-8350.

86. Brown AN, Smith K, Samuels TA, Lu J, Obare SO, Scott ME. Nanoparticles functionalized with ampicillin destroy multiple-antibiotic-resistant isolates of Pseudomonas aeruginosa and Enterobacter aerogenes and methicillin-resistant Staphylococcus aureus. Appl Environ Microbiol. 2012;78(8):2768.

87. Guiney LM, Agnello AD, Thomas JC, Takatori K, Flynn NT. Thermoresponsive behavior of charged $\mathrm{N}$-isopropylacrylamide-based hydrogels containing gold nanostructures. Colloid Polym Sci. 2009;287(5): 601-608.

88. Kozlovskaya V, Kharlampieva E, Chang S, Muhlbauer R, Tsukruk VV. $\mathrm{pH}$-responsive layered hydrogel microcapsules as gold nanoreactors. Chem Mater. 2009;21(10):2158-2167.

89. Gao W, Vecchio D, Li J, et al. Hydrogel containing nanoparticlestabilized liposomes for topical antimicrobial delivery. ACS Nano. 2014;8(3):2900-2907.

90. Ribeiro M, Ferraz MP, Monteiro FJ, et al. Antibacterial silk fibroin/ nanohydroxyapatite hydrogels with silver and gold nanoparticles for bone regeneration. Nanomedicine. 2017;13(1):231-239.

91. Jayaramudu T, Raghavendra GM, Varaprasad K, Sadiku R, Raju KM. Development of novel biodegradable Au nanocomposite hydrogels based on wheat: for inactivation of bacteria. Carbohydr Polym. 2013; 92(2):2193-2200.

92. Ranga Reddy P, Varaprasad K, Narayana Reddy N, Mohana Raju K, Reddy NS. Fabrication of Au and Ag Bi-metallic nanocomposite for antimicrobial applications. J Appl Polym Scince. 2012;125(2):1357-1362.

93. Varaprasad K, Siva Mohan Reddy G, Jayaramudu J, Sadiku R, Ramam K, Ray SS. Development of microbial resistant Carbopol nanocomposite hydrogels via a green process. Biomater Sci. 2014;2(2):257.

94. Weir E, Lawlor A, Whelan A, Regan F. The use of nanoparticles in antimicrobial materials and their characterization. Analyst. 2008;133(7): 835-845.

95. Hajipour MJ, Fromm KM, Ashkarran AA, et al. Antibacterial properties of nanoparticles. Trends Biotechnol. 2012;30(10):499-511.

96. Wu S, Du Y, Hu Y, Shi X, Zhang L. Antioxidant and antimicrobial activity of xylan-chitooligomer-zinc complex. Food Chem. 2013; 138(2-3):1312-1319.

97. James C, Pugh T, Johnson AL, Jenkins ATA. An antimicrobial zinc based molecule for cross linking poly-acrylic acid. Eur Polym J. 2011;47(6):1338-1345.

98. Sudheesh Kumar PT, Lakshmanan V-K, Anilkumar TV, et al. Flexible and microporous chitosan hydrogel/nano $\mathrm{ZnO}$ composite bandages for wound dressing: in vitro and in vivo evaluation. ACS Appl Mater Interfaces. 2012;4(5):2618-2629.

99. Hashem M, Sharaf S, Abd El-Hady MM, Hebeish A. Synthesis and characterization of novel carboxymethylcellulose hydrogels and carboxymethylcellulolse-hydrogel-ZnO-nanocomposites. Carbohydr Polym. 2013;95(1):421-427.

100. Schwartz VB, Thétiot F, Ritz S, et al. Antibacterial surface coatings from zinc oxide nanoparticles embedded in poly(N-isopropylacrylamide) hydrogel surface layers. Adv Funct Mater. 2012;22(11):2376-2386.
101. Mohandas A, Kumar PTS, Raja B, Lakshmanan VK, Jayakumar R. Exploration of alginate hydrogel/nano zinc oxide composite bandages for infected wounds. Int J Nanomed. 2015;10(suppl 1):53-66.

102. Yadollahi M, Gholamali I, Namazi H, Aghazadeh M. Synthesis and characterization of antibacterial carboxymethyl cellulose/ZnO nanocomposite hydrogels. Int J Biol Macromol. 2015;74:136-141.

103. Wang J, Hu H, Yang Z, Wei J, Li J. IPN hydrogel nanocomposites based on agarose and $\mathrm{ZnO}$ with antifouling and bactericidal properties. Mater Sci Eng C Mater Biol Appl. 2016;61:376-386.

104. Zare-Akbari Z, Farhadnejad H, Furughi-Nia B, Abedin S, Yadollahi M, Khorsand-Ghayeni M. PH-sensitive bionanocomposite hydrogel beads based on carboxymethyl cellulose/ZnO nanoparticle as drug carrier. Int J Biol Macromol. 2016;93(pt A):1317-1327.

105. Yadollahi M, Farhoudian S, Barkhordari S, Gholamali I, Farhadnejad H, Motasadizadeh H. Facile synthesis of chitosan/ZnO bio-nanocomposite hydrogel beads as drug delivery systems. Int J Biol Macromol. 2016; 82:273-278.

106. Wahid F, Yin JJ, Xue DD, et al. Synthesis and characterization of antibacterial carboxymethyl Chitosan/ZnO nanocomposite hydrogels. Int J Biol Macromol. 2016;88:273-279.

107. Huang L, Dai T, Xuan Y, Tegos GP, Hamblin MR. Synergistic combination of chitosan acetate with nanoparticle silver as a topical antimicrobial: efficacy against bacterial burn infections. Antimicrobial Agents Chemother. 2011;55(7):3432.

108. Friedman AJ, Phan J, Schairer DO, et al. Antimicrobial and antiinflammatory activity of chitosan-alginate nanoparticles: a targeted therapy for cutaneous pathogens. J Invest Dermatol. 2013;133(5):1231.

109. Fielding $\mathrm{G}$, Bose $\mathrm{S}$. $\mathrm{SiO} 2$ and $\mathrm{ZnO}$ dopants in three-dimensionally printed tricalcium phosphate bone tissue engineering scaffolds enhance osteogenesis and angiogenesis in vivo. Acta Biomater. 2013;9(11): 9137-9148.

110. Kumar NA, Rejinold NS, Anjali P, Balakrishnan A, Biswas R, Jayakumar R. Preparation of chitin nanogels containing nickel nanoparticles. Carbohydr Polym. 2013;97(2):469-474.

111. Narin G, Albayrak ÇB, Ülkü S. Preparation and characterization of antibacterial cobalt-exchanged natural zeolite/poly(vinyl alcohol) hydrogels. J Sol-Gel Sci Technol. 2013;69(1):214-230.

112. Kruk T, Szczepanowicz K, Stefanska J, Socha RP, Warszynski P. Synthesis and antimicrobial activity of monodisperse copper nanoparticles. Colloids Surf B Biointerfaces. 2015;128:17-22.

113. Ingle AP, Duran N, Rai M. Bioactivity, mechanism of action, and cytotoxicity of copper-based nanoparticles: a review. Appl Microbiol Biotechnol. 2014;98(3):1001-1009.

114. Zhong T, Oporto GS, Jaczynski J, Jiang C. Nanofibrillated cellulose and copper nanoparticles embedded in polyvinyl alcohol films for antimicrobial applications. Biomed Res Int. 2015;2015:456834.

115. Yadollahi M, Gholamali I, Namazi H, Aghazadeh M. Synthesis and characterization of antibacterial carboxymethylcellulose $/ \mathrm{CuO}$ bionanocomposite hydrogels. Int J Biol Macromol. 2015;73:109-114.

116. Rajasekaran P, Santra S. Hydrothermally treated chitosan hydrogel loaded with copper and zinc particles as a potential micronutrientbased antimicrobial feed additive. Front Vet Sci. 2015;2:62.

117. Ramanujam K, Sundrarajan M. Antibacterial effects of biosynthesized $\mathrm{MgO}$ nanoparticles using ethanolic fruit extract of Emblica officinalis. J Photochem Photobiol B Biol. 2014;141:296-300.

118. Leung $\mathrm{YH}, \mathrm{Ng} \mathrm{AM}, \mathrm{Xu} \mathrm{X}$, et al. Mechanisms of antibacterial activity of MgO: non-ROS mediated toxicity of $\mathrm{MgO}$ nanoparticles towards Escherichia coli. Small. 2014;10(6):1171-1183.

119. He Y, Ingudam S, Reed S, Gehring A, Strobaugh TP Jr, Irwin P. Study on the mechanism of antibacterial action of magnesium oxide nanoparticles against foodborne pathogens. J Nanobiotechnol. 2016; 14(1):54.

120. Hezaveh H, Muhamad II. Impact of metal oxide nanoparticles on oral release properties of $\mathrm{pH}$-sensitive hydrogel nanocomposites. Int J Biol Macromol. 2012;50(5):1334-1340.

121. Norowski PA Jr, Bumgardner JD. Biomaterial and antibiotic strategies for peri-implantitis: a review. J Biomed Mater Res B Appl Biomater. 2009;88(2):530-543. 
122. Giltrap AM, Dowman LJ, Nagalingam G, et al. Total synthesis of teixobactin. Org Lett. 2016;18(11):2788.

123. Marshall H. New antibiotic discovered for Gram-positive bacteria. Lancet Respir Med. 2015;3(2):104-104.

124. Arias CA, Murray BE. A new antibiotic and the evolution of resistance. N Engl J Med. 2015;372(12):1168-1170.

125. Kelly S. The drug push. Science. 2015;348(6237):850-853.

126. Fernandes P, Martens E. Antibiotics in late clinical development. Biochem Pharmacol. 2017;133:152-163.

127. Montanari E, D'Arrigo G, Di Meo C, et al. Chasing bacteria within the cells using levofloxacin-loaded hyaluronic acid nanohydrogels. Eur J Pharm Biopharm. 2014;87(3):518-523.

128. De Giglio E, Cometa S, Ricci MA, et al. Ciprofloxacin-modified electrosynthesized hydrogel coatings to prevent titanium-implantassociated infections. Acta Biomater. 2011;7(2):882-891.

129. Marchesan S, Qu Y, Waddington LJ, et al. Self-assembly of ciprofloxacin and a tripeptide into an antimicrobial nanostructured hydrogel. Biomaterials. 2013;34(14):3678-3687.

130. Das D, Das R, Ghosh P, Dhara S, Panda AB, Pal S. Dextrin cross linked with poly (HEMA): a novel hydrogel for colon specific delivery of ornidazole. RSC Adv. 2013;3(47):25340-25350.

131. Singh B, Varshney L, Francis S, Rajneesh. Designing tragacanth gum based sterile hydrogel by radiation method for use in drug delivery and wound dressing applications. Int J Biol Macromol. 2016; 88:586-602.

132. Andersson DI, Hughes D. Persistence of antibiotic resistance in bacterial populations. FEMS Microbiol Rev. 2011;35(5):901-911.

133. Rodriguez-Rojas A, Rodriguez-Beltran J, Couce A, Blazquez J. Antibiotics and antibiotic resistance: a bitter fight against evolution. Int J Med Microbiol. 2013;303(6-7):293-297.

134. van Hoek AH, Mevius D, Guerra B, Mullany P, Roberts AP, Aarts HJ. Acquired antibiotic resistance genes: an overview. Front Microbiol. 2011;2:203

135. Molton JS, Tambyah PA, Ang BS, Ling ML, Fisher DA. The global spread of healthcare-associated multidrug-resistant bacteria: a perspective from Asia. Clin Infect Dis. 2013;56(9):1310-1318.

136. Hosny KM. Ciprofloxacin as ocular liposomal hydrogel. AAPS PharmSciTech. 2010;11(1):241-246.

137. Lequeux I, Ducasse E, Jouenne T, Thebault P. Addition of antimicrobial properties to hyaluronic acid by grafting of antimicrobial peptide. Eur Polym J. 2014;51:182-190.

138. Bowen A, Hurd J, Hoover C, et al. Importation and domestic transmission of Shigella sonnei resistant to ciprofloxacin - United States, May 2014-February 2015. MMWR Morb Mortal Wkly Rep. 2015; 64(12):318-320.

139. Chung The H, Rabaa MA. South Asia as a reservoir for the global spread of ciprofloxacin-resistant Shigella sonnei: a cross-sectional study. PLoS Med. 2016;13(8):e1002055.

140. Bajpai AK, Gupta R. Magnetically mediated release of ciprofloxacin from polyvinyl alcohol based superparamagnetic nanocomposites. J Mater Sci Mater Med. 2011;22(2):357-369.

141. Manju S, Antony M, Sreenivasan K. Synthesis and evaluation of a hydrogel that binds glucose and releases ciprofloxacin. J Sci Mater. 2010;45(15):4006-4012.

142. Singh B, Sharma N, Sharma V. Slow release of ciprofloxacin from double potential drug delivery system. J Sci Mater. 2010;46(8): 2587-2599.

143. Zhou XH, Wei DX, Ye HM, Zhang X, Meng X, Zhou Q. Development of poly(vinyl alcohol) porous scaffold with high strength and well ciprofloxacin release efficiency. Mater Sci Eng C Mater Biol Appl. 2016; 67:326-335.

144. Das D, Ghosh P, Dhara S, Panda AB, Pal S. Dextrin and poly(acrylic acid)-based biodegradable, non-cytotoxic, chemically cross-linked hydrogel for sustained release of ornidazole and ciprofloxacin. ACS Appl Mater Interfaces. 2015;7(8):4791-4803.

145. Das D, Pal S. Dextrin/poly (HEMA): $\mathrm{pH}$ responsive porous hydrogel for controlled release of ciprofloxacin. Int J Biol Macromol. 2015;72: $171-178$.
146. Wu T, Zhang Q, Ren W, et al. Controlled release of gentamicin from gelatin/genipin reinforced beta-tricalcium phosphate scaffold for the treatment of osteomyelitis. J Mater Chem B. 2013;1(26):3304.

147. Lv YF, Wang J, Dong F, Yang DH. Meta-analysis of local gentamicin for prophylaxis of surgical site infections in colorectal surgery. Int $J$ Colorectal Dis. 2016;31(2):393-402.

148. Musters GD, Burger JW, Buskens CJ, Bemelman WA, Tanis PJ. Local application of gentamicin in the prophylaxis of perineal wound infection after abdominoperineal resection: a systematic review. World $J$ Surg. 2015;39(11):2786-2794.

149. Singh B, Pal L. Sterculia crosslinked PVA and PVA-poly(AAm) hydrogel wound dressings for slow drug delivery: mechanical, mucoadhesive, biocompatible and permeability properties. $J$ Mech Behav Biomed Mater. 2012;9:9-21.

150. Singh B, Sharma S, Dhiman A. Design of antibiotic containing hydrogel wound dressings: biomedical properties and histological study of wound healing. Int J Pharm. 2013;457(1):82-91.

151. Li H, Yang J, Hu X, Liang J, Fan Y, Zhang X. Superabsorbent polysaccharide hydrogels based on pullulan derivate as antibacterial release wound dressing. J Biomed Mater Res A. 2011;98(1):31-39.

152. Nnamani PO, Kenechukwu FC, Dibua EU, Ogbonna CC, Monemeh UL, Attama AA. Transdermal microgels of gentamicin. Eur J Pharm Biopharm. 2013;84(2):345-354.

153. Overstreet D, McLaren A, Calara F, Vernon B, McLemore R. Local gentamicin delivery from resorbable viscous hydrogels is therapeutically effective. Clin Orthop Relat Res. 2015;473(1):337-347.

154. Wu F, Meng G, He J, Wu Y, Wu F, Gu Z. Antibiotic-loaded chitosan hydrogel with superior dual functions: antibacterial efficacy and osteoblastic cell responses. ACS Appl Mater Interfaces. 2014;6(13): 10005-10013.

155. Dorati R, De Trizio A, Genta I, Merelli A, Modena T, Conti B. Gentamicin-loaded thermosetting hydrogel and moldable composite scaffold: formulation study and biologic evaluation. J Pharm Sci. 2017; 106(6):1596-1607.

156. Lovati AB, Drago L, Bottagisio M, et al. Systemic and local administration of antimicrobial and cell therapies to prevent methicillin-resistant Staphylococcus epidermidis-induced femoral nonunions in a rat model. Mediators Inflamm. 2016;2016:9595706.

157. Ng K, Mabasa VH, Chow I, Ensom MH. Systematic review of efficacy, pharmacokinetics, and administration of intraventricular vancomycin in adults. Neurocrit Care. 2014;20(1):158-171.

158. Walsh TR, Weeks J, Livermore DM, Toleman MA. Dissemination of NDM-1 positive bacteria in the New Delhi environment and its implications for human health: an environmental point prevalence study. Lancet Infect Dis. 2011;11(5):355-362.

159. Jakovac S, Bojic EF, Ibrisimovic MA, Tutis B, Ostojic M, Hukic M. Characteristics of vancomycin-resistant enterococcus strains in the west balkans: a first report. Microb Drug Resist. 2017;23(1): 122-126.

160. Yang J, Jiang Y, Guo L, Ye L, Ma Y, Luo Y. Prevalence of diverse clones of vancomycin-resistant Enterococcus faecium ST78 in a Chinese hospital. Microb Drug Resist. 2016;22(4):294-300.

161. Simoes SM, Veiga F, Torres-Labandeira JJ, et al. Syringeable pluronicalpha-cyclodextrin supramolecular gels for sustained delivery of vancomycin. Eur J Pharm Biopharm. 2012;80(1):103-112.

162. Zhao Y, Zhang X, Wang Y, et al. In situ cross-linked polysaccharide hydrogel as extracellular matrix mimics for antibiotics delivery. Carbohydr Polym. 2014;105:63-69.

163. Pakzad Y, Ganji F. Thermosensitive hydrogel for periodontal application: in vitro drug release, antibacterial activity and toxicity evaluation. J Biomater Appl. 2016;30(7):919-929.

164. Gustafson CT, Boakye-Agyeman F, Brinkman CL, et al. Controlled delivery of vancomycin via charged hydrogels. PLoS One. 2016;11(1): e0146401.

165. Lakes AL, Peyyala R, Ebersole JL, Puleo DA, Hilt JZ, Dziubla TD. Synthesis and characterization of an antibacterial hydrogel containing covalently bound vancomycin. Biomacromolecules. 2014;15(8): 3009-3018. 
166. Zhang J-Z, Xiao C-S, Wang J-C, Zhuang X-L, Chen X-S. Photo crosslinked biodegradable hydrogels for enhanced vancomycin loading and sustained release. Chin J Polym Sci. 2013;31(12):1697-1705.

167. Guzman-Trampe S, Ceapa CD, Manzo-Ruiz M, Sanchez S. Synthetic biology era: improving antibiotic's world. Biochem Pharmacol. 2017; 134:99-113.

168. Ford AC, Forman D, Hunt RH, Yuan Y, Moayyedi P. Helicobacter pylori eradication therapy to prevent gastric cancer in healthy asymptomatic infected individuals: systematic review and meta-analysis of randomised controlled trials. BMJ. 2014;348:g3174.

169. Vaghani SS, Patel MM, Satish CS. Synthesis and characterization of pH-sensitive hydrogel composed of carboxymethyl chitosan for colon targeted delivery of ornidazole. Carbohydr Res. 2012;347(1):76-82.

170. Das D, Ghosh P, Ghosh A, et al. Stimulus-responsive, biodegradable, biocompatible, covalently cross-linked hydrogel based on dextrin and Poly(N-isopropylacrylamide) for in vitro/in vivo controlled drug release. ACS Appl Mater Interfaces. 2015;7(26):14338-14351.

171. Chen T, Chen L, Li H, et al. Design and in vitro evaluation of a novel poly(methacrylic acid)/metronidazole antibacterial nanogel as an oral dosage form. Colloids Surf B Biointerfaces. 2014;118C:65-71.

172. Samanta HS, Ray SK. Controlled release of tinidazole and theophylline from chitosan based composite hydrogels. Carbohydr Polym. 2014;106:109-120.

173. El-Mahrouk GM, Aboul-Einien MH, Makhlouf AI. Design, optimization, and evaluation of a novel metronidazole-loaded gastroretentive $\mathrm{pH}$-sensitive hydrogel. AAPS PharmSciTech. 2016;17(6): $1285-1297$.

174. Lboutounne H, Chaulet J-F, Ploton C, Falson F, Pirot F. Sustained ex vivo skin antiseptic activity of chlorhexidine in poly ( $\varepsilon$-caprolactone) nanocapsule encapsulated form and as a digluconate. $J$ Controll Rel. 2002;82(2):319-334.

175. Ji QX, Zhao QS, Deng J, Lu R. A novel injectable chlorhexidine thermosensitive hydrogel for periodontal application: preparation, antibacterial activity and toxicity evaluation. J Mater Sci Mater Med. 2010;21(8):2435-2442.

176. Jones DS, Lorimer CP, McCoy CP, Gorman SP. Characterization of the physicochemical, antimicrobial, and drug release properties of thermoresponsive hydrogel copolymers designed for medical device applications. J Biomed Mater Res B Appl Biomater. 2008;85(2):417-426.

177. Morelli L, Cappelluti MA, Ricotti L, Lenardi C, Gerges I. An injectable system for local and sustained release of antimicrobial agents in the periodontal pocket. Macromol Biosci. Epub 2017 May 2.

178. Moritz S, Wiegand C, Wesarg F, et al. Active wound dressings based on bacterial nanocellulose as drug delivery system for octenidine. Int J Pharm. 2014;471(1-2):45-55.

179. Glisoni RJ, Garcia-Fernandez MJ, Pino M, et al. Beta-Cyclodextrin hydrogels for the ocular release of antibacterial thiosemicarbazones. Carbohydr Polym. 2013;93(2):449-457.

180. Sittiwong J, Niamlang S, Paradee N, Sirivat A. Electric field-controlled benzoic acid and sulphanilamide delivery from poly(vinyl alcohol) hydrogel. AAPS PharmSciTech. 2012;13(4):1407-1415.

181. Yunoki S, Kohta M, Ohyabu Y, Sekiguchi M, Kubo T, Iwasaki T. Electrostatic immobilization of cetylpyridinium chloride to poly (vinyl alcohol) hydrogels for the simple fabrication of wound dressings with the suppressed release of antibacterial agents. $J$ Appl Polym Sci. 2014;131:40456.

182. Nho Y-C, Lim Y-M, Gwon H-J, Choi E-K. Preparation and characterization of PVA/PVP/glycerin/antibacterial agent hydrogels using $\gamma$-irradiation followed by freeze-thawing. Korean J Chem Eng. 2009; 26(6):1675-1678.

183. Vogt PM, Reimer K, Hauser J, et al. PVP-iodine in hydrosomes and hydrogel - a novel concept in wound therapy leads to enhanced epithelialization and reduced loss of skin grafts. Burns. 2006;32(6): 698-705.

184. Zhao C, Li X, Li L, Cheng G, Gong X, Zheng J. Dual functionality of antimicrobial and antifouling of poly(N-hydroxyethylacrylamide)/ salicylate hydrogels. Langmuir. 2013;29(5):1517-1524.
185. Ma D, Cai X, Lin Q, et al. Alginate hydrogel sphere improves the alkali and heat resistances of isothiazolinones with long - term antibacterial activity. J Appl Polym Sci. 2013;130(3):1554-1561.

186. Lv ZF, Wang FC, Zheng HL, et al. Meta-analysis: is combination of tetracycline and amoxicillin suitable for Helicobacter pylori infection? World J Gastroenterol. 2015;21(8):2522-2533.

187. Selvakumaran S, Muhamad II, Abd Razak SI. Evaluation of kappa carrageenan as potential carrier for floating drug delivery system: effect of pore forming agents. Carbohydr Polym. 2016;135:207-214.

188. Chang $\mathrm{CH}$, Lin $\mathrm{YH}$, Yeh CL, et al. Nanoparticles incorporated in $\mathrm{pH}$-sensitive hydrogels as amoxicillin delivery for eradication of Helicobacter pylori. Biomacromolecules. 2010;11(1):133-142.

189. Moogooee M, Ramezanzadeh H, Jasoori S, Omidi Y, Davaran S. Synthesis and in vitro studies of cross-linked hydrogel nanoparticles containing amoxicillin. J Pharm Sci. 2011;100(3):1057-1066.

190. KamounEA, Kenawy E-RS, TamerTM,El-Meligy MA, Mohy Eldin MS. Poly (vinyl alcohol)-alginate physically crosslinked hydrogel membranes for wound dressing applications: characterization and bioevaluation. Arab J Chem. 2013;8(1):38-47.

191. Grohs P, Podglajen I, Guerot E, et al. Assessment of five screening strategies for optimal detection of carriers of third-generation cephalosporin-resistant Enterobacteriaceae in intensive care units using daily sampling. Clin Microbiol Infect. 2014;20(11):O879-O886.

192. Atta S, Khaliq S, Islam A, et al. Injectable biopolymer based hydrogels for drug delivery applications. Int J Biol Macromol. 2015;80: 240-245.

193. Venugopalarao G, Sreenivas Gowtham M, Sarada NC. Formulation evaluation and stability studies of hydrogel tablets containing Cefditoren Pivoxil. J Pharm Res. 2013;7(3):230-234.

194. Lai PL, Hong DW, Ku KL, Lai ZT, Chu IM. Novel thermosensitive hydrogels based on methoxy polyethylene glycol-co-poly(lactic acidco-aromatic anhydride) for cefazolin delivery. Nanomedicine. 2014; 10(3):553-560.

195. Islan GA, Dini C, Bartel LC, Bolzan AD, Castro GR. Characterization of smart auto-degradative hydrogel matrix containing alginate lyase to enhance levofloxacin delivery against bacterial biofilms. Int J Pharm. 2015;496(2):953-964.

196. Li Y, Zhou F, Wen Y, et al. (-)-Menthol based thixotropic hydrogel and its application as a universal antibacterial carrier. Soft Matter. 2014;10(17):3077.

197. He G, Chen X, Yin Y, et al. Preparation and antibacterial properties of O-carboxymethyl chitosan/lincomycin hydrogels. J Biomater Sci Polym Ed. 2016;27(4):370-384.

198. He Z-X, Wang Z-H, Zhang H-H, et al. Doxycycline and hydroxypropyl$\beta$-cyclodextrin complex in poloxamer thermal sensitive hydrogel for ophthalmic delivery. Acta Pharmaceutica Sinica B. 2011;1(4): 254-260.

199. Tormos CJ, Abraham C, Madihally SV. Improving the stability of chitosan-gelatin-based hydrogels for cell delivery using transglutaminase and controlled release of doxycycline. Drug Deliv Transl Res. 2015;5(6):575-584.

200. Hurler J, Berg OA, Skar M, Conradi AH, Johnsen PJ, SkalkoBasnet N. Improved burns therapy: liposomes-in-hydrogel delivery system for mupirocin. J Pharm Sci. 2012;101(10):3906-3915.

201. Hurler J, Sorensen KK, Fallarero A, Vuorela P, Skalko-Basnet N. Liposomes-in-hydrogel delivery system with mupirocin: in vitro antibiofilm studies and in vivo evaluation in mice burn model. Biomed Res Int. 2013;2013:498485.

202. Peng KT, Chen CF, Chu IM, et al. Treatment of osteomyelitis with teicoplanin-encapsulated biodegradable thermosensitive hydrogel nanoparticles. Biomaterials. 2010;31(19):5227-5236.

203. Nafee N, Youssef A, El-Gowelli H, Asem H, Kandil S. Antibiotic-free nanotherapeutics: hypericin nanoparticles thereof for improved in vitro and in vivo antimicrobial photodynamic therapy and wound healing. Int J Pharm. 2013;454(1):249-258.

204. Lai WF, Rogach AL. Hydrogel-based materials for delivery of herbal medicines. ACS Appl Mater Interfaces. 2017;9(13):11309-11320. 
205. Tan SP, McLoughlin P, O'Sullivan L, et al. Development of a novel antimicrobial seaweed extract-based hydrogel wound dressing. Int $J$ Pharm. 2013;456(1):10-20.

206. Varshney L. Role of natural polysaccharides in radiation formation of PVA-hydrogel wound dressing. Nucl Instrum Methods Phys Res B. 2007:255(2):343-349.

207. Engel H, Kao SW, Larson J, et al. Investigation of Dermis-derived hydrogels for wound healing applications. Biomed J. 2015;38(1):58-64.

208. Peng C-W, Lin H-Y, Wang H-W, Wu W-W. The influence of operating parameters on the drug release and anti-bacterial performances of alginate wound dressings prepared by three-dimensional plotting. Mater Sci Eng C. 2012;32(8):2491-2500.

209. Pirak T, Jangchud A, Jantawat P. Characterisation of physical, chemical and antimicrobial properties of allicin-chitosan complexes. Int J Food Sci Technol. 2012;47(7):1339-1347.

210. Qureshi MA, Khatoon F, Rizvi MA, Zafaryab M. Ethyl acetate Salix alba leaves extract-loaded chitosan-based hydrogel film for wound dressing applications. J Biomater Sci Polym Ed. 2015;26(18):1452-1464.

211. Casero C, Machin F, Mendez-Alvarez S, et al. Structure and antimicrobial activity of phloroglucinol derivatives from Achyrocline satureioides. J Nat Prod. 2015;78(1):93-102.

212. Basniwal RK, Buttar HS, Jain VK, Jain N. Curcumin nanoparticles: preparation, characterization, and antimicrobial study. J Agric Food Chem. 2011;59(5):2056-2061.

213. Varaprasad K, Mohan YM, Vimala K, Mohana Raju K. Synthesis and characterization of hydrogel-silver nanoparticle-curcumin composites for wound dressing and antibacterial application. J Appl Polym Sci. 2011;121(2):784-796.

214. Ravindra S, Mulaba-Bafubiandi AF, Rajinikanth V, Varaprasad K, Narayana Reddy N, Mohana Raju K. Development and characterization of curcumin loaded silver nanoparticle hydrogels for antibacterial and drug delivery applications. J Inorg Organometal Polym Mater. 2012; 22(6): 1254-1262.

215. Sierra-Garcia GD, Castro-Rios R, Gonzalez-Horta A, Lara-Arias J, Chavez-Montes A. Acemannan, an extracted polysaccharide from Aloe vera: a literature review. Nat Prod Commun. 2014;9(8):1217-1221.

216. Cellini L, Di Bartolomeo S, Di Campli E, Genovese S, Locatelli M, Di Giulio M. In vitro activity of Aloe vera inner gel against Helicobacter pylori strains. Lett Appl Microbiol. 2014;59(1):43-48.

217. Pereira RF, Bartolo PJ. Traditional therapies for skin wound healing. Adv Wound Care (New Rochelle). 2016;5(5):208-229.

218. Seow YX, Yeo CR, Chung HL, Yuk HG. Plant essential oils as active antimicrobial agents. Crit Rev Food Sci Nutr. 2014;54(5):625-644.

219. Vergis J, Gokulakrishnan P, Agarwal RK, Kumar A. Essential oils as natural food antimicrobial agents: a review. Crit Rev Food Sci Nutr. 2015; 55(10):1320-1323.

220. Liakos I, Rizzello L, Scurr DJ, Pompa PP, Bayer IS, Athanassiou A. All-natural composite wound dressing films of essential oils encapsulated in sodium alginate with antimicrobial properties. Int J Pharm. 2014;463(2):137-145.

221. Yusof N, Ainul Hafiza AH, Zohdi RM, Bakar MZA. Development of honey hydrogel dressing for enhanced wound healing. Radiat Phys Chem. 2007;76(11-12):1767-1770.

222. Qiao M, Chen D, Hao T, Zhao X, Hu H, Ma X. Effect of bee venom peptide-copolymer interactions on thermosensitive hydrogel delivery systems. Int J Pharm. 2007;345(1-2):116-124.

223. Zhang S, Borazjani RN, Salamone JC, Ahearn DG, Crow SA Jr, Pierce GE. In vitro deposition of lysozyme on etafilcon A and balafilcon A hydrogel contact lenses: effects on adhesion and survival of Pseudomonas aeruginosa and Staphylococcus aureus. Cont Lens Anterior Eye. 2005;28(3):113-119.

224. Lee ALZ, Ng VWL, Wang WX, Hedrick JL, Yang YY. Block copolymer mixtures as antimicrobial hydrogels for biofilm eradication. Biomaterials. 2013;34(38):10278-10286.

225. Spasojevic D, Zmejkoski D, Glamoclija J, et al. Lignin model compound in alginate hydrogel: a strong antimicrobial agent with high potential in wound treatment. Int J Antimicrob Agents. 2016;48(6):732-735.
226. Gao P, Nie X, Zou M, Shi Y, Cheng G. Recent advances in materials for extended-release antibiotic delivery system. J Antibiot. 2011;64(9): 625-634.

227. Palza H. Antimicrobial polymers with metal nanoparticles. Int J Mol Sci. 2015;16(1):2099-2116.

228. Sui X, Feng X, Di Luca A, et al. Poly (N-isopropylacrylamide)-poly (ferrocenylsilane) dual-responsive hydrogels: synthesis, characterization and antimicrobial applications. Polym Chem. 2013;4(2):337-342.

229. Jiang Q, Xu J, Li T, Qiao C, Li Y. Synthesis and antibacterial activities of quaternary ammonium salt of gelatin. J Macromol Sci B. 2014;53(1):133-141.

230. Tomić SL, Mićić MM, Dobić SN, Filipović JM, Suljovrujić EH. Smart poly(2-hydroxyethyl methacrylate/itaconic acid) hydrogels for biomedical application. Radiat Phys Chem. 2010;79(5):643-649.

231. La Y-H, McCloskey BD, Sooriyakumaran R, et al. Bifunctional hydrogel coatings for water purification membranes: improved fouling resistance and antimicrobial activity. J Memb Sci. 2011;372(1-2):285-291.

232. Parsons C, McCoy CP, Gorman SP, et al. Anti-infective photodynamic biomaterials for the prevention of intraocular lens-associated infectious endophthalmitis. Biomaterials. 2009;30(4):597-602.

233. Halpenny GM, Steinhardt RC, Okialda KA, Mascharak PK. Characterization of pHEMA-based hydrogels that exhibit light-induced bactericidal effect via release of NO. J Mater Sci Mater Med. 2009; 20(11):2353-2360.

234. Fjell CD, Hiss JA, Hancock RE, Schneider G. Designing antimicrobial peptides: form follows function. Nat Rev Drug Discov. 2011; 11(1):37-51.

235. Brogden KA. Antimicrobial peptides: pore formers or metabolic inhibitors in bacteria? Nat Rev Microbiol. 2005;3(3):238-250.

236. Lakshmaiah Narayana J, Chen JY. Antimicrobial peptides: possible anti-infective agents. Peptides. 2015;72:88-94.

237. Salick DA, Kretsinger JK, Pochan DJ, Schneider JP. Inherent antibacterial activity of a peptide-based $\beta$-hairpin hydrogel. $\mathrm{J} \mathrm{Am} \mathrm{Chem} \mathrm{Soc} \mathrm{.}$ 2007;129(47):14793-14799.

238. Veiga AS, Sinthuvanich C, Gaspar D, Franquelim HG, Castanho MARB, Schneider JP. Arginine-rich self-assembling peptides as potent antibacterial gels. Biomaterials. 2012;33(35):8907-8916.

239. Liu Y, Yang Y, Wang C, Zhao X. Stimuli-responsive self-assembling peptides made from antibacterial peptides. Nanoscale. 2013;5(14): 6413-6421.

240. Cleophas RT, Sjollema J, Busscher HJ, Kruijtzer JA, Liskamp RM. Characterization and activity of an immobilized antimicrobial peptide containing bactericidal PEG-hydrogel. Biomacromolecules. 2014; 15(9):3390-3395.

241. Li Y-Q, Han Q, Feng J-L, Tian W-L, Mo H-Z. Antibacterial characteristics and mechanisms of $\varepsilon$-poly-lysine against Escherichia coli and Staphylococcus aureus. Food Control. 2014;43:22-27.

242. Zhou C, Li P, Qi X, et al. A photopolymerized antimicrobial hydrogel coating derived from epsilon-poly-1-lysine. Biomaterials. 2011;32(11): 2704-2712.

243. Jiang L, Xu D, Sellati TJ, Dong H. Self-assembly of cationic multidomain peptide hydrogels: supramolecular nanostructure and rheological properties dictate antimicrobial activity. Nanoscale. 2015;7(45): 19160-19169.

244. Laverty G, Gorman SP, Gilmore BF. Antimicrobial peptide incorporated poly(2-hydroxyethyl methacrylate) hydrogels for the prevention of Staphylococcus epidermidis-associated biomaterial infections. J Biomed Mater Res A. 2012;100(7):1803-1814.

245. Baranova O, Kuz'min N, Samsonova T, et al. Medical hydrogels based on bioactive compounds. Synthesis, properties, and possible application for preparing bactericidal materials. Fibre Chem. 2011; 43(1):90-103.

246. Steckbeck JD, Deslouches B, Montelaro RC. Antimicrobial peptides: new drugs for bad bugs? Expert Opin Biol Ther. 2014;14(1):11-14.

247. Ashby M, Petkova A, Hilpert K. Cationic antimicrobial peptides as potential new therapeutic agents in neonates and children: a review. Curr Opin Infect Dis. 2014;27(3):258-267. 
248. Forbes S, McBain AJ, Felton-Smith S, Jowitt TA, Birchenough HL, Dobson CB. Comparative surface antimicrobial properties of synthetic biocides and novel human apolipoprotein $\mathrm{E}$ derived antimicrobial peptides. Biomaterials. 2013;34(22):5453-5464.

249. Pletzer D, Hancock RE. Antibiofilm peptides: potential as broadspectrum agents. J Bacteriol. 2016;198(19):2572-2578.

250. Song A, Rane AA, Christman KL. Antibacterial and cell-adhesive polypeptide and poly(ethylene glycol) hydrogel as a potential scaffold for wound healing. Acta Biomater. 2012;8(1):41-50.

251. Buhrman JS, Cook LC, Rayahin JE, Federle MJ, Gemeinhart RA. Proteolytically activated anti-bacterial hydrogel microspheres. J Control Rel. 2013;171(3):288-295.

252. Xie Z, Aphale NV, Kadapure TD, et al. Design of antimicrobial peptides conjugated biodegradable citric acid derived hydrogels for wound healing. J Biomed Mater Res A. 2015;103(12):3907-3918.

253. Melchionna M, Styan KE, Marchesan S. The unexpected advantages of using D-amino acids for peptide self-assembly into nanostructured hydrogels for medicine. Curr Top Med Chem. 2016;16(18): 2009-2018.

254. Liu L, Huang Y, Riduan SN, et al. Main-chain imidazolium oligomer material as a selective biomimetic antimicrobial agent. Biomaterials. 2012;33(33):8625-8631.

255. Locock KE, Michl TD, Valentin JD, et al. Guanylated polymethacrylates: a class of potent antimicrobial polymers with low hemolytic activity. Biomacromolecules. 2013;14(11):4021.

256. Lienkamp K, Kumar KN, Som A, Nüsslein K, Tew GN. "Doubly selective" antimicrobial polymers: how do they differentiate between bacteria? Chemistry. 2009;15(43):11710-11714.

257. Thaker HD, Cankaya A, Scott RW, Tew GN. Role of amphiphilicity in the design of synthetic mimics of antimicrobial peptides with Gramnegative activity. Acs Med Chem Lett. 2013;4(5):481.

258. Liu R, Chen X, Hayouka Z, et al. Nylon-3 polymers with selective antifungal activity. J Am Chem Soc. 2013;135(14):5270-5273.

259. Chakraborty S, Liu R, Lemke JJ, et al. Effects of cyclic vs. acyclic hydrophobic subunits on the chemical structure and biological properties of nylon-3 co-polymers. Acs Macro Lett. 2011;2(8): 753-756.

260. Ng VW, Ke X, Lee AL, Hedrick JL, Yang YY. Synergistic co-delivery of membrane-disrupting polymers with commercial antibiotics against highly opportunistic bacteria. Adv Mater Deerfield. 2013;25(46): 6730-6736.

261. Engler AC, Tan JP, Ong ZY, et al. Antimicrobial polycarbonates: investigating the impact of balancing charge and hydrophobicity using a same-centered polymer approach. Biomacromolecules. 2013; 14(12):4331.

262. Chin W, Yang C, Ng VWL, et al. Biodegradable broad-spectrum antimicrobial polycarbonates: investigating the role of chemical structure on activity and selectivity. Macromolecules. 2014;46(22): $8797-8807$.

263. Jiang S, Cao Z. Ultralow-fouling, functionalizable, and hydrolyzable zwitterionic materials and their derivatives for biological applications. Adv Mater Deerfield. 2010;22(9):920.

264. Cao Z, Jiang S. Super-hydrophilic zwitterionic poly(carboxybetaine) and amphiphilic non-ionic poly(ethylene glycol) for stealth nanoparticles. Nano Today. 2012;7(5):404-413.

265. Mi L, Jiang S. Synchronizing nonfouling and antimicrobial properties in a zwitterionic hydrogel. Biomaterials. 2012;33(35):8928-8933.

266. Liu SQ, Yang C, Huang Y, et al. Antimicrobial and antifouling hydrogels formed in situ from polycarbonate and poly(ethylene glycol) via Michael addition. Adv Mater Deerfield. 2012;24(48): 6484-6489.

267. Li X, Dong Q, He P. Synthesis and water absorbency of polyampholytic hydrogels with antibacterial activity. J Appl Polym Sci. 2009; 112(1):439-446.

268. Debnath S, Shome A, Das D, Das PK. Hydrogelation through selfassembly of Fmoc-peptide functionalized cationic amphiphiles: potent antibacterial agent. J Phys Chem B. 2010;114(13):4407-4415.
269. Dutta S, Kar T, Mandal D, Das PK. Structure and properties of cholesterol-based hydrogelators with varying hydrophilic terminals: biocompatibility and development of antibacterial soft nanocomposites. Langmuir. 2013;29(1):316-327.

270. Bernet A, Behr M, Schmidt H-W. Supramolecular hydrogels based on antimycobacterial amphiphiles. Soft Matter. 2012;8(18):4873.

271. Bursali EA, Coskun S, Kizil M, Yurdakoc M. Synthesis, characterization and in vitro antimicrobial activities of boron/starch/polyvinyl alcohol hydrogels. Carbohydr Polym. 2011;83(3):1377-1383.

272. Nazarzadeh Zare E, Mansour Lakouraj M, Mohseni M. Biodegradable polypyrrole/dextrin conductive nanocomposite: synthesis, characterization, antioxidant and antibacterial activity. Synth Met. 2014; 187:9-16.

273. Wang H, Wilksch JJ, Lithgow T, Strugnell RA, Gee ML. Nanomechanics measurements of live bacteria reveal a mechanism for bacterial cell protection: the polysaccharide capsule in Klebsiella is a responsive polymer hydrogel that adapts to osmotic stress. Soft Matter. 2013; 9(31):7560.

274. Sang LY, Zhou XH, Yun F, Zhang GL. Enzymatic synthesis of chitosan-gelatin antimicrobial copolymer and its characterisation. J Sci Food Agric. 2010;90(1):58-64.

275. Ding F, Nie Z, Deng H, Xiao L, Du Y, Shi X. Antibacterial hydrogel coating by electrophoretic co-deposition of chitosan/alkynyl chitosan. Carbohydr Polym. 2013;98(2):1547-1552.

276. Straccia MC, d'Ayala GG, Romano I, Oliva A, Laurienzo P. Alginate hydrogels coated with chitosan for wound dressing. Mar Drugs. 2015;13(5):2890-2908.

277. Fan L, Yang J, Wu H, et al. Preparation and characterization of quaternary ammonium chitosan hydrogel with significant antibacterial activity. Int J Biol Macromol. 2015;79:830-836.

278. Liu B, Hu J, Meng Q. Nonwoven supported temperature-sensitive poly(N-isopropylacrylamide)/polyurethane copolymer hydrogel with antibacterial activity. J Biomed Mater Res B Appl Biomater. 2009; 89(1):1-8.

279. Noppakundilograt S, Sonjaipanich K, Thongchul N, Kiatkamjornwong S. Syntheses, characterization, and antibacterial activity of chitosan grafted hydrogels and associated mica-containing nanocomposite hydrogels. J Appl Polym Sci. 2013;127(6):4927-4938.

280. Salick DA, Pochan DJ, Schneider JP. Design of an injectable $\beta$-hairpin peptide hydrogel that kills Methicillin-resistant Staphylococcus aureus. Adv Mater Deerfield. 2010;21(41):4120-4123.

281. Hughes M, Debnath S, Knapp CW, Ulijn RV. Antimicrobial properties of enzymatically triggered self-assembling aromatic peptide amphiphiles. Biomaterialsence. 2013;1(11):1138-1142.

282. Satarkar NS, Hawkins AM, Hilt JZ. Hydrogel nanocomposites in biology and medicine: applications and interactions. In: Puleo D, Bizios R, editors. Biological Interactions on Materials Surfaces. New York: Springer; 2009:319-342.

283. Reithofer MR, Lakshmanan A, Ping AT, Chin JM, Hauser CA. In situ synthesis of size-controlled, stable silver nanoparticles within ultrashort peptide hydrogels and their anti-bacterial properties. Biomaterials. 2014;35(26):7535-7542.

284. Eid M. Gamma radiation synthesis and characterization of starch based polyelectrolyte hydrogels loaded silver nanoparticles. $J$ Inorg Organometal Polym Mater. 2011;21(2):297-305.

285. Dutta S, Shome A, Kar T, Das PK. Counterion-induced modulation in the antimicrobial activity and biocompatibility of amphiphilic hydrogelators: influence of in-situ-synthesized Ag-nanoparticle on the bactericidal property. Langmuir. 2011;27(8):5000-5008.

286. Shome A, Dutta S, Maiti S, Das PK. In situ synthesized Ag nanoparticle in self-assemblies of amino acid based amphiphilic hydrogelators: development of antibacterial soft nanocomposites. Soft Matter. 2011;7(6):3011.

287. GhavamiNejad A, Park CH, Kim CS. In situ synthesis of antimicrobial silver nanoparticles within antifouling zwitterionic hydrogels by catecholic redox chemistry for wound healing application. Biomacromolecules. 2016;17(3):1213-1223. 
288. Liu Y, Ma W, Liu W, et al. Silver(i)-glutathione biocoordination polymer hydrogel: effective antibacterial activity and improved cytocompatibility. J Mater Chem. 2011;21(48):19214.

289. Anjum S, Gupta A, Sharma D, et al. Development of novel wound care systems based on nanosilver nanohydrogels of polymethacrylic acid with Aloe vera and curcumin. Mater Sci Eng C Mater Biol Appl. 2016;64:157-166.

290. Vasile BS, Oprea O, Voicu G, et al. Synthesis and characterization of a novel controlled release zinc oxide/gentamicin-chitosan composite with potential applications in wounds care. Int J Pharm. 2014; 463(2):161-169.

291. Rouabhia M, Asselin J, Tazi N, Messaddeq Y, Levinson D, Zhang Z. Production of biocompatible and antimicrobial bacterial cellulose polymers functionalized by RGDC grafting groups and gentamicin. ACS Appl Mater Interfaces. 2014;6(3):1439-1446.

292. Paradiso P, Serro AP, Saramago B, Colaco R, Chauhan A. Controlled release of antibiotics from vitamin E-loaded silicone-hydrogel contact lenses. J Pharm Sci. 2016;105(3):1164-1172.
293. Reed TP, Thomas LA, Weeren FR, Ruth JD, Anders BB. A novel dextran polymer hydrogel local antimicrobial therapy in dogs: a pilot study. Can Vet J. 2016;57(2):189-195.

294. Novac O, Lisa G, Profire L, Tuchilus C, Popa MI. Antibacterial quaternized gellan gum based particles for controlled release of ciprofloxacin with potential dermal applications. Mater Sci Eng C. 2014; 35:291-299.

295. Bardajee GR, Hooshyar Z, Rezanezhad H. A novel and green biomaterial based silver nanocomposite hydrogel: synthesis, characterization and antibacterial effect. J Inorg Biochem. 2012;117:367-373.

296. Yadollahi M, Farhoudian S, Namazi H. One-pot synthesis of antibacterial chitosan/silver bio-nanocomposite hydrogel beads as drug delivery systems. Int J Biol Macromol. 2015;79:37-43.
International Journal of Nanomedicine

\section{Publish your work in this journal}

The International Journal of Nanomedicine is an international, peerreviewed journal focusing on the application of nanotechnology in diagnostics, therapeutics, and drug delivery systems throughout the biomedical field. This journal is indexed on PubMed Central, MedLine, CAS, SciSearch $®$, Current Contents $\AA /$ Clinical Medicine,

\section{Dovepress}

Journal Citation Reports/Science Edition, EMBase, Scopus and the Elsevier Bibliographic databases. The manuscript management system is completely online and includes a very quick and fair peer-review system, which is all easy to use. Visit http://www.dovepress.com/ testimonials.php to read real quotes from published authors.

Submit your manuscript here: http://www.dovepress.com/international-journal-of-nanomedicine-journal 